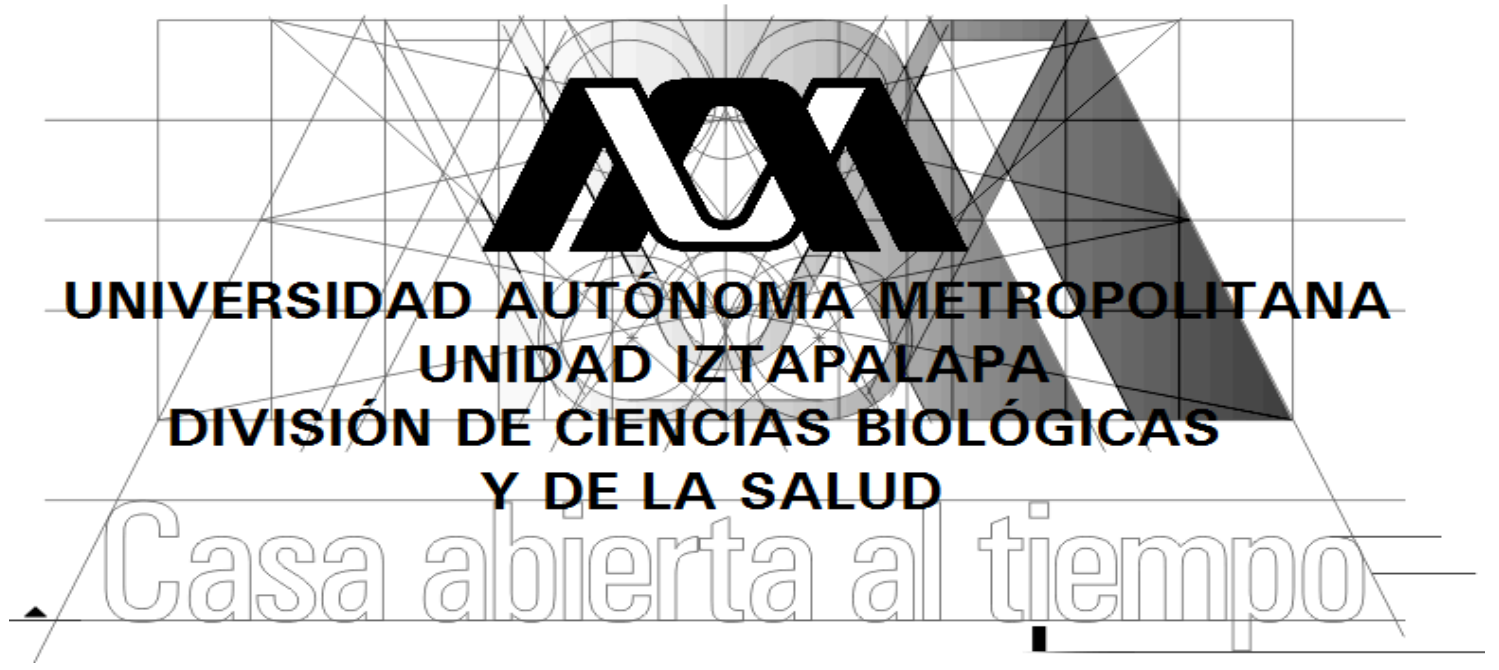

Evaluación in vitro e in vivo de las características prebióticas de las cáscaras de tuna y piña

T $\quad$ E $\quad$ S $\quad$ I $\quad$ S

QUE PARA OBTENER EL GRADO DE

DOCTOR EN BIOTECNOLOGÍA

$\begin{array}{llllllll}P & R & E & S & E & N & T & A:\end{array}$

M. en Biotec. JUAN DÍAZ VELA

Directora: Dra. María de Lourdes Pérez Chabela

Co-Director: Dr. Alfonso Totosaus Sánchez

Asesora: Dra. Alma E. Cruz Guerrero

México, D. F. Septiembre de 2014 


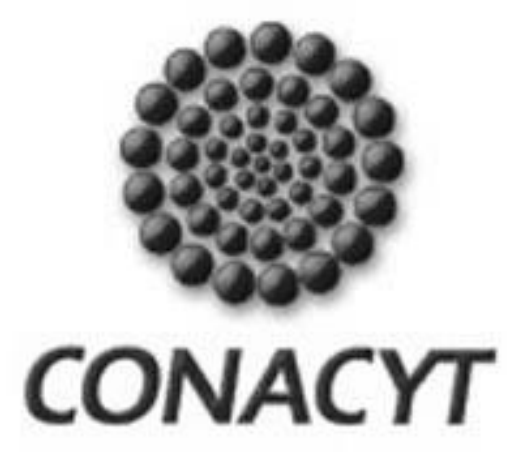

El Doctorado en Biotecnología de la Universidad Autónoma Metropolitana está incluido en el Padrón Nacional de Posgrados de Excelencia de CONACYT bajo el convenio 47101/Doctorado en Biotecnología.

Esta Tesis fue realizada con el apoyo de la Beca No. 224727 del Consejo Nacional de Ciencia y Tecnología (CONACYT). 
El H. Jurado designado por la División de Ciencias Biológicas y de la Salud de la Universidad Autónoma Metropolitana Unidad Iztapalapa aprobó la Tesis:

\section{"Evaluación in vitro e in vivo de las características prebióticas de las cáscaras de tuna y piña"}

que presentó

\section{M. en Biotec. Juan Díaz Vela}

El día 23 de Septiembre del 2014

Directora:

Dra. María de Lourdes Pérez Chabela Universidad Autónoma Metropolitana, Unidad Iztapalapa

Co-Director:

Dr. Alfonso Totosaus Sánchez

Tecnológico de Estudios Superiores de Ecatepec

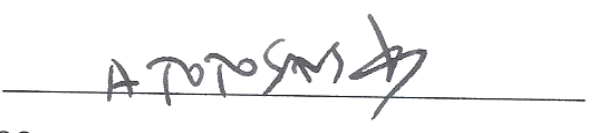

\section{H. Jurado}

Presidente: Dra. Isabel Guerrero Legarreta Universidad Autónoma Metropolitana, Unidad Iztapalapa Secretario: Dr. Manuel Viuda Martos Universidad Miguel Hernández, España.

Vocal: Dra. Alma Elizabeth Cruz Guerrero Universidad Autónoma Metropolitana, Unidad Xochimilco

Vocal: Dr. Ernesto Favela Torres
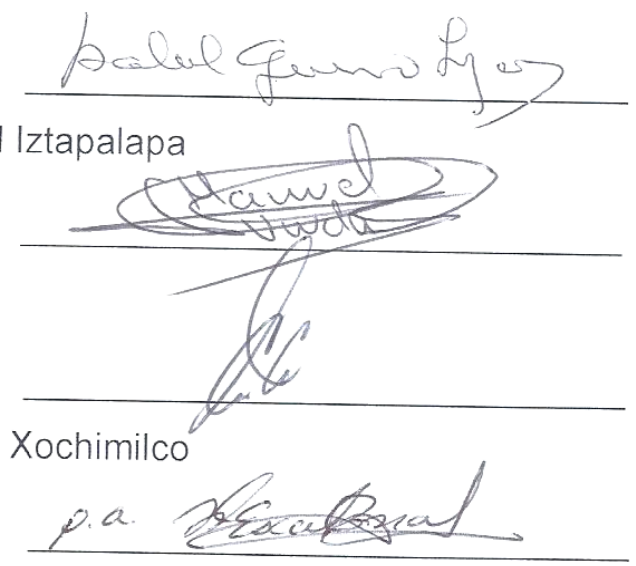

Universidad Autónoma Metropolitana, Unidad Iztapalapa 
Agradecimientos

Al Consejo Nacional de Ciencia y Tecnología (CONACYT) por el apoyo de la beca para la realización de mis estudios de Doctorado.

A la Universidad Autónoma Metropolitana-Iztapalapa por abrirme las puertas para la realización de estos estudios.

Agradezco de menera especial a la Dra. María de Lourdes Pérez Chabela, por ser una directora de Tesis ejemplar, por dirigir mi formación profesional a nivel posgrado transmitiendo sus conocimientos en todo momento y por las oportunidades de crecimiento profesional. Además por la enorme paciencia y confianza depositada en mí para la realización de este trabajo. Le agradezco el tiempo dedicado en escucharme cuando había alguna dificultad y por sus palabras de aliento. Gracias por todos sus consejos y permitirme aprender bajo su dirección, y sobretodo, por su amistad.

Al Dr. Alfonso Totosaus Sánchez, por el gran esfuerzo dedicado durante la realización de este trabajo, donde siempre tuve su apoyo resolviendome dudas y por abrirme las puertas de su laboratorio. La co-dirección de su parte fue fundamental para lograr los resultados obtenidos en este trabajo. Gracias por su amistad.

A la Dra. Alma E. Cruz Guerrero, por sus asesorías durante la realización de este trabajo y permitirme realizar parte del trabajo experimental en su laboratorio. Además por la revisión final de la Tesis y por sus valiosas aportaciones para la realización de este trabajo.

A la Dra. Isabel Guerrero Legarreta, por su amistad y consejos, así mismo, por su valiosa colaboración en la revisión del trabajo escrito de esta Tesis.

Al Dr. Ernesto Favela Torres, por sus recomendaciones durante la revisión de esta Tesis, además por compartir sus experiencias y permitirme tener mi primer contacto con la cromatografía en su laboratorio.

Al Dr. Hector Escalona Buendía, por sus asesorías y por permitirme el espacio durante la realización de los análisis sensoriales de este trabajo.

Al Dr. Manuel Viuda Martos, por su valiosa colaboración en la revisión de esta Tesis, así como por su disposición en llevar a cabo un viaje bastante largo para estar presente en la disertación pública de resultados. Muchas gracias por todo!

A la Dra. Claudia Delgadillo Puga, por su apoyo en la realización de los estudios con ratas dentro del Instituto Nacional de Ciencias Médicas y Nutrición Salvador Zubirán (INCMNSZ). 
Dedicatorias

A las dos mujeres que son mi catalizador y motivo de seguir aprendiendo y luchar día a día para cumplir mis objetivos para el beneficio de los tres. Diana y Fátima, gracias por ser complices de este camino que estamos formando y por el amor que siempre me demuestran.

A mis padres, Ana y Juan, por el gran apoyo invaluable que siempre han tenido para conmigo. Gracias por sus consejos y palabras de aliento cuando lo necesité.

A mis hermanos, Carlos y Mauricio, por sus expresiones de apoyo que siempre me han brindado.

A mis amigos y compañeros del Laboratorio S-130, por su compañía, apoyo y todos los momentos de aprendizaje mutuo, ya que fueron testigos del desarrollo de este trabajo. 


\section{INDICE}

1. RESUMEN --1

2. ABSTRACT --3

3. INTRODUCCIÓN

4. OBJETIVO GENERAL -

4.1 Objetivos Específicos -

5. CAPÍTULO I: ANTECEDENTES -

5.1 PREBIÓTICOS-

5.1.1 Definición --

5.1.2 Características -

5.1.3 Clasificación--

5.1.3.1 Prebióticos sintéticos - 10

5.1.3.1.1 10

5.1.3.1.1 Lactulosa - 10

5.1.3.1.2 Xilo-oligosacáridos - 11

5.1.3.1.3 Lactosacarosa-- 11

5.1.3.1.4 Isomalto-oligosacáridos- 11

5.1.3.1.5 Gluco-oligosacáridos --- 12

5.1.3.2 Prebióticos naturales ---_o 12

5.1.3.2.1 Fructanos tipo inulina -- 12

5.1.3.2.2 Galacto-oligosacaridos --_---13

5.1.3.2.3 Oligosacáridos de soya---13

5.1.3.2.4 Fibra dietética --- 14

5.1.3.2.5 Celulosa-- 15

5.1.3.2.6 $\beta$-glucanos ---_---_o 15

5.1.3.2.7 Pectina-- 16

5.1.3.2.8 Almidones resistentes- 16

5.2 SUBPRODUCTOS AGROINDUSTRIALES COMO FUENTE DE FIBRA-

5.2.1 Tuna-- 18

5.3 INCORPORACIÓN DE FIBRA DIETÉTICA EN PRODUCTOS CÁRNICOS-.-- 19

5.4 BIBLIOGRAFÍA- 22 
6. CAPÍTULO II: EVALUACIÓN in vitro DE LA FERMENTACIÓN DE SUBPRODUCTOS AGROINDUSTRIALES DE VALOR AGREGADO: CÁSCARA DE TUNA (Opuntia ficus-indica L) Y CÁSCARA DE PIÑA (Ananas comosus) COMO INGREDIENTES FUNCIONALES.---------- 26

6.1 OBJETIVO- 26

6.2 PROLEGÓMENO - 26

6.3 METODOLOGÍA- 29

6.3.1 Composición química y capacidad antioxidante- 29

6.3.2 Fermentación de las harinas de cáscara de tuna y piña-- 30

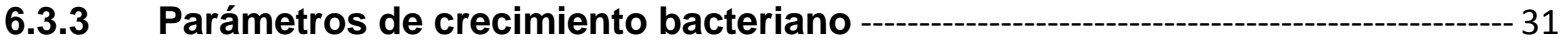

6.3.4 Parámetros de acidificación ----’o 32

6.3.5 Consumo de carbohidratos

6.3.6 Ácido láctico y ácidos grasos de cadena corta - 32

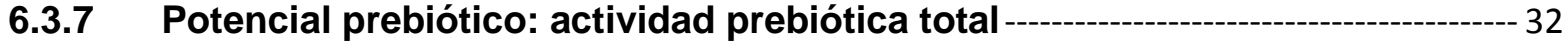

6.3.8 Diseño y análisis de datos experimentales --- 33

6.4 RESULTADOS Y DISCUSIÓN- 34

6.4.1 Composición química y capacidad antioxidante -

6.4.2 Parámetros de fermentación---_- 35

6.4.3 Potencial prebiótico - 43

6.5 CONCLUSIONES

6.6 BIBLIOGRAFÍA 46

7. CAPÍTULO III: EFECTO DE LA HARINA DE CÁSCARA DE TUNA (Opuntia ficus indica) Y PIÑA (Ananas comosus) SOBRE LAS PROPIEDADES FISICOQUÍMICAS Y DE TEXTURA DE SALCHICHAS COCIDAS INOCULADAS CON BACTERIAS ÁCIDO LÁCTICAS PROBIÓTICAS. 51

7.1 OBJETIVO- 51

7.2 PROLEGÓMENO - 51

7.3 METODOLOGÍA- 53

7.3.1 Obtención de las harinas de cáscara de tuna y piña -- 53

7.3.2 Elaboración de embutidos

7.3.3 Rendimiento de cocción, Humedad total y Humedad expresable------------ 54

7.3.4 Rancidez oxidativa - 55

7.3.5 Color instrumental- 55

7.3.6 Cuenta viable de bacterias ácido lácticas y pH - 56 


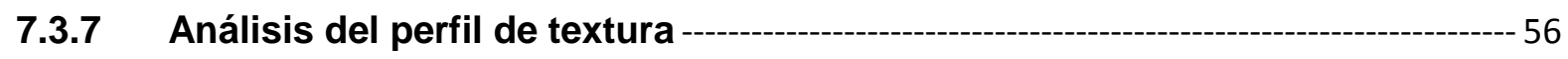

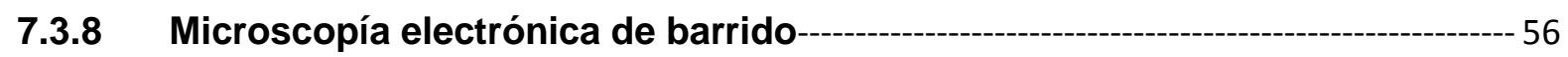

7.3.9 Diseño y análisis de datos experimentales ---

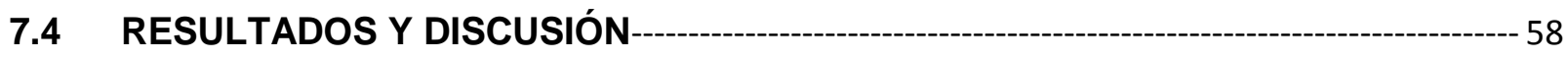

7.4.1 Rendimiento, Humedad total, Humedad expresable y Rancidez Oxidativa --- 58

7.4.2 Color instrumental------- 61

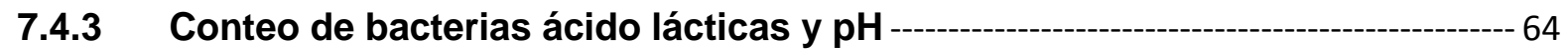

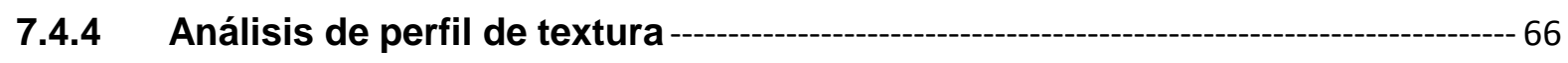

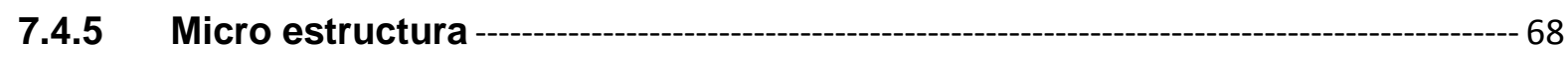

7.5 CONCLUSIONES------ 71

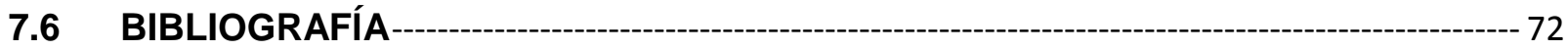

8. CAPÍTULO IV. EFECTO DE LA HARINA DE CÁSCARA DE TUNA (Opuntia ficus indica) Y PIÑA (Ananas comosus) SOBRE LAS CARACTERISTICAS SENSORIALES DE SALCHICHAS COCIDAS.-

8.1 OBJETIVO- 78

8.2 PROLEGÓMENO - 78

8.3 METODOLOGÍA- 81

8.3.1 Análisis de consumo de alimentos saludables y Neofobia alimentaria ------- 81

8.3.2 Obtención de las harinas de cáscara de tuna y cáscara de piña ------------- 85

8.3.3 Elaboración de salchichas-- 85

8.3.4 Índice $\mathbf{R}$ - 86

8.3.5 Análisis descriptivo cuantitativo (QDA) ------------------------------------------- 88

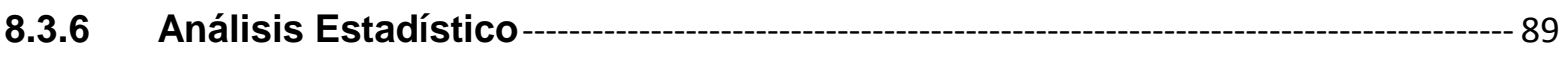

8.4 RESULTADOS Y DISCUSIÓN- 90

8.4.1 Consumo de Alimentos saludables - 90

8.4.2 Neofobia Alimentaria ---

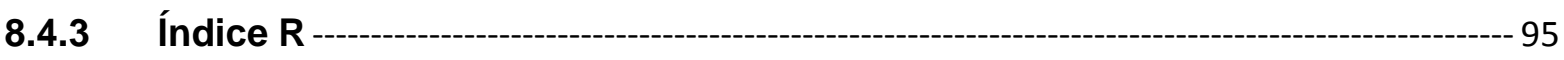

8.4.4 Análisis descriptivo cuantitativo (QDA) - 96

8.5 CONCLUSIONES 105

8.6 BIBLIOGRAFÍA- 106

9. CAPÍTULO V. EFECTOS FISIOLÓGICOS Y MICROBIOLÓGICOS DE LA CÁSCARA DE TUNA (Opuntia ficus indica) E INULINA DE AGAVE COMO FUENTES DE FIBRA EN LA ALIMENTACION DE RATAS (Rattus norvegicus) CEPA WISTAR- 
9.1 OBJETIVO-- 109

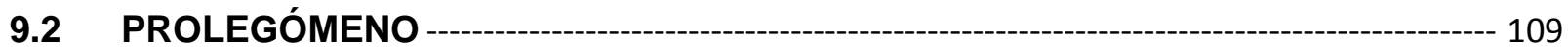

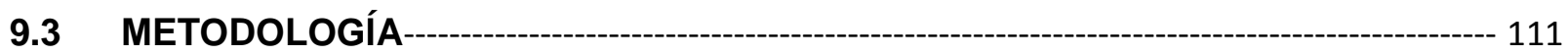

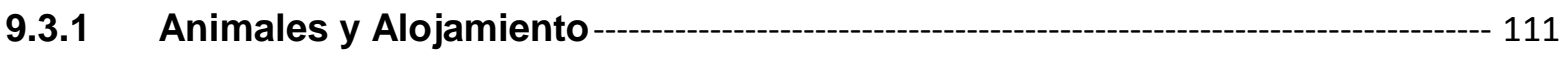

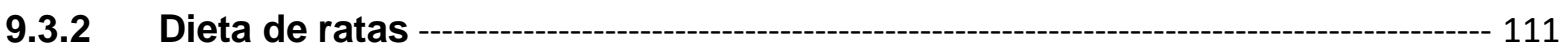

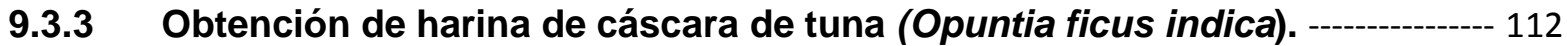

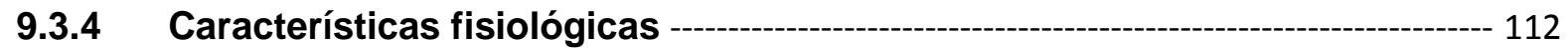

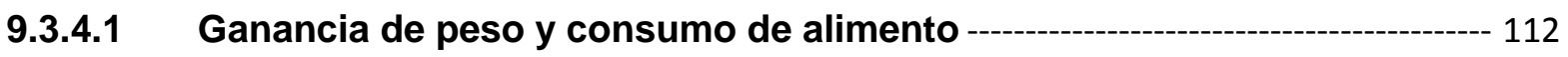

9.3.4.2 Análisis fecales de polisacáridos no digeridos----------------------------------- 113

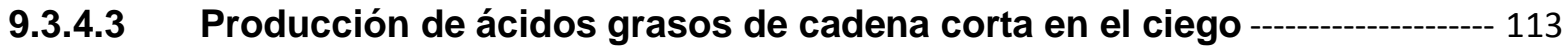

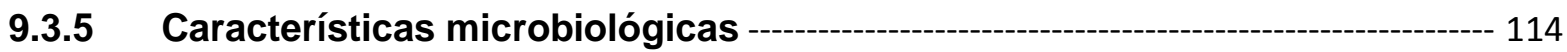

9.3.5.1 Conteo de bacterias ácido lácticas, bifidobacterias, Bacteroides sp. y enterobacterias en el contenido del ciego --- 114

9.3.6 Análisis estadístico - 114

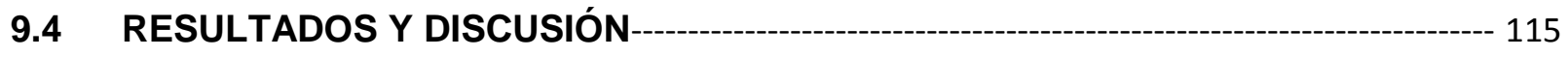

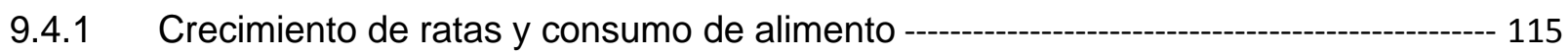

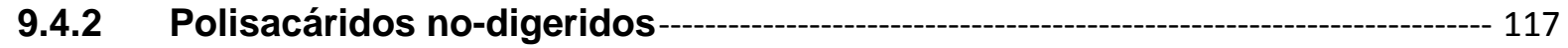

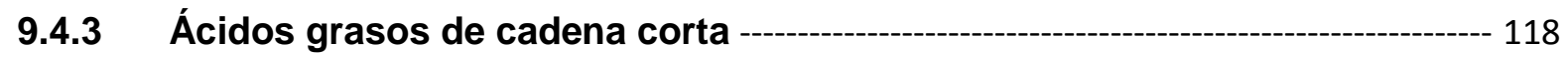

9.4.4 Análisis microbiológico - 120

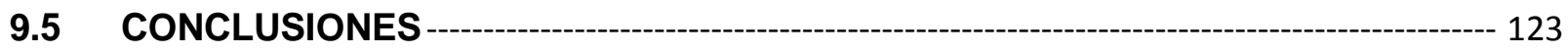

9.6 BIBLIOGRAFÍA------124

10. CAPÍTULO VI. CONCLUSIONES GENERALES --- 128 


\section{ÍNDICE DE TABLAS}

Tabla 1. Composición química y propiedades antioxidantes de las harinas de cáscara de tuna y

piña.

Tabla 2. Cinéticas de fermentación, $k$ (tasa específica de crecimiento) y $g$ (tiempo de duplicación), y parámetros de acidificación, $V \max$ (tasa maxima de acidificación), $t_{V \max }$ (tiempo para alcanzar $V$ max) y $\mathrm{pH}_{V_{\max }}(\mathrm{pH}$ a la $V$ max), para los diferentes tipos de cepas empleadas con diferentes fuentes de carbono (a $1.0 \% \mathrm{p} / \mathrm{v})$.

Tabla 3. $\mathrm{pH}$ final y cuenta viable final Log UFC/mL (N) al final de la fermentación (10 h) para las diferentes cepas con diferentes tipos de fuente de carbono (a 1.0\% p/v).

Tabla 4. Consumo de carbohidratos, determinación de ácido láctico y ácidos grasos de cadena corta durante las fermentaciones con diferentes fuentes de carbono a $1.0 \%(\mathrm{p} / \mathrm{v})$

Tabla 5. Actividad prebiótica para las cepas ácido lácticas utilizadas.

Tabla 6. Humedad total, humedad expresable y rancidez oxidativa de los diferentes tratamientos de salchichas durante su almacenamiento

Tabla 7. Color instrumental de los diferentes tratamientos de salchichas durante su almacenamiento

Tabla 8. Cuenta viable de bacterias ácido lácticas y $\mathrm{pH}$ de las diferentes formulaciones de salchichas durante su almacenamiento.

Tabla 9. Análisis de perfil de textura de los diferentes tratamientos de salchichas durante su almacenamiento.

Tabla 10. Escala múltiple de consumo de alimentos saludables. Versión original y su traducción correspondiente*

Tabla 11. Escala múltiple de neofobia alimentaria. Versión original y su traducción correspondiente. .84

Tabla 12. Tarjeta de información para la prueba de Neofobia.

Tabla 13. Matriz de respuesta para Índice $R$ por rating para sabor.

Tabla 14. Matriz de respuesta para el Índice R por ranking para firmeza.

Tabla 15. Identificación de los atributos en la evaluación de las salchichas.

Tabla 16. Perfil de consumidores de acuerdo al género y edad al consumo de alimentos nuevos.....

Tabla 17. Ji cuadrado para el nivel de neofobia por tipo de fibra..

Tabla 18. Índice $\mathrm{R}$ para diferentes tratamientos.

Tabla 19. Análisis de varianza para diferentes atributos en salchichas.

Tabla 20. Varianza explicada de componentes principales.

Tabla 21. Formulaciones de la dieta para el crecimiento de las ratas.

Tabla 22. Polisacáridos no-digeridos y producción de ácidos grasos de cadena corta en el ciego de la rata (Rattus norvegicus) de acuerdo a diferentes tipos de fibra incluidas en la dieta. ...... 119 Tabla 23. Análisis microbiológico del contenido del ciego de la rata (Rattus norvegicus) de acuerdo a diferentes tipos de fibra incluidas en la dieta. 


\section{ÍNDICE DE FIGURAS}

Figura 1. Clasificación de compuestos prebióticos en base a su origen (FOS: fructooligosacáridos; GOS: Gluco-oligosacaridos; IMO: isomaltooligosacáridos; SOS: oligosacáridos de soya; XOS: xilooligosacáridos) ........................................................................ 10

Figura 2. Microfotografías de las salchichas durante almacenamiento: control día 9 (a) y 20 (b); harina de cáscara de tuna día 9 (c) y 20 (d); harina de cáscara de tuna-BAL día 9 (e) y 20 (f). LAB: bacteria ácido láctica. MBM: matriz de batido cárnico. EPS: exopolisacárido. NSM: material no soluble.

Figura 3. Distribución general de la población para el consumo de alimentos saludables. ........ 90

Figura 4. Distribución de la población para el consumo de alimentos saludables de acuerdo al género.

Figura 5. Distribución de la población para el consumo de alimentos saludables de acuerdo a la edad.

Figura 6. Distribución de la población para el nivel de neofobia de acuerdo al tipo de fibra....... 94

Figura 7. Comparación de diferentes atributos de apariencia entre diferentes formulaciones de salchichas. $\left(^{*}\right)$ Diferencias significativas $(P<0.05)$.

Figura 8. Comparación de diferentes atributos de olor entre diferentes formulaciones de salchichas. $\left(^{*}\right)$ Diferencias significativas $(P<0.05)$.

Figura 9. Comparación de diferentes atributos de sabor entre diferentes formulaciones de salchichas. $\left(^{*}\right)$ Diferencias significativas $(P<0.05)$. 100

Figura 10. Comparación de diferentes atributos de textura entre diferentes formulaciones de salchichas. $\left(^{*}\right)$ Diferencias significativas $(P<0.05)$. 101

Figura 11. Análisis de componentes principales del análisis sensorial descriptivo de salchichas inoculadas con $P$. pentosaceus UAM22 adicionadas con harina de cáscara de tuna o piña. Apariencia (1-4;color claro/oscuro, brilloso, homogéneo y compacto, respectivamente); Olor (511; consomé de pollo, ahumado, dulce, cocido, carne de cerdo, fermentado y rancio, respectivamente); Sabor (12-23; salado, dulce, ahumado, rancio, especias, cocido, grasa, carne de cerdo, astringente, amargo, consomé de pollo y fibra, respectivamente); Textura (24-29; dureza, plástica, grasosa, fibrosa, gomosa y humedad, respectivamente).

Figura 12. Biplot de Análisis de componentes principales mediante caracterización de productos (testigo, tuna y piña).

Figura 13. Crecimiento de las ratas durante 13 semanas de alimentación con diferentes tipos de fibra.

Figura 14. Consumo de alimento semanal de diferentes tipos de fibra por parte de las ratas. 117 


\section{RESUMEN}

El objetivo de este trabajo fue evaluar in vitro e in vivo el efecto prebiótico de las harinas de cáscara de tuna y piña. Se determinó la composición química y capacidad antioxidante de la harina de cáscara de tuna y piña. Posteriormente, ambas harinas fueron usadas como fuente de carbono en cinéticas de crecimiento para Pediococcus pentosaceus UAM22 y Aerococcus viridans UAM21, para determinar el efecto prebiótico in vitro. Además, se aplicó un diseño factorial completo para determinar el efecto de la harina de cáscara de tuna y piña, $P$. pentosaceus UAM22 y tiempo de almacenamiento sobre los parámetros fisicoquímicos, funcionales y sensoriales de un producto cárnico cocido. Por último, tomando en consideración los resultados previos, el efecto in vivo se llevó a cabo suministrando harina de cáscara de tuna en la dieta de 16 ratas (Rattus norvegicus) cepa Wistar usando además inulina de agave como fuente de fibra control durante 84 días; se realizaron análisis para evaluar el efecto fisiológico y microbiológico sobre las ratas.

De acuerdo a la composición química de las harinas, la harina de cáscara de piña presentó un mayor porcentaje proteico que la harina de cáscara de tuna; sin embargo, la harina de cáscara de tuna mostró mayor contenido de minerales, carbohidratos solubles disponibles y fibra dietética total; la actividad antioxidante y la actividad antioxidante equivalente de Trolox (TEAC) también fueron mayores con harina de cáscara de tuna. Durante las cinéticas de crecimiento se observó mejor aprovechamiento de ambas harinas por parte de Pediococcus pentosaceus UAM22, siendo mayor la tasa de crecimiento y acidificación al usar harina de cáscara de tuna como fuente de carbono, viéndose reflejado en una mayor producción de ácidos grasos de cadena corta. Así mismo, Pediococcus pentosaceus UAM22 presentó los mayores niveles de actividad prebiótica con ambas harinas. Por otro lado, las salchichas con ambas harinas fueron más húmedas, pero las salchichas inoculadas presentaron menor humedad expresable; la harina de cáscara de tuna disminuyó la rancidez oxidativa durante el almacenamiento; la inoculación de bacterias ácido lácticas y las harinas causó un aumento en la luminosidad pero menos rojas y amarillas; las muestras inoculadas y con harina de cáscara de tuna tuvieron una estructura más fuerte pero menos cohesiva y menos resiliente; las microfotografías mostraron la producción de exopolisacáridos por la cepa empleada y harina de cáscara de tuna, lo cual explica las propiedades de retención de agua y textura de las salchichas. El análisis sensorial demostró interés por consumir alimentos saludables y mayor neofobia por consumir salchichas con harina de cáscara de tuna, sin embargo, los perfiles sensoriales no mostraron diferencias en olor y textura entre salchichas con harina de cáscara de 
tuna y testigo observando mayor aceptación de harina de cáscara de tuna. Los resultados del estudio in vivo reflejaron que el peso de las ratas así como el consumo de alimentos fue similar con harina de cáscara de tuna e inulina, pero con harina de cáscara de tuna hubo menor digestión de la fibra, sin embargo, hubo mayor producción de ácidos grasos de cadena corta.

El empleo de subproductos agroindustriales favorece la reducción de residuos en el ambiente, dándole un valor agregado.

La utilización de cáscaras de tuna o piña puede ser una alternativa como fuente de ingredientes funcionales alimenticios, para favorecer las características de los alimentos y generar beneficios a la salud. 


\section{ABSTRACT}

The aim of this study was to evaluate the in vitro and in vivo effect of prebiotic characteristics of cactus pear peel and pineapple peel flour. The chemical composition and antioxidant capacity of cactus pear peel and pineapple peel flour were determined. Subsequently, both samples were also used as a carbon source for growth kinetics of Pediococcus pentosaceus UAM22 and Aerococcus viridans UAM21 to determine the prebiotic effect in vitro. In addition, a factorial design was performed to determine the effect of cactus pear peel and pineapple peel flour, $P$. pentosaceus UAM22 and storage time on physicochemical, functional and sensory parameters a cooked meat product. Finally, taking into account the previous results, the in vivo effect was carried out by supplying cactus pear peel flour in the diet of 16 rats (Rattus norvegicus) Wistar strain, also using agave inulin as a fiber source of reference during 84 days; analyses were performed to assess the physiological and microbiological effects on the rats.

According to the chemical composition of flour, pineapple peel flour had a higher percentage of protein than cactus pear peel flour; however, cactus pear peel flour showed higher mineral content, soluble carbohydrates and total dietary fiber available; and the antioxidant activity of Trolox equivalent antioxidant activity (TEAC) were greater with cactus pear peel flour. During the growth kinetics better use of both flours was observed by Pediococcus pentosaceus UAM22, with a higher growth rate and acidification using cactus pear peel flour as a carbon source, seeing reflected in increased production of short-chain fatty acids. Also, Pediococcus pentosaceus UAM22 had the highest levels of prebiotic activity with both flours. Furthermore, the sausages were both flours had more moisture but inoculated sausages showed lower expressible moisture; cactus pear peel flour decreased oxidative rancidity during storage; inoculation of lactic acid bacteria and flours caused increased lightness but less redness and yellowness; inoculated and cactus pear peel flour samples had a stronger less cohesive and less resilient structure but; micrographs showed exopolysaccharide production by the strain used cactus pear peel flour, which explains the properties of water retention and texture of the sausage. Sensory analysis showed interest in consuming more healthy foods and more food neophobia to eat sausage with cactus pear peel flour than pineapple peel flour however, sensory profiles showed no difference in smell and texture attributes between sausages with cactus pear peel flour. This study reflects the in vivo rat weight and food intake was similar with cactus pear peel flour or inulin, but cactus pear peel flour was lower fiber digestion, however causing increased production of short-chain fatty acids.

The use of agroindustrial by-products helps reduce waste in the environment, giving added value. Use cactus pear and pineapple peel flour can be an alternative source of functional food ingredients to favor features food and generate the same health benefits. 


\section{INTRODUCCIÓN}

Al establecer la relación que guarda el balance en la población microbiana intestinal con la salud y bienestar del huésped se consideró necesaria la búsqueda de mecanismos alternativos que permitieran la mejora de la actividad metabólica del colon, desarrollándose el concepto prebiótico como respuesta a la necesidad de asegurar la supervivencia de los probióticos durante su paso por el tracto gastrointestinal y ayudando en los efectos antagónicos contra patógenos.

Como parte de un área de investigación reciente y por tratarse de productos de consumo humano el término prebiótico se encuentra aún en desarrollo debido principalmente al surgimiento constante de nuevas fuentes potenciales de compuestos prebióticos. Así mismo, el continuo desarrollo de productos alimenticios funcionales es una práctica que ha tomado gran importancia en la actualidad. Diversas enfermedades relacionadas con una alimentación deficiente, permiten cada vez más el creciente consumo de este tipo de productos como una alternativa más.

De esta manera, los ingredientes prebióticos se consideran parte de aquellos alimentos funcionales que tienen gran interés en la población, la industria alimentaria y la comunidad científica, ya que pueden modificar de manera positiva los procesos fisiológicos y biológicos en la nutrición o como auxiliares en el tratamiento de enfermedades humanas. Actualmente, se buscan nuevas fuentes naturales para ser utilizadas como fuente de fibra y como posibles prebióticos.

En la naturaleza, existen diversas fuentes de carbono representadas por plantas, frutos y sus respectivos sub-productos como alternativas de fuente de carbono que podrían ser utilizadas como sustratos prebióticos para el óptimo crecimiento de bacterias. Los sub-productos agrícolas son utilizados a menudo en la alimentación animal, compostas y biocombustibles; sin embargo, la mayoría de estos residuos forman parte de la contaminación habitual en el ambiente sin darle un valor agregado. Además, los residuos como la cáscara de tuna y piña son subproductos que debido a su composición pueden ser considerados como ingredientes funcionales y ser aplicados de manera exitosa tanto en el óptimo 
crecimiento de bacterias benéficas como en la formulación de diferentes alimentos.

Actualmente, el desarrollo de estudios para demostrar el efecto prebiótico de nuevas fuentes de compuestos prebióticos ha sido mediante estudios in vitro, sin llegar a tener resultados concluyentes en sistemas in vivo. Por lo que en este estudio se pretende tener resultados que soporten la hipótesis de usar cáscaras de tuna o piña como fuente prebiótica tanto in vitro como in vivo. Para este último, el uso de sistemas biológicos vivos, tales como ratas cepa Wistar, es una manera biológicamente similar a sistemas humanos que nos permite determinar tal objetivo.

Para hacer más comprensible este trabajo, se dividió en 6 capítulos, los cuales constan de un prolegómeno, metodología, resultados y discusión y la bibliografía específica. En el Capítulo 1 se presenta una revisión bibliográfica; posteriormente, en el Capítulo 2 se determina el efecto in vitro de las harinas de cáscaras de tuna y piña como fuente de carbono alterna sobfre el crecimiento de bacterias ácido lácticas. En el Capítulo 3 se presentan los resultados del efecto de las harinas de cáscara de tuna y piña sobre las características fisicoquímicas y funcionales de un batido cárnico cocido inoculado con bacterias ácido lácticas. En el Capítulo 4 se presentan los resultados de análisis sensorial de un batido cárnico adicionado con harina de cáscara de tuna. El Capítulo 5 se refiere al efecto in vivo de la harina de cáscara de tuna como fuente de fibra sobre las propiedades fisiológicas y microbiológicas de ratas (Rattus norvegicus) cepa Wistar, y por último, en el Capítulo 6 se presentan las conclusiones generales. 


\section{OBJETIVO GENERAL}

Evaluar in vitro e in vivo las características prebióticas de la harina de cáscara de tuna y piña para ser empleadas como ingredientes funcionales.

\subsection{Objetivos Específicos}

- Evaluar las harinas de cáscara de tuna y piña como fuente de carbono mediante cinéticas de crecimiento utilizando dos bacterias ácido lácticas.

- Analizar el efecto de las harinas de cáscara de tuna y piña, así como de las bacterias ácido lácticas sobre las propiedades fisicoquímicas y funcionales de un producto cárnico cocido.

- Analizar el efecto de la harina de cáscara de tuna y piña sobre las características sensoriales de un producto cárnico cocido.

- Evaluar el efecto in vivo de la harina de cáscara de tuna como fuente de fibra sobre parámetros fisiológicos y microbiológicos de la rata (Rattus norvegicus) cepa Wistar. 


\section{CAPÍTULO I: ANTECEDENTES}

Díaz-Vela, J., Parra-Matadamas, D. A. y Pérez-Chabela, M. L. Prebióticos. En: Bacterias Lácticas: conceptos y aplicaciones, editorial McGraw Latinoamericana. En prensa.

\subsection{PREBIÓTICOS}

\subsubsection{Definición}

Los alimentos con efecto prebiótico, fueron definidos primeramente como ingredientes alimenticios no-digeribles que afectan benéficamente al huésped por estimulación selectiva del crecimiento y/o actividad de una o un número limitado de bacterias en el colon, generando beneficios a la salud (Gibson y Roberfroid, 1995). La última definición del concepto de prebiótico ha sido: un ingrediente fermentable selectivo que permite cambios específicos, además de conferir beneficios sobre la composición y/o actividad de la microflora gastrointestinal (Gibson y col., 2004). Sin embargo, el concepto de prebiótico se le ha atribuido a diversos ingredientes alimenticios sin la debida consideración de los criterios requeridos. De manera que cualquier alimento que contenga carbohidratos, en particular oligosacáridos y polisacáridos (incluyendo algunas fibras dietéticas) podría ser un prebiótico, pero no todos los carbohidratos y fibras dietéticas son prebióticos (Gibson, 2004).

\subsubsection{Características}

Dentro de las características que debe reunir un ingrediente alimenticio para ser considerado como prebiótico se encuentran tres, las cuales han sido consideradas como las más importantes (Gibson y Roberfroid, 1995):

- Resistencia a los procesos digestivos en la parte superior del tracto gastrointestinal.

- Ser fermentables por la microflora intestinal, específicamente la que reside en el colon.

- Estimulación selectiva de crecimiento y/o actividad de un número limitado de las bacterias promotoras de la salud. 
La resistencia a diversos procesos enzimáticos a través del tracto gastrointestinal es parte esencial de aquellos alimentos llamados nutrientes del colon, ya que deben ser no-digeribles, y pueden ser monómeros, oligómeros o polímeros adsorbidos hasta ser hidrolizados por la microbiota que habita el colon y por consiguiente ser precursores de células procariotas. Estos nutrientes del colon pueden ser clasificados como generales (como las fibras dietéticas) o específicos de acuerdo a las funciones que estos desempeñan junto con los microorganismos benéficos (Roberfroid, 2008).

Con respecto a la fermentabilidad, los prebióticos deberán ser fermentados únicamente por bacterias del colon, lo cual puede ser demostrado por fermentaciones in vitro en reactores simuladores de alguna parte del intestino en condiciones controladas. La fermentación de los prebióticos puede promover algunas funciones fisiológicas especificas a través de la liberación de metabolitos por las bacterias, en especial los ácidos grasos de cadena corta (acetato, propionato, butirato, lactato, etc.) al lumen intestinal (Cummings y col., 2001).

Las bacterias del colon presentan diferentes grados de fermentación dependiendo de los carbohidratos que vayan a metabolizar, aquellos carbohidratos con un bajo nivel de polimerización son metabolizados de una forma más efectiva aun por encima de azúcares como la glucosa (Bustamante y col., 2006).

Aunque cada uno de estos criterios es importante, la demostración de selectividad en la estimulación del crecimiento y/o actividad de bacterias no resulta ser tan sencillo, debido al número tan variado de especies que habitan en el sistema digestivo. Siendo la selectividad, la característica más importante para un ingrediente que pueda ser considerado como prebiótico, debido a la variedad de microorganismos y por consiguiente las rutas metabólicas que utilice para metabolizar los carbohidratos (Roberfroid, 2008). Los prebióticos más que favorecer el crecimiento de bacterias exógenas como los probióticos, se dirigen a favorecer a las bacterias ya presentes en el colon, cuya atención se ha centrado en incrementar el número de bacterias como Lactobacillus y Bifidobacterium.

Otros de los beneficios que se obtienen de los prebióticos es la absorción de una variedad de minerales, como pueden ser el calcio, magnesio, hierro y zinc, 
mediante la fermentación de ácidos grasos de cadena corta, esto mediante la disminución del pH del medio y de esta manera solubilizar los minerales (ScholzAhrens y col., 2001).

\subsubsection{Clasificación}

Al igual que el concepto, la clasificación de los compuestos prebióticos no se encuentra totalmente definida, esta puede basarse en criterios como el origen de las sustancias, el grado de polimerización (número de monómeros) o sus características fisicoquímicas. La Figura 1 muestra una clasificación de los principales compuestos prebióticos estudiados en base a su origen: prebióticos sintéticos y prebióticos naturales.

Los prebióticos sintéticos son obtenidos a partir de la degradación enzimática de polisacáridos como xilanos, inulina y almidones, así como por la síntesis enzimática a partir de azúcares simples como lactosa y sacarosa mediante el uso de enzimas glicosiltransferasas y glicosidasas. Los prebióticos naturales se encuentran de forma cotidiana en las partes comestibles y estructurales de plantas y en pequeñas porciones en leche humana y calostro animal. 


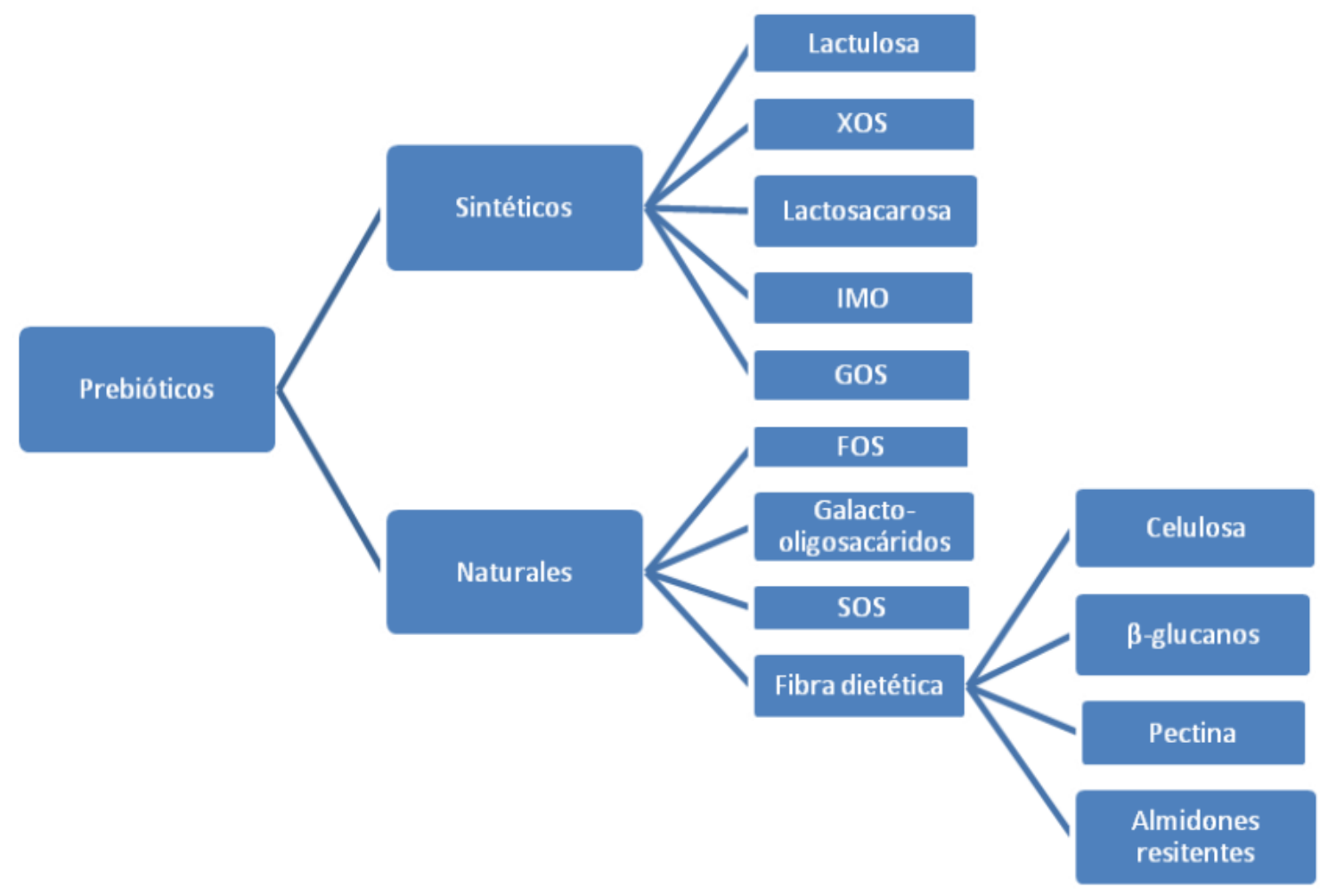

Figura 1. Clasificación de compuestos prebióticos en base a su origen (FOS: fructooligosacáridos; GOS: Gluco-oligosacaridos; IMO: isomaltooligosacáridos; SOS: oligosacáridos de soya; XOS: xilooligosacáridos).

\subsubsection{Prebióticos sintéticos}

\subsection{Lactulosa}

El disacárido lactulosa es un disacárido no digerible producido a partir de lactosa mediante un proceso de isomerización alcalina para convertir la molécula de glucosa del sustrato a un residuo de fructuosa con una estructura en la forma Gal $\beta$ (1-4) Fru. Uno de sus principales inconvenientes es el elevado costo de producción debido no solo al bajo rendimiento (20-30\%) sino también a los procesos de purificación, ya que moléculas de galactosa, ácidos iso-sacáridos y productos coloridos son producidos por la degradación parcial del mismo (Mussatto y Macilha, 2007). Se trata de un compuesto soluble en agua que puede ser fermentado por bacterias en el intestino grueso incrementando la población de los microorganismos nativos benéficos, bifidobacterias principalmente, además de ayudar en la prevención de cáncer de colon, reducir la población de patógenos y 
constipación instestinal, y mejorar la inmunidad del huesped (Thammarutwasik y col., 2009).

\subsection{Xilo-oligosacáridos}

Los xilo-oligosacáridos (XOS) son cadenas de xilosa unidas por enlaces $\beta(1-4)$ y consisten principalmente de xilobiosa, xilotriosa y xilo-tetraosa, la producción a escala industrial se lleva a cabo mediante la hidrólisis enzimática de polisacáridos de xilano extraídos de materiales lignocelulíticos como mazorcas de maíz, paja, orujos, y cascarillas de malta y salvado; los estudios en torno al efecto sobre cultivos puros indican que los XOS pueden ser metabolizados por un gran intervalo de especies pertenecientes a los géneros Bifidobacterium y Lactobacillus, sin ser susceptibles a la fermentación por patógenos como Clostridium butyricum, C. difficile y E. coli (Roberfroid, 2008).

\subsection{Lactosacarosa}

Se trata de un trisacárido producido por una reacción de transferencia reversible a partir de lactosa y sacarosa utilizando la actividad de trans-fructosilación de la enzima $\beta$-fructofuranosidasa. En esta reacción el residuo fructosil de sacarosa es transferido hacia la lactosa formando el trisacárido no digerible lactosacarosa, el inconveniente de la síntesis de este prebiótico es el bajo rendimiento de producción $(52 \%)$ debido a que la enzima no solo cataliza la reacción de transferencia sino además cataliza la hidrólisis de sacarosa y de la misma lactosacarosa. Los estudios realizados con este compuesto como parte de la dieta de individuos con constipación crónica demostraron incremento en la población de bifidobacterias con una disminución de clostridia y bacteroides (Mussatto y Macilha, 2007).

\subsection{Isomalto-oligosacáridos}

Los isomalto-oligosacáridos (IMO) contienen residuos de a-D-glucosa unidos por enlaces glicosídicos $\alpha(1-6)$. La síntesis de IMO es realizada a partir de la hidrólisis de almidón por la acción combinada de a-amilasa y pululanasa seguida de la isomerización de los malto-oligosacáridos (MOS) resultantes por a-glucosidasa que cataliza una reacción de transferencia convirtiendo los enlaces $\alpha(1-4)$ de los 
MOS en enlaces $\alpha(1-6)$ de IMO (Roberfroid, 2008). Estudios realizados con cultivos puros de $B$. adolescentis, $B$. longum, $B$. breve y $B$. infantis con IMO como fuente de carbono mostraron la capacidad de estas especies de metabolizar los oligosacáridos no digeribles con incrementos significantes en las poblaciones finales y aumento en la producción de butirato (Thammarutwasik y col., 2009).

\subsection{Gluco-oligosacáridos}

Son oligosacáridos no digeribles sintetizados por la enzima dextran-sacarasa con sacarosa y maltosa como sustratos, el oligosacárido resultante contiene enlaces $\alpha(1-2)$ como el siguiente tetra-sacárido: glucosil $\alpha(1-2)$ glucosil $\alpha(1-6)$ glucosil $\alpha(1-$ 4)glucosa. Los gluco-oligosacáridos (GOS), son también producidos por medio de fermentación en presencia de Leuconostoc mesenteroides, han mostrado ser rápidamente utilizados por bifidobacterias y lactobacilos en cultivos puros sin mostrar incrementos en la población de C. butyricum, Salmonella spp. y $E$ coli (Roberfroid, 2008).

\subsubsection{Prebióticos naturales}

\subsection{Fructanos tipo inulina}

También denominados fructo-oligosacáridos (FOS), es el grupo de los oligosacáridos no-digeribles (OND) caracterizados por una estructura del tipo Glu $\alpha(1-4)$ [ $\beta$ Fru 1-2]n, donde $n=10-14$ (Roberfroid, 2008). A este grupo pertenece el oligosacárido inulina, con un grado de polimerización menor (entre 3 y 60 unidades). La inulina es uno de los principales carbohidratos encontrados en la naturaleza (después del almidón), principalmente en la familia Chicorium, por ejemplo achicoria, plátano, cebolla, ajo, espárragos, alcachofa y agave (Thammarutwasik y col., 2009), razón por la cual es uno de los principales oligosacáridos no digeribles estudiados y utilizados en la industria alimenticia. Los estudios realizados con este compuesto han mostrado su efecto bifidogénico y han permitido entender que el impacto sobre la salud varía dependiendo de la dosis, el periodo de administración e incluso la edad del consumidor, con un impacto positivo en los niveles de triglicéridos y colesterol en sangre por la producción de ácidos grasos de cadena corta (lo que indica el cambio en la 
actividad bacteriana del colon), la disminución en el riesgo de contraer cáncer de colon (por la disminución de patógenos y los metabolitos tóxicos que estos generan) y el aumento en la absorción de minerales como calcio y magnesio (Franck y Bosscher, 2009). Entre las características que favorecen su uso (además del probado efecto prebiótico) destacan su baja carga calórica y su neutralidad sensorial al ser incorporada en sistemas alimenticios promoviendo su uso en fórmulas lácteas para infantes.

\subsection{Galacto-oligosacaridos}

Los galacto-oligosacáridos son oligosacáridos no digeribles naturales con unidades de galactosa como monómero, en la estructura Glu a (1-4)[ $\beta$ Gal 1-6]n, donde $n=2-5$, se pueden encontrar en leche humana, leche de vaca y yogurt además de poder ser sintetizados enzimáticamente a partir de lactosa con $\beta$ galactosidasa (Gibson, 2004); al ser hidrolizados en el intestino grueso producen ácidos grasos de cadena corta y gases como $\mathrm{H}_{2}, \mathrm{CH}_{4}$ y $\mathrm{CO}_{2}$ con la producción de otros compuestos a partir de su hidrólisis como el lactato, son capaces de mejorar el crecimiento de bifidobacterias y lactobacilos, microorganismos que ayudan en la síntesis de vitaminas y estimulan el sistema inmune además de inhibir la adhesión de patógenos entéricos al imitar estructuralmente los sitios de unión que cubren la superficie de las células epiteliales (Laparra y Sanz, 2010).

\subsection{Oligosacáridos de soya}

Los oligosacáridos de soya (SOS, por sus siglas en inglés), están formados por rafinosa, estaquiosa y verbascosa, principales oligosacáridos contenidos en la soya, los cuales constan de 1, 2 o 3 moléculas de galactosa unidas mediante enlaces $\alpha(1-6)$ y ligados por medio de un enlace tipo $a(1-3)$ a una molécula terminal de sacarosa; son capaces de resistir la hidrólisis ácida por el paso en el tracto gastrointestinal mejorando el crecimiento de bifidobacterias y lactobacilos en el colon (Mussatto y Mancilha, 2007). 


\subsection{Fibra dietética}

Otro grupo de compuestos prebióticos que ha tomado un papel importante por su uso y aplicación en alimentos es el de la fibra dietética (FD); existen indicios que asocian a la fibra de origen vegetal con la dieta humana desde hace decenas de miles de años atrás con una disminución notable en su consumo debido principalmente a la evolución en el estilo de vida del ser humano (Burkit y Spiller, 2001).

Trowell y col. (1976) formaron parte de los pioneros en el estudio del efecto del consumo de fibra dietética sobre la salud, definiéndola como "sustancias de origen vegetal que no pueden ser digeridas por enzimas humanas, incluyendo componentes de la pared celular y polisacáridos intracelulares de plantas"; en la actualidad la fibra dietética se define como "oligosacáridos no digeribles que se encuentran de forma intrínseca en plantas como componentes de la pared celular y/o carbohidratos de almacenamiento capaces de resistir la hidrólisis por parte de las enzimas humanas con efectos fisiológicos benéficos en el organismo al consumirlos" (American Dietetic Association, 2008) cambio originado por los avances en materia del tipo de compuestos que forman parte de la fibra dietética, sus características y su efecto sobre la salud del consumidor.

Entre los beneficios por el consumo de FD se encuentran el incremento en el bolo fecal (disminución del tiempo de tránsito en el tracto gastrointestinal), la estimulación de la fermentación en el colon, la disminución del índice glicémico y de los niveles de colesterol en sangre y la reducción en el riesgo de padecer enfermedades coronarias, diabetes y obesidad además de presentar propiedades fisicoquímicas con funcionalidad en sistemas alimenticios como son la capacidad de retención de agua y/o aceite, estabilidad a la emulsificación y formación de geles, propiedades que pueden ser aprovechadas para modificar características sensoriales y optimizar los procesos de producción (Cho, 2009). La FD puede ser dividida en dos fracciones: fibra dietética soluble (FDS) la cual es soluble en agua a $100{ }^{\circ} \mathrm{C}$ y un $\mathrm{pH}$ de 6-7 y la fibra dietética insoluble (FDI) la cual no puede ser solubilizada en las mismas condiciones. 
La fracción insoluble está principalmente asociada a la movilidad intestinal, su consumo desacelera el proceso de absorción en el intestino delgado lo que causa una extensión en el sentimiento de saciedad, el mecanismo de protección contra padecimientos gastrointestinales está relacionado con la disminución del tiempo de tránsito y el incremento del peso de las heces. La fracción soluble se encuentra involucrada con el efecto reductor de los niveles de colesterol en sangre al aumentar la excreción de ácidos biliares y con la disminución de la absorción de macro-nutrientes como grasa y carbohidratos, ambos considerados factores de riesgo de padecimientos coronarios (Fernández-López y col., 2004).

En general, la FD está constituida por una mezcla de polímeros de carbohidratos de plantas, tanto oligosacáridos como polisacáridos, entre los que destacan la celulosa, pectinas, gomas y almidones resistentes; que pueden estar asociados con lignina y otros compuestos no carbónicos (polifenoles, ceras, saponinas, proteínas resistentes, etc.).

\subsection{Celulosa}

La celulosa como componente de la estructura primaria de todas las planta verdes (incluyendo vegetales) es uno de los bio-polímeros más comunes sobre la tierra y componente cotidiano en nuestra dieta. Se trata de un polímero linear de unidades $\beta$-(1-4)-D-glucopiranosas; la insolubilidad en agua de este polímero, a causa de su estructura cristalina, y la dificultad de ser digerida por enzimas humanas provoca el aumento en el volumen de las heces fecales con tiempos más cortos de tránsito en el tracto gastrointestinal; otro efecto benéfico es el aumento en la producción de AGCC como producto final, al ser metabolizado en el intestino delgado lo que se refleja en la disminución de la lipólisis y la estimulación en la proliferación de células epiteliales (Takahashi, 2009).

\subsubsection{6 $\beta$-glucanos}

Son polisacáridos ramificados compuestos por D-glucopiranosas unidas mediante enlaces $\beta(1-4)$ y $\beta(1-3)$ en variadas proporciones, se encuentra comúnmente en cereales como la avena, el trigo y el centeno junto con arabinoxilanos y celulosa. Son usados en la industria alimenticia como espesantes además de mejorar la 
calidad sensorial en productos de panificación (Tapola y Sarkkinen, 2009). Respecto a su uso terapéutico, importantes efectos positivos han sido reconocidos tras su ingesta recurrente como la reducción en el riesgo de padecimientos del corazón, disminución del colesterol y la respuesta glucémica y el crecimiento selectivo de lactobacilos y bifidobacterias (Charalampopoulos y col., 2002).

\subsection{Pectina}

La pectina es un polisacárido formado por moléculas de ácido D-galacturónico en cadenas lineares unidas por enlaces glicosídicos $\alpha(1-4)$, en las cuales se encuentran insertadas unidades de L-ramnopiranosas por un enlace tipo $\alpha(1-2)$, lo que interrumpe la cadena linear resultando moléculas con forma de zig-zag. La pectina junto con la celulosa, hemicelulosa, glicoproteínas y lignina forma parte de la pared celular de plantas mayores, frutas y vegetales; lo que explica su abundancia en subproductos agroindustriales. La pectina además de ser soluble en agua es estable a valores bajos de $\mathrm{pH}(2-4.5)$ debido principalmente al grado de esterificación permitiendo su paso a través del tracto gastrointestinal sin ser absorbido hasta llegar al colon donde existe flora microbiana capaz de producir enzimas degradadoras de pectinas (pectin esterasa, endo-poligalacturonasa y pectin liasa), como algunas especies pertenecientes a los géneros Bacteroides, Lactobacillus y Bifidobacterium; la capacidad de estos microorganismos para utilizar pectina como sustrato genera un aumento en la población microbiana benéfica, incrementando los niveles de producción de AGCC y gases como metano, dióxido de carbono e hidrógeno afectando positivamente la salud del huésped (Endress y Mattes, 2009).

\subsection{Almidones resistentes}

Otro grupo de polisacáridos agrupado como fibra dietética es el de los almidones resistentes, polímeros de glucosa que se forma por dos polisacáridos muy similares entre sí, amilosa y amilopectina; el primero es producto de la condensación de D-glucopiranosas por medio de enlaces glicosídicos $\alpha(1-4)$, estableciendo largas cadenas lineales de entre 200 y 2500 unidades cuya unidad repetitiva es la $\alpha$-maltosa. Por su parte la amilopectina contiene ramificaciones 
unidas a la cadena central (amilosa) por enlaces $\alpha(1-6)$ localizadas cada 15-25 unidades lineales de glucosa (Valdés, 2006).

La resistencia a la digestión de los almidones depende de una variedad de factores incluyendo la estructura granular, la relación amilosa-amilopectina y la fuente de almidón; son divididos en cuatro grupos en función de sus propiedades fisicoquímicas: 1) almidones resistentes tipo 1 (AR1), se encuentran incrustados en la matriz de alimentos como granos de cereales y legumbres y son susceptibles de ser liberados por procesos físicos como la masticación o la molienda; 2) los del tipo 2 (AR2) o cristalizados, los cuales no pueden ser degradados enzimáticamente sin antes ser gelatinizados, se encuentran comúnmente en papa, plátano y harina de maíz; 3) los del tipo 3 (AR3) o retrogrado, se trata de almidones que cambian su conformación ante fenómenos como el calor o el frio por lo que se encuentran comúnmente en el pan, cereales, papas cocidas o enfriadas y alimentos precocinados y 4) los almidones tipo 4 (AR4) o modificados, obtenidos químicamente de forma industrial encontrándose en alimentos procesados como pasteles o alimentos infantiles (Escudero y González, 2006).

Entre los efectos sobre la salud destacan la producción de AGCC provocando una disminución en el pH del medio lo que inhibe el desarrollo de patógenos en el tracto gastrointestinal, el incremento en la masa fecal con una disminución en el tiempo de transito de la misma y una disminución en la respuesta glicémica, esto bajo un consumo recurrente (Finocchiaro y col., 2009).

\subsection{SUBPRODUCTOS AGROINDUSTRIALES COMO FUENTE DE FIBRA}

De los diferentes sub-productos agroindustriales investigados alrededor del mundo destacan los de origen cítrico, debido a la gran cantidad de alimentos procesados como jugos y bebidas, además de ser de los principales frutos consumidos a nivel mundial, destacando la obtención de compuestos con importancia biotecnológica como fibra, ácidos orgánicos, aminoácidos, vitaminas, minerales, y aceites esenciales (Marín y col., 2007), además de algunos compuestos antioxidantes, principalmente flavonoides (Balasundram y col., 2006). Leontowicz y col. (2003) estudiaron la composición química de la cáscara de manzana y pera encontrando 
concentraciones superiores al $20 \%$ de fibra dietética compuesta en su mayoría por la fracción insoluble además de importantes concentraciones de compuestos fenólicos (alrededor de 120 ppm).

Emaga y col. (2008) evaluaron el potencial de cáscara de plátano como fuente de fibra dietética y pectina al analizar la composición química de éstos y reportaron una concentración superior al $30 \%$ de fibra dietética total con importantes concentraciones de pectina, celulosa y hemicelulosa. Por otra parte, Chantaro y col. (2008) encontraron concentraciones de fibra dietética total superiores al $50 \%$ en cáscaras de zanahoria, además determinaron el efecto que tiene sobre estos materiales el procesamiento previo como el secado y "blanqueado" para la obtención de la fibra determinando que no existe efecto negativo sobre el contenido de fibra y compuestos antioxidantes al escaldar los subproductos agroindustriales mientras que temperaturas superiores a los $80^{\circ} \mathrm{C}$ por tiempos superiores a los 45 min provocan una disminución en la fibra dietética total y la actividad antioxidante.

\subsubsection{Tuna}

La tuna es un fruto de las plantas pertenecientes a la familia de las cactáceas, del genero Opuntia, especie según el tipo comercial, de forma oval u oblonga; de cascara gruesa que va del color verde al amarillo o rojo y cubierta de gloquidios, de pulpa verdosa amarilla, anaranjada o roja, de sabor dulce y jugosa, la cual contiene un gran número de semillas (NMX-FF-030-1995-SCFI).

A nivel mundial, la producción de tuna es de gran relevancia, siendo países como Italia, Israel, Sudáfrica, Estados Unidos, Colombia y Chile con una competencia significativa contra México. Siendo Italia y México los principales exportadores. La tuna se cultiva principalmente en zonas áridas y semiáridas, por lo que en México su cosecha es de temporal. La cosecha se contempla entre los meses de Marzo a Noviembre, representada principalmente por el estado de Puebla, Estado de México, Hidalgo y algunos de la región del Centro-Norte. La variedad "Villanueva" es posible cultivarla desde Marzo a Noviembre en la región de sur (San Sebastián Villanueva, Puebla) con una mayor producción en los meses de Junio, Julio y Agosto. En México más de 20,000 productores se dedican a la cosecha de la tuna, 
distribuida en zonas del Norte-Centro, Centro y Sur del país alcanzando un promedio de 500,000 toneladas al año (Flores y Gallegos, 1995).

El aprovechamiento de este fruto a nivel industrial es reducido considerando solo la elaboración de yogurt y mermelada. El mayor consumo se realiza generalmente como fruta fresca y en jugo; en la cocina tradicional se elaboran productos como el queso de tuna, "melcocha" (producto lácteo) y "colonche" (bebida fermentada) (Flores y Gallegos, 1995). De manera general, se contempla un amplio aprovechamiento de la pulpa, existiendo escasos estudios de investigación sobre subproductos de este fruto, como la cáscara.

Recientemente, Chávez-Zepeda y col. (2009) realizaron análisis fisicoquímicos a diferentes residuos agroindustriales de frutos, dentro de los cuales se encontraba la cáscara de tuna. Ellos reportan un alto contenido de fibra dietética total (64.15 $\%$ peso seco) en la cáscara de tuna comparado con otras fuentes como jícama, plátano, manzana, mango, zanahoria, hoja de maguey, albedo de toronja y piña.

\subsection{INCORPORACIÓN DE FIBRA DIETÉTICA EN PRODUCTOS CÁRNICOS}

El uso de oligosacáridos no digeribles en productos cárnicos puede tener dos objetivos principales: 1) el aprovechamiento de sus propiedades fisicoquímicas en el procesamiento de este tipo de productos 0 2) como fuente de compuestos prebióticos para el desarrollo de productos enriquecidos en fibra o productos simbióticos, denominando así a aquellos productos que incorporan en un mismo sistema compuestos pro y prebióticos (Kuan y Liong, 2008). Las propiedades fisicoquímicas de la FD que afectan las propiedades del producto durante su procesamiento y la calidad final del mismo son la absorción de moléculas orgánicas, la capacidad de retención de agua y aceite, la retención de minerales y la actividad antioxidante que presentan estos materiales (Mussatto y Mancilha, 2007).

Algunas fibras han mostrado la absorción de moléculas orgánicas como los ácidos biliares y algunos carcinógenos como los benzopiranos disminuyendo la concentración sérica de colesterol y el riesgo de padecer algunos tipos de cáncer, respectivamente. Por otra parte la capacidad de retención de agua indica la cantidad de agua que puede ser retenida por la fibra, que al ser incorporada en 
productos cárnicos representa un aumento en los rendimientos finales confiriendo una mayor estabilidad durante el proceso y un enriquecimiento nutricional del mismo; la baja capacidad de retención de aceite de estos materiales significa una disminución en los contenidos de grasa del sistema alimenticio permitiendo la formulación de productos cárnicos bajos en grasa sin comprometer propiedades como la textura. Otra propiedad interesante es la actividad antioxidante de estas fibras, debido al contenido de compuestos fenólicos, lo que mejora la estabilidad del alimento al retrasar la peroxidación de lípidos, proceso responsable del deterioro de los mismos, que se traduce en un aumento de la vida de anaquel (Tungland y Meyer, 2002).

La utilización de fibras de cereales (tales como trigo y avena) y de frutos (como manzana, durazno y naranja) en concentraciones de 1.5 y $3 \%$ respectivamente, se han utilizado satisfactoriamente para la sustitución de grasa en embutidos fermentados (García y col., 2002). Obteniendo mejores resultados cuando se utilizaron formulaciones con $1.5 \%$ de fibra de naranja y $10 \%$ de grasa.

Aleson-Carbonell y col. (2003) utilizaron albedo de limón en salchichas secas curadas como fuente de fibra, ellos evaluaron su efecto sobre el perfil sensorial y composición química, encontrando que la incorporación de este sub-producto además de representar una importante fuente nutricional, disminuyó la concentración de nitritos residuales así como el retraso en la oxidación del producto, sin embargo, la aceptación del mismo se vio influenciada negativamente de forma proporcional a la concentración de albedo incorporada.

Cáceres y col. (2004) reportaron buena aceptación en salchichas cocidas elaboradas con fibra dietética soluble como sustituto de grasa, mejorando además, características como color y textura sin afectar de manera significativa la apariencia de estos productos. Fernández-López y col. (2007) evaluaron el potencial de fibra de naranja como ingrediente funcional durante el secado de salchichas curadas al monitorear el cambio en la composición química (nitritos residuales y peroxidación lipídica) y en parámetros físico-químicos (color y $\mathrm{pH}$ ), los resultados obtenidos mostraron una disminución en la producción de sustancias reactivas con ácido tiobarbitúrico (TBARS, por sus siglas en inglés), lo que indica 
una disminución en la peroxidación de lípidos, así como en la concentración de nitritos residuales, por otro lado, el comportamiento del $\mathrm{pH}$ en las salchichas curadas mostró un aumento durante el proceso de secado, asociado al incremento en la población de BAL durante la fermentación, indicando la susceptibilidad de la FD para ser empleada como fuente de carbono.

En un estudio realizado por Hur y col. (2009) fue evaluada la digestión in vitro de lípidos en hamburguesas de carne de res adicionadas con celulosa quitosano y pectina $(0.5 \%)$, los resultados obtenidos mostraron una disminución en la concentración de ácidos grasos libres así como en la concentración de TBARS principalmente en las formulaciones con quitosano y pectina.

Sánchez-Zapata y col. (2011) estudiaron las propiedades tecnológicas de una pasta obtenida a partir de los sub-productos AGI de dátiles así como su efecto sobre un producto cárnico cocido, obteniendo un producto bajo en grasa y con alto contenido de fibra además de mejorar las propiedades de textura del mismo junto con una calidad sensorial satisfactoria.

En la práctica, los niveles de uso de prebióticos oscilan entre 2 y $4 \mathrm{~g} / \mathrm{kg}$ de producto, ofreciendo un valor calórico estimado entre 1 y 2 kcal/g (Livesey, 1992; Roberfroid y col., 1993). 


\subsection{BIBLIOGRAFÍA}

Aleson-Carbonell, L., Fernández-López, J., Sayas-Barberá, E., Sendra, E. y PérezÁlvarez, J. A. (2003). Utilization of lemon albedo in dry cured sausages. Journal of Food Science. 68: 1826-1830.

American Dietetic Association. (2008). Position of the American Dietetic Association: Health implications of dietary fiber. Journal of the American Dietetic Association. 108: 1716-1731.

Balasundram, N., Kalyana, S. y Samman, S. (2006). Phenolic compounds in plants and agroindustrial by-products: antioxidant activity, occurrence, and potential uses. Food Chemistry. 99: 191-203.

Burkitt, D. P. y Spiller, G. A. (2001). Dietary fiber: from early hunter-gatherers to the 1990's. En: Handbook of dietary fiber in human nutrition (3rd. Ed.). Spiller G. A. (Ed.). Nueva York, USA: CRC press.

Bustamante, C. P., Mayorga, R. L., Ramírez, S. H., Martínez, C. P., Barranco, F. E. y Azaola, E. A. (2006). Evaluación microbiológica de compuestos con actividad prebiótica. Revista Mexicana de Ciencia Farmacéuticas. 37: 5-9.

Cáceres, E., García, M. L., Toro, J. y Selgas, M. D. (2004). The effect of fructooligosaccharides on the sensory characteristics of cooked sausages. Meat Science. 68: 87-96.

Chantaro, P., Devahastin, S. y Chiewchan, N. (2008). Production of antioxidant high dietary fiber powder from carrot peels. LWT-Food Science and Technology. 41: 1987-1994.

Charalampopoulos, D., Wang, R., Padiella, S. S. y Webb, C. (2002). Application of cereals and cereal components in functional foods: a review. International Journal of Food Microbiology. 79: 131-141.

Chávez-Zepeda, L. P., Cruz-Méndez, G., Gracia de Caza, L., Díaz-Vela, J. y Pérez-Chabela, M. L. (2009). Utilización de sub-productos agroindustriales como fuente de fibra para productos cárnicos. NACAMEH. 3(2): 71-82.

Cho, S. (2009). Functional and dietary fibers: an introduction. En: Fiber ingredients, food applications and health benefits. Cho S. S. y Samuel P. (Eds.). Florida, USA: CRC press.

Cummings, J. I., Macfarlane, G. T. y Englyst, I. N. (2001). Prebiotic digestion and fermentation. American Journal of Clinical Nutrition. 73: 415- 420.

Emaga, T. H., Robert, C., Ronkart, S. N., Wathelet, B. y Paquot, M. (2008). Dietary fibre components and pectin chemical features of peels during ripening in banana and plantain varieties. Bioresource Technology. 99: 4346-4354.

Endress, H. U. y Mattes, F. (2009). Pectin En: Fiber ingredients, food applications and health benefits. Cho S. S. y Samuel P. (Eds.). Florida, USA: CRC Press. 
Escudero, Á. E. y González, S. P. (2006). La fibra dietética. Nutrición Hospitalaria. 21: 61-72.

Fernández-López, J., Fernández-Ginés, M., Aleson-Carbonell, L., Sendra, E., Sayas-Barberá, E. y Pérez-Álvarez, J. A. (2004). Application of functional citrus by-products to meat products. Food Science and Technology. 15: 176-185.

Fernández-López, J., Viuda-Martos, M., Sendra, E., Sayas-Barberá, E., Navarro, C. y Pérez-Álvarez, J. A. (2007). Orange fibre as potential functional ingredient for dry cured sausages. Europe Food Research Technology. 226: 1-6.

Finocchiario, E. T., Birkett, A. y Okoniewska, M. (2009). Resistant Starch En: Fiber ingredients, food applications and health benefits. Cho, S. S., y Samuel, P. (Eds.). Florida, USA: CRC Press.

Flores, V. C. A. y Gallegos, V. (1995). La producción de la tuna en México. En: Conocimiento y aprovechamiento del nopal. 6to Congreso Nacional y 4to Internacional. Memorias. Universidad de Guadalajara, Jalisco. México. pp. 274-278.

Franck, A. y Bosscher, D. (2009). Inulin En: Fiber ingredients, food applications and health benefits. Cho, S. S., y Samuel, P. (Eds.). Florida, USA: CRC Press.

García, M. L., Domínguez, R., Gálvez, M. D., Casas, C. y Selgas, M. D. (2002). Utilization of cereal and fruit fibres in low fat dry fermented sausages. Meat Science. 60: 227-236.

Gibson, G. R. (2004). Fibre and effects on probiotics (the prebiotic concept). Clinical Nutritions Supplements. 1:25-31.

Gibson, G. R. y Roberfroid, M. B. (1995). Dietary modulation of the colonic microbiota: Introducing the concept of prebiotics. Journal of Nutrition. 125: 1401-1412.

Gibson, G. R., Probert, H. M., Van Loo, J. A., Rastall, R. A. y Roberfroid, M. B. (2004). Dietary modulation of the human colonic microbiota: Updating the concept of prebiotics. Nutrition Research Reviews. 17: 259.

Hur S. J., Lim B. O., Park G. B. y Joo S. T. (2009). Effects of various fiber additions on lipid digestion during In vitro digestion of beef patties. Journal of Food Science. 74: 653-658.

Kuan, Y. H., y Liong, M. T. (2008). Chemical and physicochemical characterization of agrowaste fibrous materials and residues. Journal of Agricultural and Food Chemistry. 56: 9252-9257.

Laparra, J. M., y Sanz, Y. (2010). Interactions of gut microbiota with functional food components and nutraceuticals. Pharmacological Research. 61:219-225.

Leontowickz, M., Gorinstein, S., Leontowickz, H., Krzeminski, R., Lojek, A., Katrich, E., Ciz, M. Martin Belloso, O., Soliva-Fortuny, R., Haruenkit, R. y 
Trakhtenberg, S. (2003). Apple and pear peel and pulp and their influence on plasma lipids and antioxidant potentials in rats fed cholesterol-containing diets. Journal of Agricultural and Food Chemistry. 51: 5780-5785.

Livesey, G. (1992). The energy values of dietary fibre and sugar alcohols for man. Nutrition Research Reviews. 5: 61.

Marín, F.R., Soler Rivas, C., Benavente-García, O., Castillo, J. y Pérez-Álvarez, J. A. (2007). By-products from different citrus processes as a source of customized functional fibres. Food Chemistry. 100: 736-741.

Mussatto, S. I. y Mancilha, I. M. (2007). Non-digestible oligosaccharides: A review. Carbohydrate Polymers. 68: 587-597.

NMX-FF-030-1995-SCFI. Productos alimenticios no industrializados para uso humano-fruta seca-tuna (Opuntia spp). Especificaciones. Consultada de: http://200.77.231.100/work/normas/nmx/1995/nmx-ff-030-1995.pdf. Fecha de consulta: 3 de Julio de 2014.

Roberfroid, M. B. (2008). Prebiotics: concept, definition, criteria, methodologies, and products. En: Handbook of Prebiotics. Gibson, G. R. y Roberfroid, M. B. (Eds.). Boca Raton, FL: CRC Press.

Roberfroid, M. B., Gibson, G. R. y Delzenne, N. (1993). The biochemistry of oligofructose, a non-digestible fiber: An approach to calculate its caloric value. Nutrition Reviews. 51: 137.

Sánchez Zapata, E., Fernández López, J., Peñaranda, M., Fuentes Zaragoza, E., Sendra, E., Sayas, E. y Pérez Álvarez, J. A. (2011). Technological properties of date paste obtained from date by-products and its effect on the quality of cooked meat product. Food Research International. 44: 24012407.

Scholz Ahrens, K. E., Schaafsma, G., van den Heuvel, E. G. y Schrezenmeir, J. (2001). Effects of prebiotics on mineral metabolism. American Journal of Clinical Nutrition. 73: 459-464.

Takahashi, T. (2009). Cellulose En: Fiber ingredients, food applications and health benefits. Cho, S. S. y Samuel, P. (Eds.). Florida, USA: CRC Press.

Tapola, N. y Sarkkinen, E. (2009). Oat $\beta$-glucan En: Fiber ingredients, food applications and health benefits. Cho, S. S. y Samuel, P. (Eds.). CRC Press (Ed.) Florida, USA.

Thammarutwasik, P., Hongpattarakere, T., Chantachum, S., Kijroongroyana, K., Itharat, A., Reanmongkol, W., Tewtrakul, S. y Ooraikul, B. (2009). Prebiotics - A review. Songklanakarin Journal of Science and Technology. 31: 401408.

Trowell, H., Southgate, D. A. T., Wolever, T. M. S., Leeds, A. R., Gassull, M. A. y Jenkins, D. A. (1976). Dietary fiber redefined. Lancet. 1: 967-972. 
Tungland, B. C. y Meyer, D. (2002). Nondigestible oligo- and polysaccharides (dietary fiber): their physiology and role in human health and food. Comprehensive Reviews in Food Science and Food Safety. 3: 90-109.

Valdés S. E. (2006). Hidratos de carbono. En: Química de los alimentos (4a. Ed.). Badui-Dergal, S. (Ed.). México D. F.: Pearson Addison Wesley. 
6. CAPÍTULO II: EVALUACIÓN in vitro DE LA FERMENTACIÓN DE SUBPRODUCTOS AGROINDUSTRIALES DE VALOR AGREGADO: CÁSCARA DE TUNA (Opuntia ficus-indica L) Y CÁSCARA DE PIÑA (Ananas comosus) COMO INGREDIENTES FUNCIONALES.

Díaz-Vela, J., Totosaus, A., Cruz-Guerrero, A. E. and Pérez-Chabela, M. L. 2013. In vitro evaluation of the fermentation of added-value agroindustrial byproducts: cactus pear (Opuntia ficus-indica L.) peel and pineapple (Ananas comosus) peel as functional ingredients" International Journal of Food Science and Technology: 48 (7):1460-1467.

\subsection{OBJETIVO}

Determinar la capacidad antioxidante, contenido de fibra, cinéticas de fermentación y cinéticas de acidificación in vitro de dos ingredientes prebióticos potenciales: cáscara de tuna y cáscara de piña.

\subsection{PROLEGÓMENO}

Dada la constante y creciente demanda de cultivos para el consumo humano, alimento para animales y biocombustibles, la búsqueda de ingredientes funcionales para alimentos procesados lleva a los científicos de alimentos explorar subproductos agroindustriales como una nueva fuente de fibra dietética, oligosacáridos y/o antioxidantes. En el procesamiento de la fruta, alrededor del 70 $\%$ del peso de la materia prima, como cáscara y semillas, son considerados como residuos. La correcta eliminación de estos materiales por lo general representa un problema ambiental y sólo se resuelve parcialmente mediante el uso de ellos como alimento para animales o composta como fertilizante. Los nutrientes valiosos contenidos en estos residuos agroindustriales se pierden (Larrauri, 1999; Oreopoulou y Tzia, 2007; Federici y col., 2009; Espirito-Santo y col., 2012). Las cáscaras de frutos son subproductos prometedores debido a su alto contenido de fibra dietética insoluble, pectina y fructo-oligosacáridos, así como compuestos fenólicos, proteínas, minerales y vitaminas (Nawirska y Kwasniewska, 2005; Espirito-Santo y col., 2012). El uso de subproductos agroindustriales con alto valor 
nutricional como nuevo aditivos alimentarios o suplementos ha ganado cada vez más interés, ya que son productos de alto valor y su recuperación puede ser económicamente atractiva (Oreopoulou y Tzia, 2007;Lamsal y Faubion, 2009). Como ingredientes alimentarios, pueden ser considerados como una fuente de fibra, prebióticos y antioxidantes. El consumo de fibra se asocia con la reducción del riesgo en enfermedades coronarias y ciertos tipos de cáncer (Rodríguez y col., 2006). Otros compuestos interesantes que se pueden obtener a partir de residuos vegetales son mono-, di- y oligosacáridos, así como oligosacáridos no digeribles, actualmente considerados prebióticos ya que llegan al colon sin digerirse y luego se fermentan principalmente por bifidobacterias y bacterias ácido lácticas, produciendo así un efecto positivo sano (Gibson y Roberfroid, 1995). Otros componentes bioactivos son carotenoides, fitoestrógenos, antioxidantes naturales, tales como compuestos fenólicos y compuestos funcionales. Recientemente, los compuestos fenólicos y flavonoides han atraído mucho interés, ya que son antioxidantes potentes y exponen otras actividades fisiológicas incluyendo antiinflamatorios, antimicrobianos, actividades antialérgicas, anticancerígenos y antihipertensivos (Schieber y col., 2001; Federici y col., 2009).

México es el primer productor de tuna a nivel mundial con un volumen superior a las 400,000 TM anualmente. La tuna es un fruto que aporta beneficios nutricionales, su composición química consiste de $85 \%$ de agua, $14 \%$ de azúcares y $1 \%$ de proteína (Sumaya-Martínez y col., 2011). La cáscara de tuna representa alrededor del $60 \%$ de la fruta y es un importante fuente de carbohidratos, ácidos grasos poliinsaturados y antioxidantes naturales como tocoferol, vitaminas $\mathrm{C}$ y $\mathrm{E}$ (Ramadán y Morcel, 2003; Cerezal y Duarte, 2005). La cáscara de piña, por otro lado, es rica en celulosa, hemicelulosa y otros carbohidratos y se ha reportado que es un sustrato potencial de generación de metano por la digestión anaerobia y una fuente de fibra dietética (Tran y Mitchel, 1995; Rani y Nand, 2004; Aida y col., 2011; Ketnawa y col., 2011). En 2010 la región central de México consumió el 47\% de la producción total $(398.361 \mathrm{~kg})$, con un consumo medio anual de $4.28 \mathrm{~kg} / \mathrm{per}$ cápita. En México, la piña se produce durante todo el año y en 2010 la producción total fue de $361.728 \mathrm{~kg}$. 
En años recientes, la investigación acerca del uso de diversos componentes naturales como fuente de carbono en estudios in vitro ha sido una alternativa viable; como el uso de cáscara de naranja (Martínez y col., 2010), residuos de caña de azúcar como fuente de pectina (Meyer y col., 2011), subproductos de oliva (Lama-Muños y col., 2012) y cáscara piña (Namsree y col., 2012). Sin embargo, se requiere más investigación en el uso de residuos de cáscara de tuna como fuente de carbono, debido a que se ha reportado la presencia de polisacáridos de pectina (Habibi y col., 2004a), arabinogalactanos (Habibi y col; 2004b) y protopectinas (Habibi y col., 2005). 


\subsection{METODOLOGÍA}

La cáscara de tuna (Opuntia ficus indica) y piña (Ananas comosus) fueron recuperadas en un establecimiento local de frutas frescas ubicado en Ecatepec, al norte de la Ciudad de México, de mayo a agosto del 2011. La temporada de cultivo de tuna va de abril a septiembre.

Las cáscaras se recogieron semanalmente y transportaron al campus de la Universidad en cajas de plástico (aproximadamente $2 \mathrm{~kg}$ cada uno), fueron lavadas con agua fría y se almacenaron un día antes de su procesamiento en condiciones de refrigeración $\left(4 \pm 1^{\circ} \mathrm{C}\right)$. Las cáscaras de ambas frutas fueron equilibradas a temperatura ambiente durante 2 horas antes de ser cortadas en piezas de $2 \times 2 \mathrm{~cm}$ y se secaron a $60^{\circ} \mathrm{C}$ durante aproximadamente 24 horas en un horno de convección de aire (Barco Instrumentos Científicos, Ciudad de México). Las cáscaras secas se molieron en un molino de discos motorizado (Arisa Maquinaria S.A de C.V, México) y se tamizaron consecutivamente con tamaños de malla $100,80,50$ y 20 para obtener un polvo regular y homogéneo, llamado harina. Las harinas de cáscara de tuna y piña fueron almacenadas en recipientes herméticamente cerrados hasta su uso.

\subsubsection{Composición química y capacidad antioxidante}

La composición química de las harinas de cáscara de tuna y piña se determinó de acuerdo con el método AOAC Oficial Methods (1996), para la humedad (Método Oficial 925.10), ceniza (Método Oficial 942.05), proteína total (Método Oficial 984.13, donde el factor de conversión fue 6.25), extracto etéreo (Método Oficial 920.39) y fibra dietética total, soluble e insoluble (Método Oficial 991.43). Los carbohidratos totales disponibles se calcularon por diferencia de humedad, cenizas, proteína total, extracto etéreo y fibra dietética total (Figuerola y col., 2005; Morales y col., 2012). Los carbohidratos totales solubles se evaluaron por el método de fenol-sulfúrico (Dubois y col., 1956) para los azúcares reductores totales a fin de formular el medio de cultivo (Vergara-Valencia y col., 2007). La capacidad antioxidante se llevó a cabo de acuerdo al método descrito por Re y col. (1999). La extracción de polifenoles y compuestos relacionados se llevó a cabo 
mediante la maceración de $1 \mathrm{~g}$ de cada harina en $100 \mathrm{ml}$ de una solución de metanol:agua $(1: 2, \mathrm{v} / \mathrm{v})$ durante $4 \mathrm{~h}$ a temperatura ambiente con agitación magnética constante. Los extractos se filtraron con papel de filtro Whatman No. 1 y se evaporaron en un rotavapor Büchi R-3 (BUCHI Labortechnik AG, Flawil) a 40 ${ }^{\circ} \mathrm{C}$. El catión radical $\mathrm{ABTS}^{+}$fue generado por la reacción de $7 \mathrm{mM}$ de 2,2'-Azinobis (2,2'-Azino-bis (3-etil ácido benzothiazoneline-6-sulfónico) sal de diamonio (ABTS) (Sigma Aldrich, St. Louis) y $2.45 \mathrm{mM}$ de persulfato de potasio después de la incubación a temperatura ambiente en la oscuridad durante $12 \mathrm{~h}$. La solución de ABTS $^{+}$se diluyó en agua destilada hasta alcanzar una absorbancia de $0.700 \pm 0.020$ a $734 \mathrm{~nm}$. Una solución Trolox $(20 \mu \mathrm{M})$ fue preparada para el curva estándar, $495 \mu \mathrm{L}$ de solución de $\mathrm{ABTS}^{+}$se añadieron a $5 \mu \mathrm{L}$ de la muestra y el reactivo mezclado se dejó en reposo a temperatura ambiente durante 6 min y la absorbancia fue inmediatamente registrada a $734 \mathrm{~nm}$.

El porcentaje de actividad antioxidante se calculó por la siguiente ecuación:

$$
\text { Actividad antioxidante }(\%)=\frac{A b s_{\text {control }}-A b s_{\text {muestra }}}{A b s_{\text {control }}} \times 100
$$

Donde $\mathrm{Abs}_{\text {control }}$ es la absorbancia de control y Abs muestra es la absorbancia de la extracto metanólico de la harina de cáscara de frutos. Los resultados se expresaron en términos de capacidad antioxidante equivalente de Trolox (TEAC, Amol Trolox equivalentes por $100 \mathrm{~g}$ de muestra seca).

\subsubsection{Fermentación de las harinas de cáscara de tuna y piña}

Las fermentaciones se llevaron a cabo mediante la adaptación de la metodología descrita por Bustamante y col. (2006). Los medios de cultivo se formularon mediante el empleo de las diferentes harinas como fuente de carbono para evaluar su efecto sobre el crecimiento y la acidificación de las diferentes cepas. Dos bacterias ácido lácticas reportadas anteriormente como termotolerantes con potencial probiótico (Ramírez-Chavarín, 2009; Ramírez-Chavarín y col., 2010), Pediococcus pentosaceus UAM22 y Aerococcus viridans UAM21, se utilizaron 
junto con el probiótico Lactobacillus rhamnosus GG. La cepa enteropatógena Escherichia coli $\mathrm{K} 12$ fue utilizada como cepa de referencia. Las cepas de bacterias ácido lácticas se reactivaron en caldo MRS a $37^{\circ} \mathrm{C}$ durante $24 \mathrm{~h}$ hasta alcanzar una densidad óptica cerca de uno $\left(\lambda=600 \mathrm{~nm}\right.$ ), equivalente a $10^{7} \mathrm{UFC} / \mathrm{ml}$. La cepa $E$. coli $\mathrm{K} 12$ se reactivó en caldo $\mathrm{BX}$ biotriptasa a $35^{\circ} \mathrm{C}$ durante $18 \mathrm{~h}$. Los medios de cultivo fueron compuestos de $0.5 \%$ de peptona de caseína (p/v), $0.3 \%$ de extracto de levadura y fuente de carbono a tres concentraciones diferentes (0.5, 1.0 y $1.5 \%$, p/v). La glucosa se empleó como el control y la cantidad de harina de cáscara utilizada se calculó de acuerdo a la los carbohidratos solubles totales (azúcares reductores totales) con el fin de añadir la misma cantidad de fuente de carbono. Las cepas ( $10 \mathrm{ml}$ con $10^{7} \mathrm{UFC} / \mathrm{ml}$ ) se inocularon en $90 \mathrm{ml}$ de los diferentes medios de cultivo en un matraz serológico (100 ml) y se incubaron a $37^{\circ} \mathrm{C}$ bajo condiciones anaeróbicas utilizando jarras de anaerobiosis con sistema de bolsas GasPak Anaerobe EZ TM (BD, Franklin Lakes). Las fermentaciones se monitorearon durante $10 \mathrm{~h}$, muestreando cada hora para determinar el recuento de células viables de cada cepa mediante cuenta en placa y el pH del medio.

\subsubsection{Parámetros de crecimiento bacteriano}

El crecimiento bacteriano se determinó por recuento en placa estándar en sus respectivos medios de cultivo, haciendo las diluciones pertinentes, incubando a 37 ${ }^{\circ} \mathrm{C}$ durante $24 \mathrm{~h}$ bajo condiciones anaeróbicas. La constante $k$ (tasa media de crecimiento) y tiempo de duplicación $(g)$ fueron determinados de acuerdo con Willey y col. (2008), las ecuaciones son las siguientes:

$$
\begin{gathered}
k=\frac{\log N_{10}-\log N_{0}}{\log 2 \times 10} \\
g=\frac{1}{k}
\end{gathered}
$$

Donde $\mathrm{N}_{10}=\mathrm{UFC} / \mathrm{ml}$ al final de la fermentación (10 h) y $\mathrm{N}_{0}=\mathrm{UFC} / \mathrm{ml}$ en el inicio de la fermentación $(0 \mathrm{~h})$ 


\subsubsection{Parámetros de acidificación}

Los parámetros cinéticos de acidificación calculados fueron Vmax (velocidad máxima de acidificación, $\mathrm{pH} \times 10^{-3} \min ^{-1}$ ), $t_{V \max }$ (tiempo para alcanzar $V \max , \mathrm{h}$ ), $\mathrm{pH}_{V \max }\left(\mathrm{pH}\right.$ a $V_{\text {max }}$, y el $\mathrm{pH}$ final (Spinnler y Corrieu, 1989).

\subsubsection{Consumo de carbohidratos}

Los carbohidratos totales fueron determinados a las $10 \mathrm{~h}$ de fermentación de acuerdo con la metodología propuesto por Manderson y col. (2005). Las muestras de las diferentes fermentaciones se filtraron previamente a través de filtros de nitrato de celulosa (tamaño de poro $0.2 \mu \mathrm{m}$ ) para ser analizado por cromatografía líquida de alta resolución (HPLC) con una columna Rezex-RPM Monosacárido (300 x $75 \mathrm{~mm}$ ) (Phenomenex, Rezek) y una bomba digital (LabAlliance serie II), utilizando agua como fase móvil a $0.3 \mathrm{ml} / \mathrm{min}$ y $75^{\circ} \mathrm{C}$, equipado con un detector de dispersión de luz (PL-ELS-1000, Polymer Laboratories, Shropshire, UK) a $110^{\circ} \mathrm{C}$.

\subsection{6 Ácido láctico y ácidos grasos de cadena corta}

Los ácidos grasos de cadena corta y el ácido láctico también se determinaron a las $10 \mathrm{~h}$ de fermentación siguiendo la metodología propuesta por Desai y col. (2004). El ácido láctico se determinó por HPLC equipado con una columna Rezex ROA (300 x $7.8 \mathrm{~mm}$ ) (Phenomenex, Rezek) y una bomba digital (LabAlliance serie II), utilizando agua como fase móvil a $0.3 \mathrm{ml} / \mathrm{min}$ y $75^{\circ} \mathrm{C}$, equipado con un detector de dispersión de luz (PL-ELS-1000, Polymer Laboratories, Shropshire, UK) a 110 ${ }^{\circ} \mathrm{C}$. El ácido acético y propiónico se determinaron mediante cromatografía de gases en un cromatografo HP5890 GC equipado con un detector de ionización de flama con una columna AT-1000 (10m $\times 0.25 \mathrm{~mm})$ con una rampa temperatura de 90 a $120^{\circ} \mathrm{C} @ 5^{\circ} \mathrm{C} / \mathrm{min}$, empleando $\mathrm{N}_{2}$ como gas portador a $1 \mathrm{ml} / \mathrm{min}$, inyectando $50 \mu \mathrm{L}$ de cada muestra. Se determinaron las curvas de calibración para cada compuesto.

\subsubsection{Potencial prebiótico: actividad prebiótica total}

La actividad prebiótica se determinó de acuerdo con la ecuación descrita por Huebner y col. (2007), teniendo en cuenta el crecimiento de cada bacteria durante 
la fermentación ( $\Delta \mathrm{N}=\mathrm{N}_{\mathrm{t} 10}-\mathrm{N}_{\mathrm{t} 0}$ ), usando la harina de cáscara de tuna o piña y glucosa como fuente de carbono, de la siguiente manera:

$$
P A=B A L \frac{\Delta N_{\text {prebiotico }}}{\Delta N_{\text {glucosa }}}-\text { enterica } \frac{\Delta N_{\text {prebiotico }}}{\Delta N_{\text {glucosa }}}
$$

Donde BAL es $P$. pentosaceus, $A$. viridans o $L$. rhamnosus, y entérica es $E$. coli. De acuerdo a Huebner y col. (2007), por definición, los sustratos con una alta actividad prebiótica promueven un buen crecimiento de las bacterias probióticas, con crecimiento celular comparable a la observada cuando se crece en glucosa. El crecimiento celular de las cepas entéricas cultivadas con prebióticos debe ser, en teoría, muy baja en relación con el crecimiento con glucosa.

\subsubsection{Diseño y análisis de datos experimentales}

Se utilizó un diseño factorial completo para determinar el efecto de la cepa, fuente de carbono y concentración de la fuente de carbono sobre los parámetros cinéticos y de acidificación. El modelo propuesto es:

$$
y_{i j k}=\mu+\alpha_{i}+\beta_{j}+\gamma_{k}+\epsilon_{i j k}
$$

donde $y_{i j k}$ representa los parámetros cinéticos y de acidificación del k-ésimo tipo cepa ( $P$. pentosaceus, A. viridans, L. rhamnosus o E. coll), j-ésimo tipo de fuente de carbono (harina de cáscara de tuna, harina de cáscara de piña o glucosa) e iésima concentración de fuente de carbono; $\mu$ es la media general; $\alpha_{i}, \beta_{j}$ y $\gamma_{k}$ son los efectos principales del tipo de cepa, fuente de carbono y concentración de la fuente de carbono; $\epsilon_{i j k}$ es el error residual o error que supone que se distribuye normalmente con media cero y varianza $\sigma 2$ (Der y Everitt, 2002). Los resultados se analizaron con el procedimiento PROC ANOVA de SAS Software v 8.0 (Sistema SAS, Cary). Las diferencias significativas entre las medias se determinaron mediante la prueba de Duncan del mismo paquete estadístico. 


\subsection{RESULTADOS Y DISCUSIÓN}

\subsubsection{Composición química y capacidad antioxidante}

La composición química de las harinas de cáscara tuna y cáscara de piña aparecen en la Tabla 1. La harina de tuna presenta menor contenido de proteína de la harina de piña, con un valor cercano en el contenido de grasa cruda entre ambas muestras de harina. El contenido de cenizas fue mayor para la harina de tuna, lo que sugiere un mayor contenido de minerales. Una de las principales características de estos ingredientes es el contenido relativamente alto de carbohidratos solubles, haciéndolos más fermentables por las bacterias ácido lácticas. La harina de cáscara de tuna tenía un contenido superior de carbohidratos solubles que la harina de cáscara de piña $(30.67 \%$ y $21.66 \%$, respectivamente). Del mismo modo, la fibra dietética total fue uno de los principales componentes de las harinas de cáscara de los frutos (soluble y contenido insoluble hasta el $60 \%$ ), donde la harina de cáscara de piña contiene más fibra soluble $(40,88 \%)$ que la harina de cáscara de tuna $(33.8 \%)$. Ambas características, carbohidratos totales solubles y fibra dietética soluble en la cáscara de tuna y piña hacen que las harinas sean ingredientes alimentarios con potencial fermentable. El porcentaje de actividad de captación del radical ABTS o la actividad antioxidante para las harinas de cáscara de tuna fue mayor que para la harina de cáscara de piña (89 y 69\%, respectivamente), con el valor TEAC resultante fue más alto para la harina de cáscara de tuna (2.6 y 1.5, respectivamente). 
Tabla 1. Composición química y propiedades antioxidantes de las harinas de cáscara de tuna y piña.

\begin{tabular}{lcc}
\hline Composición (\%) & $\begin{array}{c}\text { Harina de cáscara } \\
\text { de tuna }\end{array}$ & $\begin{array}{c}\text { Harina de cáscara } \\
\text { de piña }\end{array}$ \\
\hline Humedad & $9.62 \pm 1.32$ & $11.57 \pm 2.54$ \\
Proteína & $0.08 \pm 0.1$ & $0.32 \pm 0.05$ \\
Extracto etéreo & $0.11 \pm 0.1$ & $0.17 \pm 0.01$ \\
Cenizas & $3.88 \pm 0.99$ & $2.81 \pm 1.52$ \\
Carbohidratos disponibles totales & $22.16 \pm 2.13$ & $22.59 \pm 1.99$ \\
Carbohidratos solubles totales & $18.13 \pm 1.75$ & $17.60 \pm 2.18$ \\
Fibra dietética total & $64.15 \pm 2.05$ & $62.54 \pm 3.21$ \\
Fibra dietética insoluble & $33.48 \pm 1.66$ & $40.88 \pm 1.79$ \\
Fibra dietética soluble & $30.67 \pm 1.54$ & $21.66 \pm 1.63$ \\
Actividad antioxidante (\%) & 89 & 69 \\
TEAC & 2.6 & 1.5 \\
\hline
\end{tabular}

TEAC, actividad antioxidante equivalente de Trolox.

Se ha reportado recientemente el uso de cáscara de tuna como una fuente de ingrediente funcional tal como fibra (Cardador-Martínez y col., 2011), antioxidante (Besadón y col., 2010.; Fernández-López y col., 2010) y flavonoides (Cai y col., 2010). Del mismo modo, la cáscara de piña también se ha estudiado como ingrediente funcional como una fuente de fibra (Huang y col., 2011), polifenoles (Larrauri y col., 1997), o compuestos contra el estrés oxidativo (Erukainure y col., 2011). Sin embargo, el potencial de fermentación de las harinas de cáscara de frutos no se ha determinado.

\subsubsection{Parámetros de fermentación}

Se obtuvo una constante de tasa de crecimiento (k) significativamente mayor $(\mathrm{P}<0.05)$ con una concentración de $1.0 \%$ de fuente de carbono. Sin embargo, no 
hubo diferencia significativa $(\mathrm{P}<0.05)$ para las otras concentraciones de fuente de carbono para el resto de los parámetros cinéticos o de acidificación. La Tabla 2 muestra los resultados para los parámetros de crecimiento y de acidificación de la diferentes cepas de fermentación con las diferentes fuentes de carbono a una concentración de $1.0 \%$. P. pentosaceus presentó los valores significativamente $(\mathrm{P}<0.05)$ más altos que los otros microorganismos, donde $E$. coli obtuvo la tasa de crecimiento específica más baja. Por el contrario, el tiempo de generación ( $\mathrm{g}$ ) fue significativamente $(P<0.05)$ más bajo para $P$. pentosaceus. La glucosa como fuente de carbono resultó significativamente $(P<0.05)$ mayor para las constantes de velocidad de crecimiento y significativamente $(\mathrm{P}<0.05)$ menor para el tiempo de generación. Del mismo modo, los valores de la tasa máxima de acidificación fueron significativamente $(\mathrm{P}<0.05)$ más altos para $P$. pentosaceus, y, como era de esperar, la más baja fue para E. coli. El tiempo para alcanzar el máximo de acidificación fue significativamente $(P<0.05)$ más bajo para $P$. pentosaceus y $A$. viridans. En consecuencia, el $\mathrm{pH}$ en este punto fue significativamente $(P<0.05)$ más bajo para $L$. rhamnosus. Las fermentaciones con harina de tuna resultaron con valores de $V \max$ significativamente $(\mathrm{P}<0.05)$ más altos. El pH a la Vmáx no fue significativamente $(P>0.05)$ diferente para las diferentes fuentes de carbono utilizadas.

Se ha reportado que los compuestos prebióticos dan como resultado un crecimiento más lento de las bacterias ácido lácticas en comparación con los monosacáridos (hexosas), pero con biomasa final similar (Gullón y col., 2008, Chen y col., 2007; Bañuelos y col., 2008, Yeo y Liong, 2010). En las harinas de cáscara de las frutas utilizadas, la presencia de componentes como monómeros libres en el medio de cultivo con sustratos complejos resultó en menor tasa de crecimiento, pero la biomasa final fue similar. Esto implica que las harinas de cáscaras de frutos presentes en el medio de cultivo como ingredientes prebióticos fueron metabolizados por las cepas empleadas como fuente de carbono (Kaplan y Hutkins, 2000; Rossi y col., 2005; Bañuelos y col., 2008; Yeo y Liong, 2010). Las diferencias en la tasa de crecimiento de las bacterias ácido lácticas podría atribuirse a las preferencias individuales de los monosacáridos en lugar de los 
carbohidratos con mayor grado de polimerización (Gopal y col., 2001). Amaretti y col. (2006) propusieron varios mecanismos para el uso de hidratos de carbono poliméricos, ya sea intracelularmente o extracelularmente, para hidrolizar componentes monoméricos y facilitar la asimilación de estos compuestos. 
Tabla 2. Cinéticas de fermentación, $k$ (tasa específica de crecimiento) y $g$ (tiempo de duplicación), y parámetros de acidificación, $V_{\max }$ (tasa maxima de acidificación), $\mathrm{t}_{V_{\max }}\left(\right.$ tiempo para alcanzar $V$ max) y $\mathrm{pH}_{V \max }(\mathrm{pH}$ a la $V \max$ ), para los diferentes tipos de cepas empleadas con diferentes fuentes de carbono (a 1.0\% p/v).

\begin{tabular}{llccccc}
\hline Cepa & Fuente de carbono & $\mathrm{k}(\mathrm{h})$ & $\mathrm{g}\left(\mathrm{h}^{-1}\right)$ & $\mathrm{Vmax}(\mathrm{pH} \mathrm{min})$ & $\mathrm{t}$ Vmax $(\mathrm{h})$ & $\mathrm{pH} V \max$ \\
\hline P. pentosaceus UAM22 & Glucosa & $1.52 \pm 0.00^{\mathrm{A}, \mathrm{a}}$ & $0.66 \pm 0.00^{\mathrm{C}, \mathrm{b}}$ & $1.68 \pm 0.07^{\mathrm{A}, \mathrm{b}}$ & $3.50 \pm 0.7^{\mathrm{B}, \mathrm{a}}$ & $5.94 \pm 0.01^{\mathrm{B}, \mathrm{a}}$ \\
& Harina de tuna & $1.42 \pm 0.01^{\mathrm{A}, \mathrm{b}}$ & $0.71 \pm 0.01^{\mathrm{C}, \mathrm{a}}$ & $1.80 \pm 0.08^{\mathrm{A}, \mathrm{a}}$ & $3.51 \pm 0.8^{\mathrm{B}, \mathrm{a}}$ & $6.09 \pm 0.02^{\mathrm{B}, \mathrm{a}}$ \\
& Hartina de piña & $1.44 \pm 0.01^{\mathrm{A}, \mathrm{b}}$ & $0.76 \pm 0.00^{\mathrm{C}, \mathrm{a}}$ & $1.62 \pm 0.07^{\mathrm{A}, \mathrm{b}}$ & $2.50 \pm 0.7^{\mathrm{B}, \mathrm{b}}$ & $6.11 \pm 0.01^{\mathrm{B}, \mathrm{a}}$ \\
A. viridans UAM21 & Glucosa & $1.13 \pm 0.02^{\mathrm{C}, \mathrm{a}}$ & $0.90 \pm 0.01^{\mathrm{B}, \mathrm{b}}$ & $0.91 \pm 0.10^{\mathrm{B}, \mathrm{b}}$ & $3.50 \pm 0.7^{\mathrm{B}, \mathrm{a}}$ & $6.61 \pm 0.02^{\mathrm{B}, \mathrm{a}}$ \\
& Harina de tuna & $0.81 \pm 0.09^{\mathrm{C}, \mathrm{b}}$ & $1.05 \pm 0.16^{\mathrm{B}, \mathrm{a}}$ & $1.69 \pm 0.17^{\mathrm{B}, \mathrm{a}}$ & $3.52 \pm 0.7^{\mathrm{B}, \mathrm{a}}$ & $5.74 \pm 0.02^{\mathrm{B}, \mathrm{a}}$ \\
& Hartina de piña & $1.07 \pm 0.01^{\mathrm{C}, \mathrm{b}}$ & $0.98 \pm 0.00^{\mathrm{B}, \mathrm{a}}$ & $1.01 \pm 0.07^{\mathrm{B}, \mathrm{b}}$ & $3.00 \pm 0.7^{\mathrm{B}, \mathrm{b}}$ & $5.85 \pm 0.01^{\mathrm{B}, \mathrm{a}}$ \\
& Glucosa rhamnosus GG $^{*}$ & $1.36 \pm 0.01^{\mathrm{B}, \mathrm{a}}$ & $0.72 \pm 0.01^{\mathrm{B}, \mathrm{b}}$ & $0.97 \pm 0.07^{\mathrm{B}, \mathrm{b}}$ & $6.50 \pm 0.7^{\mathrm{A}, \mathrm{a}}$ & $5.65 \pm 0.06^{\mathrm{C}, \mathrm{a}}$ \\
& Harina de tuna & $0.99 \pm 0.01^{\mathrm{B}, \mathrm{b}}$ & $0.86 \pm 0.01^{\mathrm{B}, \mathrm{a}}$ & $1.50 \pm 0.07^{\mathrm{B}, \mathrm{a}}$ & $5.59 \pm 0.7^{\mathrm{A}, \mathrm{a}}$ & $5.50 \pm 0.01^{\mathrm{C}, \mathrm{a}}$ \\
& Hartina de piña & $1.19 \pm 0.02^{\mathrm{B}, \mathrm{b}}$ & $0.82 \pm 0.01^{\mathrm{B}, \mathrm{a}}$ & $1.05 \pm 0.00^{\mathrm{B}, \mathrm{b}}$ & $4.80 \pm 0.7^{\mathrm{A}, \mathrm{b}}$ & $5.66 \pm 0.01^{\mathrm{C}, \mathrm{a}}$ \\
& Glucosa & $0.98 \pm 0.16^{\mathrm{D}, \mathrm{a}}$ & $1.25 \pm 0.18^{\mathrm{A}, \mathrm{b}}$ & $0.05 \pm 0.17^{\mathrm{C}, \mathrm{b}}$ & $5.90 \pm 0.7^{\mathrm{A}, \mathrm{a}}$ & $6.35 \pm 0.04^{\mathrm{A}, \mathrm{a}}$ \\
& Harina de tuna & $0.63 \pm 0.00^{\mathrm{D}, \mathrm{b}}$ & $1.70 \pm 0.01^{\mathrm{A}, \mathrm{a}}$ & $0.18 \pm 0.07^{\mathrm{C}, \mathrm{a}}$ & $6.50 \pm 0.7^{\mathrm{A}, \mathrm{a}}$ & $6.30 \pm 0.02^{\mathrm{A}, \mathrm{a}}$ \\
& Hartina de piña & $0.62 \pm 0.16^{\mathrm{D}, \mathrm{b}}$ & $1.68 \pm 0.45^{\mathrm{A}, \mathrm{a}}$ & $0.09 \pm 0.07^{\mathrm{C}, \mathrm{b}}$ & $4.50 \pm 0.7^{\mathrm{A}, \mathrm{b}}$ & $6.48 \pm 0.01^{\mathrm{A}, \mathrm{a}}$
\end{tabular}

A, B, C, D Medias con la misma letra en la misma columna no son significativamente diferentes $(P>0.05)$ por tipo de cepa.

a, b Medias con la misma letra en la misma columna no son significativamente diferentes $(P>0.05)$ por fuente de carbono. 
La Tabla 3 muestra los resultados para el $\mathrm{pH}$ final y recuento viable final de las bacterias ácido lácticas y crecimiento de la cepa entérica con las diferentes fuentes de carbono en $1.0 \%(\mathrm{p} / \mathrm{v})$. El pH final después de $10 \mathrm{~h}$ de fermentación fue significativamente $(P<0.05)$ más bajo para $P$. pentosaceus y $L$. rhamnosus. El recuento viable final de microorganismos fue significativamente $(P<0.05)$ más alta para $P$. pentosaceus, y menor para $E$. coli. No hubo diferencia significativa $(P>0.05)$ para el $\mathrm{pH}$ final o conteo viable final por el tipo de fuente de carbono.

Tabla 3. $\mathrm{pH}$ final y cuenta viable final $\log \mathrm{UFC} / \mathrm{mL}(\mathrm{N})$ al final de la fermentación $(10 \mathrm{~h})$ para las diferentes cepas con diferentes tipos de fuente de carbono (a 1.0\% $\mathrm{p} / \mathrm{v})$.

\begin{tabular}{llcc}
\hline Cepa & Fuente de carbon & $\mathrm{pH}$ final & $N(\log \mathrm{UFC} / \mathrm{mL})$ \\
\hline $\begin{array}{lll}\text { P. pentosaceus } \\
\text { UAM22 }\end{array}$ & Glucosa & $4.39 \pm 0.28^{\mathrm{C}, \mathrm{a}}$ & $9.52 \pm 0.25^{\mathrm{A}, \mathrm{a}}$ \\
& Harina de tuna & $5.81 \pm 0.35^{\mathrm{C}, \mathrm{a}}$ & $9.65 \pm 0.25^{\mathrm{A}, \mathrm{a}}$ \\
& Hartina de piña & $4.89 \pm 0.42^{\mathrm{C}, \mathrm{a}}$ & $9.56 \pm 0.31^{\mathrm{A}, \mathrm{a}}$ \\
A. viridans UAM21 & Glucosa & $6.12 \pm 0.63^{\mathrm{B}, \mathrm{a}}$ & $9.22 \pm 0.24^{\mathrm{B}, \mathrm{a}}$ \\
& Harina de tuna & $5.64 \pm 0.85^{\mathrm{B}, \mathrm{a}}$ & $8.73 \pm 0.25^{\mathrm{B}, \mathrm{a}}$ \\
& Hartina de piña & $7.88 \pm 0.21^{\mathrm{B}, \mathrm{a}}$ & $9.33 \pm 0.13^{\mathrm{B}, \mathrm{a}}$ \\
L. rhamnosus GG & Glucosa & $5.82 \pm 0.57^{\mathrm{C}, \mathrm{a}}$ & $9.24 \pm 0.27^{\mathrm{B}, \mathrm{a}}$ \\
& Harina de tuna & $4.63 \pm 0.85^{\mathrm{C}, \mathrm{a}}$ & $8.77 \pm 0.15^{\mathrm{B}, \mathrm{a}}$ \\
& Hartina de piña & $5.15 \pm 0.56^{\mathrm{C}, \mathrm{a}}$ & $9.38 \pm 0.26^{\mathrm{B}, \mathrm{a}}$ \\
& Glucosa & $5.91 \pm 0.21^{\mathrm{A}, \mathrm{a}}$ & $8.46 \pm 0.11^{\mathrm{C}, \mathrm{a}}$ \\
& Harina de tuna & $6.29 \pm 0.14^{\mathrm{A}, \mathrm{a}}$ & $8.63 \pm 0.24^{\mathrm{C}, \mathrm{a}}$ \\
& Hartina de piña & $6.68 \pm 0.42^{\mathrm{A}, \mathrm{a}}$ & $8.21 \pm 0.22^{\mathrm{C}, \mathrm{a}}$ \\
\hline
\end{tabular}

$\mathrm{A}, \mathrm{B}, \mathrm{C}, \mathrm{D}$ Medias con la misma letra en la misma columna no son significativamente diferentes $(P>0.05)$ por tipo de cepa.

$a, b$ Medias con la misma letra en la misma columna no son significativamente diferentes $(P>0.05)$ por fuente de carbono. 
Al final de la fermentación con las diferentes fuentes de carbono, $P$. pentosaceus tuvo un valor significativamente $(P>0.05)$ mayor de consumo de carbohidratos que L. rhamnosus o $A$. viridans. El consumo de carbohidratos fue significativamente $(P>0.05)$ mayor con harina de cáscara de tuna como fuente de carbono que con glucosa o harina de cáscara de piña (Tabla 4). Para el ácido láctico, $P$. pentosaceus y $L$. rhamnous produjeron cantidades significativamente $(P>0.05)$ mayores que $A$ viridans. De manera significativa $(P>0.05)$ el valor de producción de ácido láctico más alto fue con harina de cáscara de tuna. 
Tabla 4. Consumo de carbohidratos, determinación de ácido láctico y ácidos grasos de cadena corta durante las fermentaciones con diferentes fuentes de carbono a $1.0 \%(\mathrm{p} / \mathrm{v})$

\begin{tabular}{|c|c|c|c|c|c|}
\hline Cepa & Fuente de carbono & $\begin{array}{c}\text { Consumo de } \\
\text { carbohidratos (\%) }\end{array}$ & Ácido láctico (g/L) & $\begin{array}{c}\text { Ácido acético } \\
(\mathrm{g} / \mathrm{L})\end{array}$ & $\begin{array}{c}\text { Ácido propiónico } \\
(\mathrm{g} / \mathrm{L})\end{array}$ \\
\hline \multirow{3}{*}{$\begin{array}{l}P . \text { pentosaceus } \\
\text { UAM22 }\end{array}$} & Glucosa & $41.0 \pm 0.6^{\mathrm{A}, \mathrm{b}}$ & $2.70 \pm 0.23^{A, b}$ & $0.58 \pm 0.01^{\mathrm{A}, \mathrm{b}}$ & $0.16 \pm 0.01^{\mathrm{A}, \mathrm{a}}$ \\
\hline & Harina de tuna & $67.1 \pm 0.4^{\mathrm{A}, \mathrm{a}}$ & $4.01 \pm 0.42^{\mathrm{A}, \mathrm{a}}$ & $0.78 \pm 0.10^{\mathrm{A}, \mathrm{a}}$ & $0.19 \pm 0.10^{\mathrm{A}, \mathrm{a}}$ \\
\hline & Hartina de piña & $49.8 \pm 0.6^{\mathrm{A}, \mathrm{b}}$ & $2.59 \pm 0.29^{A, C}$ & $0.49 \pm 0.01^{\mathrm{A}, \mathrm{C}}$ & $0.15 \pm 0.01^{\mathrm{A}, \mathrm{b}}$ \\
\hline \multirow[t]{3}{*}{ A. viridans UAM21 } & Glucosa & $56.2 \pm 0.1^{\mathrm{B}, \mathrm{b}}$ & $2.03 \pm 0.15^{\mathrm{B}, \mathrm{b}}$ & $0.24 \pm 0.04^{\mathrm{c}, \mathrm{b}}$ & $0.12 \pm 0.04^{\mathrm{C}, \mathrm{a}}$ \\
\hline & Harina de tuna & $60.7 \pm 0.4^{\mathrm{B}, \mathrm{a}}$ & $2.64 \pm 0.42^{\mathrm{B}, \mathrm{a}}$ & $0.38 \pm 0.10^{\mathrm{c}, \mathrm{a}}$ & $0.14 \pm 0.10^{\mathrm{c}, \mathrm{a}}$ \\
\hline & Hartina de piña & $51.8 \pm 0.6^{\mathrm{B}, \mathrm{b}}$ & $1.82 \pm 0.16^{B, C}$ & $0.22 \pm 0.03^{\mathrm{C}, \mathrm{c}}$ & $0.12 \pm 0.03^{\mathrm{c}, \mathrm{b}}$ \\
\hline \multirow[t]{3}{*}{ L. rhamnosus GG } & Glucosa & $35.6 \pm 0.1^{c, b}$ & $2.53 \pm 0.34^{\mathrm{A}, \mathrm{b}}$ & $0.33 \pm 0.05^{\mathrm{B}, \mathrm{b}}$ & $0.11 \pm 0.05^{\mathrm{B}, \mathrm{a}}$ \\
\hline & Harina de tuna & $50.5 \pm 0.4^{\mathrm{c}, \mathrm{a}}$ & $3.38 \pm 0.34^{A, a}$ & $0.68 \pm 0.03^{\mathrm{B}, \mathrm{a}}$ & $0.15 \pm 0.03^{\mathrm{B}, \mathrm{a}}$ \\
\hline & Hartina de piña & $31.7 \pm 1.6^{\mathrm{c}, \mathrm{b}}$ & $2.63 \pm 0.33^{A, C}$ & $0.30 \pm 0.09^{B, C}$ & $0.12 \pm 0.09^{\mathrm{B}, \mathrm{b}}$ \\
\hline
\end{tabular}

A, B, C, D Medias con la misma letra en la misma columna no son significativamente diferentes (P>0.05) por tipo de cepa.

a, b Medias con la misma letra en la misma columna no son significativamente diferentes $(P>0.05)$ por fuente de carbono. 
Para los ácidos grasos de cadena corta, P. pentosaceus produjo cantidades significativamente $(P<0.05)$ más altas de ácido acético y del ácido propiónico que las otras bacterias ácido lácticas. El ácido acético fue significativamente $(P<0.05)$ mayor cuando se utilizó harina de cáscara de tuna como fuente de carbono. Para el ácido propiónico, el uso de la glucosa o harina de cáscara de tuna resultó significativamente $(\mathrm{P}<0.05)$ más alta (Tabla 4). No hubo diferencia significativa $(P>0.05)$ a diferentes concentraciones de fuente de carbono en la producción de ácidos orgánicos (sólo se presentaron los resultados en 1.0 \%). La composición heterogénea de carbohidratos en las harinas de cáscara de frutos utilizados permitió valores similares en la acidificación del medio ( $\mathrm{pH}$ final) y el crecimiento (recuento viable final) de las bacterias ácido lácticas. Desde la composición monomérica, grado de polimerización y el tipo de enlaces glicosídicos pueden afectar el crecimiento de cepas probióticas (Rastall y col., 2005), se espera que las cepas utilizadas hayan consumido los monosacáridos poliméricos presentes en cada harina de cáscara de frutos, pero también se ha reportado que las bacterias ácido lácticas metabolizan compuestos tales como fructo-oligosacáridos (Habibi y col., 2008). Kaplan y Hutkins (2000), utilizaron FOS comerciales como prebiótico, donde reportaron que el uso de fructooligosacáridos no requiere un periodo de introducción con glucosa como un sustrato para apoyar el crecimiento de bacterias probióticas. El crecimiento de bacterias probióticas con diferentes fuentes de carbono es dependiente de la cepa y expresa el potencial adicional para su crecimiento como implementación de alimentos funcionales (Georgieva y col., 2009).

La harina de tuna se consumió en mayor proporción que la de piña o la glucosa, probablemente debido a la composición diferente de carbohidratos. Las diferencias metabólicas en cepas son relacionadas con las diferentes capacidades para utilizar o consumir compuestos poliméricos y puede ser basado en la actividad específica de las enzimas implicadas en la degradación de tales compuestos (Rehberger y Glatz, 1998). La mayor tasa de acidificación se relaciona con aumento del metabolismo de carbohidratos (Ogunbanwio y Okanlawon, 2009). De acuerdo con los resultados obtenidos en las condiciones 
experimentales particulares, con la harina de tuna se detectó un mejor consumo y metabolismo de carbohidratos y valores mayores de Vmax.

\subsubsection{Potencial prebiótico}

Para la actividad prebiótica, a una concentración del $1.0 \%$ de fuente de carbono, fueron obtenidos valores significativamente $(\mathrm{P}<0.05)$ más altos para $P$. pentosaceus, seguido por L. rhamnosus. Valores negativos o menores fueron obtenidos con $A$. viridans. No hubo diferencia significativa $(P>0.05)$ para la fuente de carbono, es decir, tanto con harinas de cáscara de tuna o cáscara de piña se obtuvo el mismo efecto en el crecimiento de bacterias ácido lácticas (Tabla 5).

Tabla 5. Actividad prebiótica para las cepas ácido lácticas utilizadas.

\section{Cepa}

P. pentosaceus UAM22

L. rhamnosus GG

A. viridans UAM21

\section{Fuente de carbono}

Harina de piña

Harina de tuna

Harina de piña

Harina de tuna

Harina de piña
Harina de tuna

\section{Actividad prebiótica}

$0.33 \pm 0.03^{A, a}$

$0.32 \pm 0.01^{\mathrm{A}, \mathrm{a}}$

$-0.03 \pm 0.02^{\mathrm{C}, \mathrm{a}}$

$0.09 \pm 0.02^{\mathrm{C}, \mathrm{a}}$

$0.19 \pm 0.01^{\mathrm{B}, \mathrm{a}}$

$0.21 \pm 0.02^{\mathrm{B}, \mathrm{a}}$

$\mathrm{A}, \mathrm{B}, \mathrm{C}, \mathrm{D}$ Medias con la misma letra en la misma columna no son significativamente diferentes $(P>0.05)$ por tipo de cepa.

$a, b$ Medias con la misma letra en la misma columna no son significativamente diferentes $(P>0.05)$ por fuente de carbono.

Este resultado indica que los ingredientes propuestos pueden tener una puntuación positiva si se metabolizan de forma selectiva por los probióticos, pero no por otros microorganismos, tales como agentes patógenos. Si el crecimiento de los microorganismos utilizados es menor que con glucosa, los puntajes son bajos o negativos. Huebner y col. (2007) reportaron valores diferentes de actividad prebiótica para diferentes microorganismos. Por ejemplo, con inulina, L. paracasei obtuvo una puntuación de actividad prebiótica de 1.17, mientras que con gluco- 
oligosaccharides como fuente de carbono, los valores de L. plantarum y B. bifidum fueron 0.82 y -1.24 , respectivamente. La mayoría de las bifidobacterias con diferentes prebióticos obtuvieron puntajes en el rango de 0.2 a 0.4 . Estos valores coinciden con los obtenidos en este trabajo, ya que $P$. pentosaceus obtuvo puntuaciones de actividad prebiótica de 0.33 y 0.32 con la harina de cáscara de tuna y piña, respectivamente. Según estos autores, los microorganismos reaccionan de manera diferente a los diferentes azúcares. Esto es importante para la formulación de alimentos simbióticos, aunque otros azúcares fermentables y microorganismos estén presentes. En este sentido, de acuerdo con Huebner y col. (2007) la actividad prebiótica refleja la capacidad de un sustrato dado para favorecer el crecimiento de los microorganismos en comparación con otros microorganismos y se compararon con el crecimiento en un sustrato no-prebiotico, tal como la glucosa.

En este caso, $P$. pentosaceus obtuvo puntuaciones de actividad prebiótica, parámetros de crecimiento y de acidificación más altas que las otras cepas lácticas, lo que indica una mejor asimilación de los carbohidratos fermentables presentes en las harinas de cáscara de frutos. Los valores negativos o más bajos de $A$. viridans están relacionados con su desempeño inferior durante las fermentaciones. No se observó diferencia entre ambos tipos de harina (tuna 0 piña) lo que indica que los carbohidratos son igualmente disponibles al fermentar. Se observaron efectos positivos utilizando estas harinas de cáscara, lo que indica que, en las condiciones experimentales utilizadas, estos ingredientes tuvieron un efecto prebiótico positivo, aunque con diferencias en los parámetros de tasa especifica de crecimiento y acidificación como consecuencia de diferentes estructuras en las fuentes de carbono (Hopkins y col, 1998; Cardelle-Cobas y col., 2011). 


\subsection{CONCLUSIONES}

La harina de cáscara de tuna y piña producen resultados aceptables como fuentes de carbono (parámetros cinéticos y acidificación), además de la obtención de propiedades prebióticas satisfactorias.

Bajo las condiciones experimentales utilizadas, el crecimiento de bacterias ácido lácticas con fuentes de carbono alternas se obtuvo una producción de ácidos orgánicos más alta en comparación con glucosa. $P$. pentosaceus, bacteria con potencial probiótico, tuvo mejor rendimiento durante la fermentación. En este sentido, la harina de cáscara de tuna y harina de cáscara de piña pueden ser utilizados como ingrediente funcional debido a sus propiedades fermentables, además de su alto contenido de fibra dietética total y antioxidantes. 


\subsection{BIBLIOGRAFÍA}

Aida, H.I., Mahanom, H. y Norhartini, A.S. (2011). Dietary fibre powder from pineapple by-product as a potential functional food ingredient. Acta Horticulturae. 902: 565-568.

Amaretti, A., Tamburini, E. y Bernardi, T. (2006). Substrate preference of Bifidobacterium adolescentis MB239: compared growth on single and mixed carbohydrates. Applied Microbiology and Biotechnology. 73: 654-662.

AOAC. (1996). Official Methods of Analysis of AOAC International, 16th edn. Gaithersburg: AOAC International.

Bañuelos, O., Fernández, L., Corral, J.M., Valdivieso-Ugarte, M., Adrio, J.L. y Velasco, J. (2008). Metabolism of prebiotic products containing $\beta$ (2-1) fructan mixtures by two Lactobacillus strain. Food Microbiology. 14: 184189.

Besadon, S., Hervert-Hernández, D., Sáyago-Ayerdi, S.G. y Goñi, I. (2010). Byproducts of Opuntia ficus-indica as a source of antioxidant dietary fiber. Plant Foods for Human Nutrition. 65: 210-216.

Bustamante, C.P., Mayorga, R.L., Ramírez, S.H., Martínez, C.P., Barranco, F.E. y Azaola, E.A. (2006). Evaluación microbiológica de compuestos con actividad prebiótica. Revista Mexicana de Ciencia Farmacéuticas. 37: 5-9.

Cai, W., Gu, X. y Tang, J. (2010). Extraction, purification, and characterization of the flavonoids from Opuntia ficus indica skin. Czech Journal of Food Science. 28: 108-116.

Cardador-Martínez, A., Jiménez-Martínez, C. y Sandoval, G. (2011). Revalorization of cactus pear (Opuntia spp.) wastes as a source of antioxidants. Ciencia e Tecnología de Alimentos, Campiñas. 31: 782-788.

Cardelle-Cobas, A., Corzo, N., Olano, A., Peláez, C., Requena, T. y Ávila, M. (2011). Galactooligosaccharides derived from lactose and lactulose: influence of structure on Lactobacillus, Streptococcus and Bifidobacterium growth. International Journal of Food Microbiology. 149: 81-87.

Cerezal, P. y Duarte, G. (2005). Use of skin in the elaboration of concentrated products of cactus pear (Opuntia ficus-indica (L.) Miller). Journal of the Professional Association for Cactus Development. 7: 61-83.

Chen, Y.S., Srionnual, S., Onda, T. y Yanagida, F. (2007). Effect of prebiotic oligosaccharides and trehalose on growth and production of bacteriocins by lactic acid bacteria. Letters in Applied Microbiology. 45: 190-193.

Der, G. y Everitt, B.S. (2002). Handbook of Statistical Analyses Using SAS. Boca Raton, FL: Chapman \& Hall/CRC.

Desai, R.A., Powell, B.I. y Shah, N.P. (2004). Survival and activity of probiotic Lactobacilli in skim milk containing prebiotics. Journal of Food Science. 89: S57-S60. 
Dubois, M., Gilles, K.A., Hamilton, J.K., Revers, P.A. y Smith, F. (1956). Colorimetric method for determination of sugars and related substances. Analytical Chemistry. 28: 350-356.

Erukainure, O.L., Ajiboye, J.A., Adejobi, R.O., Okafor, O.Y. y Adenekan, S.O. (2011). Protective effect of pineapple (Ananas comosus) peel extract on alcohol-induced oxidative stress in brain tissues of male albino rats. Asian Pacific Journal of Tropical Disease. 4: 182-184.

Espírito-Santo, A.P., Cartolano, N.S. y Silva, T.F. (2012). Fibers from fruit byproducts enhance probiotic viability and fatty acid profile and increase CLA content in yoghurts. International Journal of Food Microbiology. 154: 135144.

Federici, F., Fava, F., Kalogerakisc, N. y Mantzavinos, D. (2009). Valorisation of agro-industrial by-products, effluents and waste: concept, opportunities and the case of olive mill wastewaters. Journal of Chemical Technology and Biotechnology. 84: 895-900.

Fernández-López, J.A., Almela, L., Obón, J.M. y Castellar, R. (2010). Determination of antioxidant constituents in cactus pear fruits. Plant Foods for Human Nutrition. 65: 253-259.

Figuerola, F., Hurtado, M.L., Estévez, A.M., Chiffelle, I. y Asenjo, F. (2005). Fibre concentrates from apple pomace and citrus peel as potential fibre sources for food enrichment. Food Chemistry. 91: 395-401.

Georgieva, R., Koleva, P., Nikolova, D., Yankov, D. y Danova, S. (2009). Growth parameters of probiotic strain Lactobacillus plantarum, isolated from traditional white cheese. Biotechnology and Biotechnological Equipment. 23: 861-865.

Gibson, G.R. y Roberfroid, M.R. (1995). Dietary modulation of the human colonic microbiota: introducing the concept of prebiotics. Journal of Nutrition. 125: 1401-1412.

Gopal, P.K., Sullivan, P.A. y Smart, J.B. (2001). Utilisation of galactooligosaccharides as selective substrates for growth by lactic acid bacteria including Bifidobacterium lactis DR10 and Lactobacillus rhamnosus DR20. International Dairy Journal. 11: 19-25.

Gullón, P., Moura, P., Esteves, M.P., Girio, F.M., Domínguez, H. y Parajó, J.C. (2008). Assessment on the fermentability of xylooligosaccharides from rice husks by probiotic bacteria. Journal of Agricultural and Food Chemistry. 56: 7482-7487.

Habibi, Y., El-Zawawy, W.K., Ibrahim, M.M. y Dufresne, A. (2008). Processing and characterization of reinforcement polyethylene composites made with lignocellulosic fibers from Egyptian agro-industrial residues. Composites Science and Technology. 68: 1877-1885. 
Habibi, Y., Heyraud, A., Mahrouz, M. y Vignon, M. R. (2004a). Structural features of pectic polysaccharides from the skin of Opuntia ficus-indica prickly pear fruits. Carbohidrate Research. 339: 1119-1127.

Habibi, Y., Mahrouz, M., Marais, M. F. y Vignon, M. R. (2004b). An arabinogalactan from the skin of Opuntia ficus-indica prickly pear fruits. Carbohidrate Research. 339: 1201-1205.

Habibi, Y., Mahrouz, M. y Vignon, M. R. (2005). Isolation and structural of protopectin from the skin of Opuntia ficus-indica prickly pear fruits. Carbohydrate Polymers. 60: 205-213.

Hopkins, M.J., Cummings, J.H. y Macfarlane, G.T. (1998). Interspecies differences in maximum specific growth rates and cell yields of bifidobacteria cultured on oligosaccharides and other simple carbohydrate sources. Journal of Applied Microbiology. 85: 381-386.

Huang, Y. L., Chow, C. J. y Fang, Y. J. (2011). Preparation and physicochemical properties of fiber-rich fraction from pineapple peels as potential ingredient. Journal of Food and Drug Analysis. 3: 318-323.

Huebner, J., Wehling, R.L. y Hutkins, R.W. (2007). Functional activity of commercial prebiotics. International Dairy Journal. 17: 770-775.

Kaplan, H. y Hutkins, R.W. (2000). Fermentation of fructooligosaccharides by lactic acid bacteria and bifidobacteria. Applied and Environmental Microbiology. 66: 2582-2684.

Ketnawa, S., Chaiwut, P. y Rawdkuen, S. (2011). Extraction of bromelain from pineapple peels. Food Science and Technology International. 17: 395-402.

Lama-Muñoz, A., Rodríguez-Gutiérrez, G., Rubio-Senent, F. y Fernández-Bolaños, J. (2012). Production, characterization and isolation of neutral and pectic oligosaccharides with low molecular weights from olive by-products thermally treated. Food Hydrocolloids. 28: 92-104.

Lamsal, B.P. y Faubion, J.M. (2009). The beneficial use of cereal and cereal components in probiotic foods. Food Reviews International. 25: 103-114.

Larrauri, J.A. (1999). New approaches in the preparation of high dietary fibre powders from fruit by-products. Trends in Food Science and Technology. 10: 3-8.

Larrauri, J.A., Rupérez, P. y Saura Calixto, F. (1997). Pineapple shell as a source of dietary fiber with associated polyphenols. Journal of Agricultural and Food Chemistry. 45: 4028-4031.

Manderson, K., Pinart, M., Tuohy, K.M. (2005). In vitro determination of prebiotic properties of oligosaccharides derived from an orange juice manufacturing by-product stream. Applied and Environmental Microbiology. 71: 8383-8389.

Martínez, M., Yáñez, R., Alonsó, J. L. y Parajó, J. C. (2010). Chemical production of pectic oligosaccharides from orange peel wastes. Industrial and Engineering Chemistry Research. 49: 8470-8476. 
Meyer, A. S., Holck, J., Hjerno, K., Lorentzen, A., Vigsnaes, L. K., Hemmingsen, L., Licht, T. R. y Mikkelsen, J. D. (2011). Tailored enzymatic production of oligosaccharides from sugar beet pectin and evidence of differential effects of a single DP chain length difference on human faecal microbiota composition after in vitro fermentation. Process Biochemistry. 46: 10391049.

Morales, P., Ramírez-Moreno, E., Sánchez-Mata, M.C., Carvalho, A.M. y Isabel Ferreira, I.C.F.R. (2012). Nutritional and antioxidant properties of pulp and seeds of two xoconostle cultivars (Opuntia joconostle F.A.C. Weber ex Diguet and Opuntia matudae Scheinvar) of high consumption in Mexico. Food Research International. 46: 279-285.

Namsree, P., Suvajittanont, W., Puttanlek, Ch, Dudsadee, U. y Rungsardthong, V. (2012). Anaerobic digestion of pineapple pulp and peel in a plug-flow reactor. Journal of Environmental Management. 110: 40-47.

Nawirska, A. y Kwasniewska, M. (2005). Dietary fibre fractions from fruit and vegetable processing waste. Food Chemistry. 91:221-225.

Ogunbanwo, S.T. y Okanlawon, B.M. (2009). Influence of nutrients utilization and cultivation conditions on the production of lactic acid by homolactic fermenters. Biotechnology. 8: 107-113.

Oreopoulou, V. y Tzia, C. (2007). Utilization of plant by-products for the recovery of proteins, dietary fibers, antioxidants, and colorants. In: Utilization of ByProducts and Treatment of Waste in the Food Industry (edited by V. Orelpoulou \& W. Russ). pp. 209-232. New York: Springer.

Ramadan, M.F. y Mörcel, J.T. (2003). Recovered lipids from prickly pear (Opuntia ficus-indica (L.) Miller) peel: a good source of polyunsaturated fatty acids, natural antioxidant vitamins and sterols. Food Chemistry. 83: 447-456.

Ramírez-Chavarín, N.L. (2009). Evaluación de bacterias lácticas termorresistentes como posibles probióticos en productos cárnicos cocidos. Ph.D. Dissertation. México: Departamento de Biotecnología, Universidad Autónoma Metropolitana.

Ramírez-Chavarín, N.L., Wacher-Rodarte, C. y Pérez-Chabela, M.L. (2010). Characterization and identification of thermotolerant lactic acid bacteria isolated from cooked sausage as bioprotective cultures. Journal of Muscle Foods. 21: 585-596.

Rani, D.S. y Nand, K. (2004). Ensilage of pineapple processing waste for methane generation. Waste Management. 24: 523-528.

Rastall, R.A., Gibson, G.R., Gill, H.S. (2005). Modulation of the microbial ecology of the human colon by probiotics, prebiotics and synbiotics to enhance human health: an overview of enabling science and potential applications. FEMS Microbiology Ecology. 52: 145-152. 
Re, R., Pellegrini, N., Proteggente, A., Pannala, A., Yang, M. y Rice-Evans, C. (1999). Antioxidant activity applying an improved ABTS radical cation decolorization assay. Free Radical Biology and Medicine. 26: 1231-1237.

Rehberger, J.L. y Glatz, B.A. (1998). Response of cultures of Propionibacterium to acid and low pH: tolerance and inhibition. Journal of Food Protection. 61: 211-216.

Rodríguez, R., Jiménez, A., Fernández-Bolaños, J., Guillen, R. y Heredia, A. (2006). Dietary fibre from vegetable products as source of functional ingredients. Trends in Food Science and Technology. 17: 3-15.

Rossi, M., Corradini, C., Amaretti, A. (2005). Fermentation of fructooligosaccharides and inulin by Bifidobacteria: a comparative study of pure and fecal culture. Applied and Environmental Microbiology. 71: 61506158.

Schieber, A., Stintzing, F.C. y Carle, R. (2001). By-products of plant food processing as a source of functional compounds recent developments. Trends in Food Science and Technology. 12: 401-413.

Spinnler, H.E. y Corrieu, G. (1989). Automatic method to quantify starter activity based on pH measurement. Journal of Dairy Research. 56: 755-764.

Sumaya-Martínez, M. T., Cruz-Jaime, S., Madrigal-Santillan, E., García-Paredes, J. D., Cariño-Cortes, R., Cruz-Cansino, N., Valadez-Vega, C., MartínezCardenas, L. y Alanís-García, E. (2011). Betalain, acid ascorbic, phenolic contents and antioxidant properties of purple, red, yellow and white cactus pears. International Journal of Science. 12: 6452-6468.

Tran, C.H. y Mitchel, D.A. (1995). Pineapple waste -a novel substrate for citric acid production by solid-state fermentation. Biotechnology Letters. 17: 11071110.

Vergara-Valencia, N., Granados-Pérez, E., Agama-Acevedo, E., Tovar, J., Ruales, J. y Bello-Pérez, L.A. (2007). Fibre concentrate from mango fruit: characterization, associated antioxidant capacity and application as a bakery product ingredient. LWT-Food Science and Technology. 40: 722729.

Willey, J.M., Sherwood, L.M. y Woolverton, C.J. (2008). Prescott, Harley and Klein's Microbiology, 7th edition. pp. 126-127. New York: McGraw Hill.

Yeo, S.K. y Liong, M.T. (2010). Effect of prebiotics on viability and growth characteristics of probiotics in soymilk. Journal of the Science of Food and Agriculture. 90: 267-275. 
7. CAPÍTULO III: EFECTO DE LA HARINA DE CÁSCARA DE TUNA (Opuntia ficus indica) Y PIÑA (Ananas comosus) SOBRE LAS PROPIEDADES FISICOQUÍMICAS Y DE TEXTURA DE SALCHICHAS COCIDAS INOCULADAS CON BACTERIAS ÁCIDO LÁCTICAS PROBIÓTICAS.

Díaz-Vela, J., Pérez-Chabela, M. L. y Totosaus, A. Effect of cactus pear (Opuntia ficus indica) and pineapple (Ananas comosus) peel flour on physicochemical and textural properties of cooked sausages inoculated with probiotic lactic acid bacteria. Enviado.

\subsection{OBJETIVO}

Evaluar el efecto de la harina de cáscara de tuna y piña sobre las propiedades fisicoquímicas, funcionales y microestructurales de salchichas inoculadas con una bacteria ácido láctica (Pedicoccus pentosaceus UAM22).

\subsection{PROLEGÓMENO}

La utilización integral de frutas ha sido un reto para la industria alimenticia debido a la generación de co-productos agroindustriales tales como cáscaras. Estos coproductos pueden ser usados como ingredientes primarios o secundarios para la nutrición humana o animal como fuente de fibra dietética y compuestos bioactivos. Las semillas y cáscaras son las únicas partes no comestibles de la fruta cuando estas son procesadas o consumidas en fresco, las cuales han sido ampliamente estudiadas debido a la extracción de varios compuestos de valor agregado (Rezzadori y col., 2012; Ketnawa y col., 2012).

Las sustancias poliméricas que se encuentran en la pared celular de las plantas y frutos representan lo que se conoce como fibra dietética (Southgate, 1975). La definición química de la fibra dietética corresponde a la suma de polisacaridos noalmidonados y lignina, mientras que la definición fisiológica es el residuo de plantas comestibles resistentes a la hidrólisis de enzimas digestivas humanas (Furda, 1977).

Se ha reportado que la cáscara de tuna (Opuntia ficus indica) contiene ácidos grasos poliinsaturados, como ácido linoléico, y antioxidantes tales como: 
tocoferoles, vitamina E, C y K, con un contenido de fibra dietética total de $64.15 \%$ (Ramadan y Mörcel, 2003). La cáscara de piña es un co-producto con un contenido de fibra dietética total de $62.54 \%$, con capacidad antioxidante (Larrauri y col., 1997). Además, los estudios in vitro han demostrado el efecto prebiótico de la harina de cáscara de tuna y piña con el crecimiento de cepas probióticas (DíazVela y col., 2013).

Por otro lado, el desarrollo continuo de los alimentos funcionales es muy importante hoy en día con el fin de ofrecer alimentos más sanos a los consumidores. Los co-productos de frutas son una fuente importante de fibra dietética y antioxidantes para el desarrollo de alimentos funcionales. El uso de la fibra dietética en salchichas ha sido estudiado como el efecto sobre sus propiedades fisicoquímicas y tecno-funcionales (Hernández-García y GüemesVera, 2010; Tomaschunas y col., 2013; Ktari y col., 2014). Además, Cáceres y col. (2004) reportaron que la fibra dietética soluble mejoró las características de color y textura de los productos cárnicos cocidos. Estudios previos han incorporado fructo-oligosacáridos en productos cárnicos bajos en grasa generando gran interés debido al porcentaje de grasa que puede ser reducido (desde 20 hasta $80 \%$ ) sin afectar propiedades sensoriales (Devereux y col., 2003). Así mismo, ciertos oligosacáridos de fuente vegetal dependiendo de lo largo de sus cadenas poliméricas, pueden presentar resistencia a temperaturas relativamente altas (100 ${ }^{\circ} \mathrm{C}$ ) así como condiciones ácidas ó básicas (Courtin y col., 2009) lo que les permitirían formar parte de productos alimenticios que requieran estas condiciones de elaboración. La fibra dietética en general, al ser incorporada en alimentos procesados, interactúa con otros componentes permitiendo cambios en la biodisponibilidad de nutrientes, sabor y textura de los alimentos (Dello-Staffolo y col., 2004). 


\subsection{METODOLOGÍA}

\subsubsection{Obtención de las harinas de cáscara de tuna y piña}

Las cáscaras se recogieron semanalmente y transportaron al campus de la Universidad en cajas de plástico (aproximadamente $2 \mathrm{~kg}$ cada uno), fueron lavadas con agua fría y se almacenaron un día antes de su procesamiento en condiciones de refrigeración $\left(4 \pm 1^{\circ} \mathrm{C}\right)$. Las cáscaras de ambas frutas fueron equilibradas a temperatura ambiente durante 2 horas antes de ser cortadas en piezas de $2 \times 2 \mathrm{~cm}$ y se secaron a $60^{\circ} \mathrm{C}$ durante aproximadamente 24 horas en un horno de convección de aire (Barco Instrumentos Científicos, Ciudad de México). Las cáscaras secas se molieron en un molino de discos motorizado (Arisa Maquinaria S.A de C.V, México) y se tamizaron consecutivamente con tamaños de malla $100,80,50$ y 20 para obtener un polvo regular y homogéneo, llamado harina. Las harinas de cáscara de tuna y piña fueron almacenadas en recipientes herméticamente cerrados hasta su uso.

\subsubsection{Elaboración de embutidos}

La carne magra de cerdo y el lardo de cerdo fueron comprados en una carnicería local. La carne $(50 \% \mathrm{p} / \mathrm{p})$ se molió a través de una placa de $0.42 \mathrm{~cm}$ en una picadora de carne y se mezcló con sal $(2 \% \mathrm{p} / \mathrm{p})$, sal cura $(0.3 \% \mathrm{p} / \mathrm{p})$, mezcla de fosfato comercial Hamine ${ }^{\circledR}$ (McCormick-Pesa, Ciudad de México, México; 0.8\% $\mathrm{p} / \mathrm{p})$ y con la mitad del total de hielo durante un minuto en un procesador de alimentos Moulinex DPA2 (Moulinex, Ecully, Francia). Se añadió el lardo de cerdo congelado (grasa dorsal del cerdo) y se emulsionó durante dos minutos más. Se añadió el resto del hielo y se emulsionó durante 2-3 min con harina de trigo (5\% $\mathrm{p} / \mathrm{p}$ ) hasta la incorporación total de los ingredientes, teniendo cuidado de mantener la temperatura de la masa $\left(12 \pm 2^{\circ} \mathrm{C}\right)$. El batido fue embutido en fundas de celulosa con diámetro de $20 \mathrm{~mm}$ y se cocinó en un baño de agua hasta alcanzar una temperatura interna de $70 \pm 2{ }^{\circ} \mathrm{C}$ (aproximadamente $15 \mathrm{~min}$ ) y se enfrió en un baño de hielo. Las salchichas fueron empaquetadas al vacío y almacenadas a $4{ }^{\circ} \mathrm{C}$ hasta su posterior análisis en el día 1, 9 y 20. Se preparó un total de dos lotes de 1 $\mathrm{kg}$ de cada formulación para cada tratamiento. Para los diferentes tratamientos, se 
añadió la harina de cáscara de piña o de harina de cáscara de tuna (1\% p/p). De igual forma, la suspensión de Pedioccocus pentosaceus UAM22, reportada previamente como termotolerante y probiótica (Ramírez-Chavarín y col., 2010, 2013), se preparó para la reactivación de las células en $10 \mathrm{ml}$ de caldo Man, Rogosa y Sharpe (MRS) (deMan y col., 1960), incubando a $37^{\circ} \mathrm{C}$ durante $24 \mathrm{~h}$ hasta llegar a una densidad óptica cercana a uno $(\lambda=600 \mathrm{~nm})$, que contiene aproximadamente $10^{8} \mathrm{CFU} / \mathrm{mL}$, la adición de $1 \%(\mathrm{v} / \mathrm{p}$ ) de las bacterias cultivadas al batido de la carne se realizó antes de embutir. Los seis diferentes tratamientos se muestran se a continuación:

\begin{tabular}{|l|c|c|}
\cline { 2 - 3 } \multicolumn{1}{l|}{} & Sin inóculo & P. pentosaceus UAM22 \\
\hline Sin harina & 1 & 2 \\
\hline Harina de cáscara de tuna & 3 & 4 \\
\hline Harina de cáscara de piña & 5 & 6 \\
\hline
\end{tabular}

\subsubsection{Rendimiento de cocción, Humedad total y Humedad expresable}

El rendimiento a la cocción de las salchichas se determinó de acuerdo con la metodología propuesta por Shand (2000). Las salchichas se pesaron antes y después de la cocción, eliminando el agua contenida en las tripas de celulosa después de la cocción. El rendimiento de cocción se reportó como el peso del producto obtenido en porcentaje después de la cocción.

El contenido total de humedad se llevó a cabo de acuerdo con el Método de Prueba Oficial No 950.46 (AOAC, 1996), se colocaron $3 \mathrm{~g}$ de muestra en una cápsula de aluminio a peso constante y se calentó en un horno a $110^{\circ} \mathrm{C}$ durante $12 \mathrm{~h}$. Después, las muestras se retiraron del horno y se colocan en un desecador hasta una temperatura constante. La humedad total fue determinada de acuerdo a las diferencias de peso.

La humedad expresable se realizó de acuerdo al método propuesto por Jáuregui y col. (1981). Se colocaron 2-3 g de la muestra y fueron envueltas en papel de filtro 
Whatman \# 1 y \# 45 a peso constante y se colocaron en un tubo de centrífuga de $25 \mathrm{ml}$, después se centrifugó a $2000 \times \mathrm{g}$ durante 15 min a temperatura ambiente. El porcentaje de agua eliminada por centrifugación se reportó como la humedad expresable. Esta técnica se basa en la capacidad que tiene la muestra problema en retener su agua ligada después de ejercer una fuerza sobre esta.

\subsubsection{Rancidez oxidativa}

La determinación de la rancidez oxidativa fue determinada utilizando la metodología modificada por Zipser y Watts (1962). Se mezcló 10 gramos de muestra con $49 \mathrm{ml}$ de agua destilada a $50^{\circ} \mathrm{C}$, se adicionó $1 \mathrm{ml}$ de la solución de sulfanilamida- $\mathrm{HCl}(0.5 \%$ y $20 \%$, respectivamente, $\mathrm{v} / \mathrm{v})$. Posteriormente, la muestra se transfirió a un matraz Erlenmeyer de $500 \mathrm{ml}$ que contenía $48 \mathrm{ml}$ de agua destilada a $50{ }^{\circ} \mathrm{C}$ y $2 \mathrm{ml}$ de solución de $\mathrm{HCl}(50 \% \mathrm{v} / \mathrm{v})$, más 2 gotas de antiespumante a base de silicona. El contenido del matraz se separó por destilación en 10-15 minutos o hasta obtener $50 \mathrm{ml}$ de destilado. Fue tomada una alícuota de $5 \mathrm{ml}$ y se mezcló con $5 \mathrm{ml}$ de solución de ácido tiobarbitúrico (0.02 M en ácido acético glacial 90\%). Las muestras se colocaron en agua hirviendo durante 35 minutos, se enfrió y se midió la absorbancia a $538 \mathrm{~nm}$. La concentración de malonaldehído ( $\mathrm{mg} / \mathrm{kg}$ de muestra) se calculó interpolando la absorbancia contra una solución control 1,1,3-tetraetoxipropano ( $3 \times 0.066 \mathrm{~g} / \mathrm{L})$, de acuerdo con Lawlor y col. (2000).

\subsubsection{Color instrumental}

El color de los diferentes tratamientos se determinó usando un colorímetro Chroma Meter CR-200 Hunter-Lab (Hunter Lab Associated, Inc., Reston, Virginia, EE.UU.) frente a un patrón blanco $(L=97,38, a=0,17$ y $b=1,94)$. Las lecturas se tomaron de la sección interna de salchichas y se colocaron en el porta muestras, esta se giró cada $90^{\circ}$ para proporcionar una lectura media de color por muestra. Las coordenadas CIE LAB se reportaron como luminosidad $\left(\mathrm{L}^{*}\right)$, componente roja $\left(a^{*}\right)$ y componente amarilla $\left(b^{*}\right)$. (Hunt y col., 1991). 


\subsubsection{Cuenta viable de bacterias ácido lácticas y $\mathrm{pH}$}

El recuento de bacterias ácido lácticas viables en la formulación de las diferentes salchichas se determinó al 1, 9 y 20 días de almacenamiento. Se homogeneizó 10 $\mathrm{g}$ de muestra en $90 \mathrm{ml}$ de solución salina estéril $(\mathrm{NaCl}$ al $0.9 \%, \mathrm{p} / \mathrm{v})$, se realizaron las diluciones pertinentes en serie hasta obtener un número contable de colonias, la siembra se realizó en placas de agar MRS y se incubaron a $37^{\circ} \mathrm{C}$ durante $24 \mathrm{~h}$. La determinación del pH se realizó de acuerdo al método propuesto por Landvogt (1991). Se homogeneizó $10 \mathrm{~g}$ de muestra con $90 \mathrm{ml}$ de $\mathrm{NaCl}$ (5\% p/v) de solución, la medición de $\mathrm{pH}$ se realizó con un potenciómetro (Beckman Instruments 540 metros de $\mathrm{pH}$, Palo Alto, EE.UU.).

\subsubsection{Análisis del perfil de textura}

El análisis de perfil de textura de las salchichas se realizó con un analizador de textura Brookfield Analizador de Textura LFRA 4500. Las muestras se cortaron en cilindros de $21 \mathrm{~mm}$ de altura y se comprimieron $30 \%$ de su altura original con un disco de acrílico con diámetro de $4 \mathrm{~cm}$ a una velocidad constante de $1 \mathrm{~mm} / \mathrm{s}$, y un período de espera $5 \mathrm{~s}$. De las curvas de esfuerzo-deformación se calcularon dureza (fuerza máxima detectada durante la compresión), cohesividad (resistencia de unión interna que dan estructura a la muestra) y la resiliencia (la energía almacenada en la muestra que permite recuperar en cierta medida su forma original) (Szczesniak, 1963; Bourne, 1978).

\subsubsection{Microscopía electrónica de barrido}

El análisis microestructural de las muestras se llevó a cabo en un microscopio electrónico de barrido con una adaptación de la metodología reportada por Julavittayanukul y col. (2006). Se cortaron muestras del interior de las salchichas en piezas rectangulares de $1 \times 1 \mathrm{~cm}$ con $2-3 \mathrm{~mm}$ de espesor y se fijaron con $5 \%$ de glutaraldehído en buffer de fosfato $0.1 \mathrm{~mol} / \mathrm{L}(\mathrm{pH} 7.0)$ durante $48 \mathrm{~h}$. Las muestras fijadas se lavaron tres veces con el mismo buffer de fosfato $(0.1 \mathrm{~mol} / \mathrm{L}, \mathrm{pH} 7.0)$ durante 15 min y después se fijó con el mismo buffer de fosfato que contenía 1\% de tetróxido de osmio durante $2 \mathrm{~h}$. Las muestras fijadas se deshidrataron con concentraciones crecientes de etanol $(30,40,50,60,70,80,90$, y $100 \%$ durante 
$30 \mathrm{~min}$ ). Las muestras fueron secadas a punto crítico con $\mathrm{CO}_{2}$, y se montaron en soportes de aluminio, revestidas con oro por bombardeo iónico y se examinaron bajo un microscopio electrónico de barrido JEOL JSM-5900LV (JEOL Ltd., Tokio, Japón) con 20 kV de voltaje de aceleración.

\subsubsection{Diseño y análisis de datos experimentales}

Se utilizó un diseño factorial completo para determinar el efecto de la harina de cáscara de la fruta, $P$. pentosaceus y tiempo de almacenamiento sobre parámetros físico-químicos y funcionales. El modelo propuesto fue:

$$
y_{i j k}=\mu+\alpha_{i}+\beta_{j}+\gamma_{k}+\epsilon_{i j k}
$$

Donde, $y_{i j k}$ representa la variable respuesta para el i-ésimo tipo de harina de cáscara de fruto (tuna o piña), al j-ésimo tipo de cepa (sin inocular y $P$. pentosaceus UAM22), al k-ésimo día de almacenamiento (día 1, 9 y 20); $\mu$ es la media global del modelo; $\alpha_{i}, \beta_{j}, \gamma_{k}$ son los efectos principales por tipo de fibra, cepa y tiempo de almacenamiento; $\epsilon_{i j k}$ es el error residual o el error asumiendo la distribución normal de los datos con media cero y varianza $\delta^{2}$ (Der y Everitt, 2002). Los resultados fueron analizados con el procedimiento PROC ANOVA con el software SAS v8.0 (SAS System, Cary, NC, USA). Las diferencias significativas entre las medias fueron determinadas con la prueba de Duncan del mismo paquete estadístico. 


\subsection{RESULTADOS Y DISCUSIÓN}

\subsubsection{Rendimiento, Humedad total, Humedad expresable y Rancidez Oxidativa}

El rendimiento de las salchichas fue significativamente $(\mathrm{P}<0.05)$ mayor en los tratamientos con harina de cascara de tuna $(108.7 \%$ y $107.72 \%$ para los tratamientos sin y con $P$. pentosaceus inoculado, respectivamente), seguidos del control (105.30\%). Valores de rendimiento menores fueron observados en la muestra inoculada con $P$. pentosaceus $(103.23 \%$ ) y harina de cascara de piña con P. pentosaceus (103.19\%). El menor rendimiento fue para las muestra con harina de cascara de piña (101.22\%). La capacidad de ligar agua por parte de las harinas de cáscara de frutos (El Kossori y col., 1998) pudo ser la causa de obtener un mejor rendimiento en las salchichas. Varios estudios han demostrado que la incorporación de fibra dietética a la formulación de productos cárnicos favorece el rendimiento debido a la capacidad de retención de agua y grasa que presenta (Crehan y col., 2000; Grigelmo-Miguel y col., 1999).

En la Tabla 6 se muestra el porcentaje de humedad total y humedad expresable de los diferentes tratamientos de las salchichas durante el tiempo de almacenamiento. Las salchichas formuladas con las harinas de cáscara de tuna y cáscara de piña tuvieron los valores significativamente $(p<0.05)$ mayores de humedad, donde el control tuvo el valor menor de humedad total. Durante el periodo de almacenamiento, la humedad total fue significativamente $(p<0.05)$ mayor al día 1, disminuyendo al día 9 y 20. Para la humedad expresable, la incorporación de harina de cáscara de piña resultó en valores significativamente $(P<0.05)$ mayores de liberación de agua, seguido de los tratamientos con harina de cáscara de tuna. Los menores resultados de humedad expresable se obtuvieron en ambas muestras con harina de cáscara tuna y cáscara de piña inoculadas con $P$. pentosaceus. La humedad expresable aumentó significativamente $(\mathrm{P}<0.05)$ durante el tiempo de almacenamiento. 
Tabla 6. Humedad total, humedad expresable y rancidez oxidativa de los diferentes tratamientos de salchichas durante su almacenamiento

\begin{tabular}{|c|c|c|c|c|c|c|c|c|c|}
\hline \multirow{3}{*}{ Tratamiento } & \multicolumn{3}{|c|}{ Humedad total (\%) } & \multicolumn{3}{|c|}{ Humedad expresable (\%) } & \multicolumn{3}{|c|}{$\begin{array}{c}\text { Rancidez Oxidativa } \\
\text { (mg Malonaldehído/kg) }\end{array}$} \\
\hline & \multicolumn{3}{|c|}{ Tiempo (días) } & \multicolumn{3}{|c|}{ Tiempo (días) } & \multicolumn{3}{|c|}{ Tiempo (días) } \\
\hline & 1 & 9 & 20 & 1 & 9 & 20 & 1 & 9 & 20 \\
\hline Control & $55.06^{\mathrm{cA}}$ & $49.42^{\mathrm{cB}}$ & $49.88^{\mathrm{cB}}$ & $19.18^{\mathrm{bcc}}$ & $28.63^{b c B}$ & $29.63^{\mathrm{bcA}}$ & $0.02^{\mathrm{aC}}$ & $0.077^{\mathrm{aB}}$ & $0.105^{\mathrm{aA}}$ \\
\hline P. pentosaceus & $50.98^{\mathrm{bA}}$ & $54.55^{\mathrm{bB}}$ & $54.07^{\mathrm{bB}}$ & $21.59^{\mathrm{cC}}$ & $23.51^{\mathrm{cB}}$ & $29.17^{\mathrm{cA}}$ & $0.025^{\mathrm{bC}}$ & $0.041^{\mathrm{bB}}$ & $0.064^{\mathrm{bA}}$ \\
\hline Harina de cáscara de tuna & $58.02^{\mathrm{aA}}$ & $54.02^{\mathrm{aB}}$ & $54.14^{\mathrm{aB}}$ & $19.25^{\mathrm{bC}}$ & $25.23^{\mathrm{bB}}$ & $25.99^{\mathrm{bA}}$ & $0.028^{\mathrm{eC}}$ & $0.028^{\mathrm{eB}}$ & $0.032^{\mathrm{eA}}$ \\
\hline Harina de cáscara de piña & $56.43^{\mathrm{aA}}$ & $56.25^{\mathrm{aB}}$ & $55.42^{\mathrm{aB}}$ & $39.30^{\mathrm{aC}}$ & $40.05^{\mathrm{aB}}$ & $44.23^{\mathrm{aA}}$ & $0.027^{\mathrm{deC}}$ & $0.029^{\mathrm{deB}}$ & $0.044^{\mathrm{deA}}$ \\
\hline $\begin{array}{l}\text { Harina de cáscara de tuna }+ \\
P . \text { pentosaceus }\end{array}$ & $54.08^{\mathrm{bA}}$ & $53.84^{\mathrm{bB}}$ & $53.13^{\mathrm{bB}}$ & $20.32^{c C}$ & $25.38^{c B}$ & $25.70^{\mathrm{cA}}$ & $0.028^{c d C}$ & $0.039^{\mathrm{cdB}}$ & $0.040^{\mathrm{cdA}}$ \\
\hline $\begin{array}{l}\text { Harina de cáscara de piña }+ \\
P . \text { pentosaceus }\end{array}$ & $53.40^{\mathrm{bcA}}$ & $52.40^{\mathrm{bcB}}$ & $52.76^{\mathrm{bcB}}$ & $22.82^{\mathrm{cC}}$ & $27.70^{\mathrm{cB}}$ & $32.37^{\mathrm{cA}}$ & $0.029^{b c c}$ & $0.032^{b c B}$ & $0.060^{\mathrm{bcA}}$ \\
\hline
\end{tabular}


La capacidad de retener agua en un sistema alimenticio es una propiedad importante desde el punto de vista tecnológico. Esta propiedad muestra la capacidad de un material a retener agua durante la aplicación de una fuerza gravitacional o compresión, la cual está compuesta por agua ligada, agua hidrodinámica y, principalmente, agua atrapada físicamente (Yamazaki y col., 2005). De manera similar, la humedad expresable se refiere a la cantidad de líquido retenido durante la aplicación de una fuerza (Jauregui y col. 1981). De acuerdo a Thebaudin y col. (1997), la adición de fibra dietética favorece la capacidad de retención de agua y grasa en productos cárnicos. La fibra dietética en solución forma una matriz polimérica con diversas propiedades fisicoquímicas favoreciendo la capacidad de retención de agua, donde las macromoléculas que la conforman son las responsables de la hidratación de la fibra mediante adsorción formando una matriz de gel cuando esta es sometida a calor (Cáprita y col., 2010). Del mismo modo que la composición de las fibras, el contenido de pectina, presencia de iones como el calcio y mucilagos pueden modificar el agua ligada a estos compuestos y a la matriz proteica que haya retenido agua, aun ejerciendo alguna fuerza física (ElKossori y col., 1998; García y col. 2002; Habibi y col. 2004; Habibi y col., 2005; Ulrich-Endress y Mattes, 2012), como fue el caso de la harina de cáscara de piña. Además, en las condiciones experimentales utilizadas, la diferencia en la humedad expresable entre los diferentes tratamientos pudo ser debido a la estructura química y morfología de las macromoléculas de las fibras utilizadas, así como por el pH de los batidos cárnicos (Robertson y Eastwood, 1981).

La incorporación de las harinas de cáscara tuna y/o la bacteria láctica resultaron en valores significativamente $(p<0.05)$ menores de rancidez que el control, seguidas de las salchichas inoculadas con $P$. pentosaceus pero con harina de cáscara de frutas. Las muestras con harina de cáscara de tuna tuvieron los valores menores de rancidez, junto con las muestras conteniendo harina de cáscara de piña. Las muestras conteniendo harina de cáscara de frutas e inoculadas tuvieron valores intermedios. Al pasar el tiempo de almacenamiento, la concentración de malonaldehído aumentó de manera significativa $(p<0.05)$ (Tabla 
6). Los productos cárnicos conservados en refrigeración sufren procesos de oxidación a causa de la combinación de fenómenos de oxidación lipídica y proteica (Batifoulier y col., 2002; Estévez y Cava, 2004.). La menor rancidez detectada es debido a la composición de la harina de cáscara de frutos de cactus y piña como fuente de antioxidantes. La cáscara de tuna contiene taninos, flavonoides y polifenoles (Ramadan y Mörsel, 2003; Cerezal y Duarte, 2005; Cardador-Martínez y col., 2011), mientras que la cáscara de piña tiene un elevado contenido de miricetina, polifenol con actividad antioxidante (Larrauri y col., 1997). De este modo, las harinas de las cáscaras tuvieron un efecto antioxidante durante el almacenamiento. Los valores intermedios observados en la rancidez oxidativa podría ser un efecto de la actividad lipolítica de la bacteria láctica inoculada, ya que los ácidos grasos libres producto de la lipólisis son los precursores de la oxidación lipídica (Toldrá y col., 2001). En productos fermentados se ha observado cierta actividad lipolítica por $P$. pentosaceus, aumentando la rancidez oxidativa del producto (Johansson y col., 1994). Sin embargo, debido a la presencia de los compuestos con actividad antioxidante de las harinas de cáscara de frutas, los valores de rancidez fueron menores que la muestra inoculada y sin harinas. La actividad antioxidante reportada para estas harinas fue de 89 y $69 \%$ para harina de cáscara de fruto de cactus y de cáscara de piña, respectivamente (Díaz-Vela y col., 2013).

\subsubsection{Color instrumental}

La luminosidad de las salchichas control (sin harina de cáscara de fruta o bacteria láctica) fue significativamente $(P<0.05)$ mayor que el resto de las formulaciones, seguida de la muestra inoculada con $P$. pentosaceus sin harina de cáscara de frutos. Las muestras más oscuras fueron las que contenían harina de cáscara de piña y harina de cáscara de piña con $P$. pentosaceus. Respecto al tiempo de almacenamiento, las salchichas se hicieron significativamente $(P<0.05)$ más oscuras conforme paso el tiempo de almacenamiento (Tabla 7). La componente roja del color instrumental de las salchichas fue significativamente $(P<0.05)$ mayor para ambos tratamientos conteniendo harina de cáscara de tuna. Los valores más bajos de componente roja de color fueron observados en las muestras control, las 
inoculadas con $P$. pentosaceus y las que contenían harina de cáscara de piña con $P$. pentosaceus. Durante el tiempo de almacenamiento, los valores de la componente roja aumentaron significativamente $(p<0.05)$ al día 9 , para disminuir al día 20. (Tabla 7). Para la componente amarilla, las muestras con harina de cáscara de piña tuvieron valores significativamente $(P<0.05)$ mayores que el resto de los tratamientos. Los valores menores de componente amarilla fueron para ambas muestras, control e inoculadas con $P$. pentosaceus (Tabla 7).

La incorporación de las harinas de cáscaras disminuyó la luminosidad de las muestras, ya que los tratamientos control e inoculado con $P$. pentosaceus tuvieron valores más altos. Las diferencias en la coloración de las diferentes formulaciones pueden ser atribuidas a la presencia de pigmentos vegetales en las harinas de las cáscaras de frutas, sobre todo debido a que las muestras sin harina de cáscara de frutos (control e inoculada con $P$. pentosaceus) tuvieron los valores menores de rojosidad y amarillosidad, en comparación con las muestras que contenían estas harinas. La harina de cáscara de tuna aumentó los valores de la componente roja, mientras que la harina de cáscara de piña aumentó los valores de la componente amarilla. Los cambios de coloración en los productos cocidos durante el almacenamiento en refrigeración pueden estar relacionados con la oxidación de los componentes del producto, como lípidos o nitroso-hemo-pigmentos (Akamittath y col., 1990; Carballo y col., 1991; Jo y col., 1999). 
Tabla 7. Color instrumental de los diferentes tratamientos de salchichas durante su almacenamiento

\begin{tabular}{|c|c|c|c|c|c|c|c|c|c|}
\hline \multirow{3}{*}{ Tratamiento } & \multicolumn{3}{|c|}{ Luminosidad $\left(\mathrm{L}^{*}\right)$} & \multicolumn{3}{|c|}{ Componente roja $\left(a^{*}\right)$} & \multicolumn{3}{|c|}{ Componente amarilla $\left(b^{\star}\right)$} \\
\hline & \multicolumn{3}{|c|}{ Tiempo (días) } & \multicolumn{3}{|c|}{ Tiempo (días) } & \multicolumn{3}{|c|}{ Tiempo (días) } \\
\hline & 1 & 9 & 20 & 1 & 9 & 20 & 1 & 9 & 20 \\
\hline Control & $69.53^{\mathrm{aB}}$ & $68.36^{\mathrm{aAB}}$ & $68.39^{\mathrm{aA}}$ & $3.92^{\mathrm{cA}}$ & $4.00^{\mathrm{cB}}$ & $4.53^{\mathrm{CA}}$ & $8.39^{\mathrm{dB}}$ & $8.52^{\mathrm{dB}}$ & $8.87^{\mathrm{dA}}$ \\
\hline P. pentosaceus & $67.17^{\mathrm{bB}}$ & $67.88^{\mathrm{bAB}}$ & $67.88^{\mathrm{bA}}$ & $4.27^{\mathrm{cA}}$ & $4.37^{\mathrm{cB}}$ & $4.33^{\mathrm{cA}}$ & $8.77^{\mathrm{dB}}$ & $8.77^{\mathrm{dB}}$ & $8.88^{\mathrm{dA}}$ \\
\hline Harina de cáscara de tuna & $62.46^{\mathrm{dB}}$ & $63.00^{\mathrm{dAB}}$ & $64.10^{\mathrm{dA}}$ & $6.17^{\mathrm{aA}}$ & $6.12^{\mathrm{aB}}$ & $6.04^{\mathrm{aA}}$ & $10.14^{\mathrm{cB}}$ & $10.20^{\mathrm{cB}}$ & $10.44^{\mathrm{cA}}$ \\
\hline Harina de cáscara de piña & $56.56^{\mathrm{eB}}$ & $56.93^{\mathrm{eAB}}$ & $57.16^{\mathrm{eA}}$ & $5.87^{\mathrm{bA}}$ & $5.65^{\mathrm{bB}}$ & $5.59^{\mathrm{bA}}$ & $13.72^{\mathrm{aB}}$ & $13.70^{\mathrm{aB}}$ & $14.65^{\mathrm{aA}}$ \\
\hline $\begin{array}{l}\text { Harina de cáscara de tuna }+ \\
P . \text { pentosaceus }\end{array}$ & $63.62^{\mathrm{cB}}$ & $64.15^{\mathrm{cAB}}$ & $65.41^{\mathrm{cA}}$ & $6.35^{\mathrm{aA}}$ & $5.80^{\mathrm{aB}}$ & $5.78^{\mathrm{aA}}$ & $10.14^{\mathrm{cB}}$ & $10.20^{\mathrm{cB}}$ & $10.44^{\mathrm{cA}}$ \\
\hline $\begin{array}{l}\text { Harina de cáscara de piña }+ \\
P . \text { pentosaceus }\end{array}$ & $56.85^{\mathrm{eB}}$ & $57.23^{\mathrm{eAB}}$ & $57.08^{\mathrm{eA}}$ & $5.36^{\mathrm{cA}}$ & $5.29^{\mathrm{cB}}$ & $5.54^{\mathrm{cA}}$ & $13.48^{\mathrm{bB}}$ & $13.34^{\mathrm{bB}}$ & $13.40^{\mathrm{bA}}$ \\
\hline
\end{tabular}

a-e Medias con la misma letra en la misma columna no son significativamente $(P>0.05)$ diferentes por tratamiento.

A-B Medias con la misma letra en la misma fila no son significativamente $(P>0.05)$ diferentes por tiempo de almacenamiento. 


\subsubsection{Conteo de bacterias ácido lácticas y pH}

Las muestras inoculadas con $P$. pentosaceus y harina de cáscara de tuna presentaron conteos de bacterias lácticas significativamente $(P<0.05)$ mayores que el resto de los tratamientos, seguidas de las muestras inoculadas con $P$. pentosaceus e inoculadas más harina de cáscara de piña. Los menores conteos de bacterias viables fueron en las muestras con las harinas de cáscara de frutas sin inocular. El conteo de bacterias lácticas aumentó significativamente $(P<0.05)$ después de los 9 días de almacenamiento (Tabla 8). Para el pH de las salchichas, como era de esperarse, las muestras control tuvieron los valores significativamente $(\mathrm{P}<0.05)$ mayores de $\mathrm{pH}$, seguidos de las muestras inoculadas con harina de cáscara de fruto de cactus más $P$. pentosaceus y las muestras inoculadas sin harina. Las muestras inoculadas y con harina de cáscara de tuna 0 cáscara de piña tuvieron los valores menores de $\mathrm{pH}$ (Tabla 8). La presencia de las harinas de cáscara de tuna y de cáscara de piña promovió el crecimiento de la bacteria láctica inoculada. En estudios in vitro, esta misma cepa tuvo valores menores pero aceptables para la constante de tasa de crecimiento medio $(\mathrm{k})$ al utilizar harina de cáscara de tuna o harina de cáscara de piña, 1.42 y $1.44 \mathrm{~h}$, respectivamente, en comparación con la glucosa (1.52 h). Sin embargo, el conteo final después de $10 \mathrm{~h}$ de fermentación in vitro no fue diferente (cercano a 9.5 UFC/mL) (Díaz-Vela y col., 2013). Las bacterias ácido lácticas son uno de los

principales grupos de bacterias presentes en productos cárnicos, produciendo ácido láctico que puede provocar un descenso del pH (Kavan y Kaya, 2009), participando de manera importante como bioconservadores (Victoria-León y col., 2006). 
Tabla 8. Cuenta viable de bacterias ácido lácticas y $\mathrm{pH}$ de las diferentes formulaciones de salchichas durante su almacenamiento.

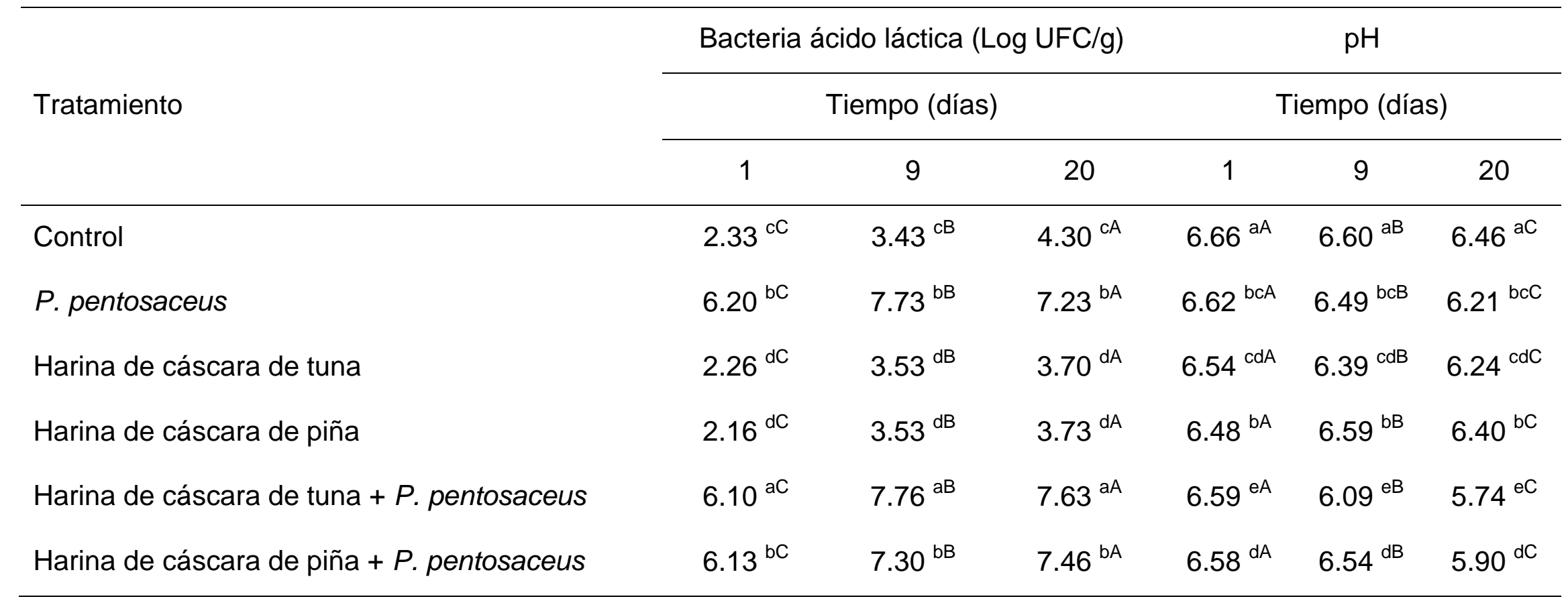

a-e Medias con la misma letra en la misma columna no son significativamente $(P>0.05)$ diferentes por tratamiento.

A-B Medias con la misma letra en la misma fila no son significativamente $(P>0.05)$ diferentes por tiempo de almacenamiento. 


\subsubsection{Análisis de perfil de textura}

En la textura instrumental, las muestras inoculadas con $P$. pentosaceus y harina de cáscara de tuna fueron significativamente $(\mathrm{P}<0.05)$ más duras que el resto de los tratamientos. Las muestras inoculadas con $P$. pentosaceus sin harina de cáscara de frutos y el tratamiento control tuvieron los mismos valores de dureza. Las muestras más suaves fueron las que contenían harina de cáscara de tuna. Para el tiempo de almacenamiento, la dureza de las muestras aumentó significativamente $(P<0.05)$ al día 9 de almacenamiento (Tabla 9$)$. Para la cohesividad, las muestras con harina de cáscara de piña fueron significativamente $(P<0.05)$ mayor, seguidas de las muestras control y de las muestras inoculadas con $P$. pentosaceus. Las muestras con menor cohesividad fueron las que contenían harina de cáscara de tuna. La cohesividad de las muestras disminuyó significativamente después de los 9 días de almacenamiento (Tabla 9). La resiliencia de las salchichas fue significativamente $(\mathrm{P}<0.05)$ mayor para el control, seguido de las muestras inoculadas con $P$. pentosaceus (sin harina de cáscaras). Los valores menores de resiliencia se detectaron en las muestras con harina de cáscara de tuna. Durante el tiempo de almacenamiento, la resiliencia fue significativamente $(P<0.05)$ menor después de los 9 días de almacenamiento (Tabla 9). 
Tabla 9. Análisis de perfil de textura de los diferentes tratamientos de salchichas durante su almacenamiento.

\begin{tabular}{|c|c|c|c|c|c|c|c|c|c|}
\hline \multirow{3}{*}{ Tratamiento } & \multicolumn{3}{|c|}{ Dureza $(\mathrm{N})$} & \multicolumn{3}{|c|}{ Cohesividad } & \multicolumn{3}{|c|}{ Resiliencia } \\
\hline & \multicolumn{3}{|c|}{ Tiempo (días) } & \multicolumn{3}{|c|}{ Tiempo (días) } & \multicolumn{3}{|c|}{ Tiempo (días) } \\
\hline & 1 & 9 & 20 & 1 & 9 & 20 & 1 & 9 & 20 \\
\hline Control & $17.15^{\mathrm{cC}}$ & $18.80^{\mathrm{cA}}$ & $15.70^{\mathrm{cB}}$ & $0.37^{\mathrm{bB}}$ & $0.35^{\mathrm{bB}}$ & $0.38^{\mathrm{bA}}$ & $0.72^{\mathrm{aB}}$ & $0.70^{\mathrm{Ab}}$ & $0.73^{\mathrm{aA}}$ \\
\hline P. pentosaceus & $15.00^{\mathrm{cC}}$ & $20.25^{\mathrm{cA}}$ & $16.10^{\mathrm{CB}}$ & $0.33^{\mathrm{cB}}$ & $0.33^{\mathrm{cB}}$ & $0.37^{\mathrm{CA}}$ & $0.68^{\mathrm{bB}}$ & $0.68^{\mathrm{bB}}$ & $0.73^{\mathrm{bA}}$ \\
\hline Harina de cáscara de tuna & $10.80^{\mathrm{eC}}$ & $11.90^{\mathrm{eA}}$ & $10.60^{\mathrm{eB}}$ & $0.20^{\mathrm{fB}}$ & $0.23^{\mathrm{fB}}$ & $0.25^{\mathrm{fA}}$ & $0.54^{\mathrm{eB}}$ & $0.56^{\mathrm{eB}}$ & $0.60^{\mathrm{eA}}$ \\
\hline Harina de cáscara de piña & $18.30^{\mathrm{bC}}$ & $23.15^{\mathrm{bA}}$ & $22.90^{\mathrm{bB}}$ & $0.37^{\mathrm{aB}}$ & $0.38^{\mathrm{aB}}$ & $0.38^{\mathrm{aA}}$ & $0.72^{\mathrm{aB}}$ & $0.72^{\mathrm{aB}}$ & $0.72^{\mathrm{aA}}$ \\
\hline $\begin{array}{l}\text { Harina de cáscara de tuna }+ \\
\text { P. pentosaceus }\end{array}$ & $24.70^{\mathrm{aC}}$ & $22.60^{\mathrm{aA}}$ & $26.40^{\mathrm{aB}}$ & $0.33^{\mathrm{dB}}$ & $0.33^{\mathrm{dB}}$ & $0.33^{\mathrm{dA}}$ & $0.68^{\mathrm{cB}}$ & $0.69^{\mathrm{cB}}$ & $0.68^{\mathrm{cA}}$ \\
\hline $\begin{array}{l}\text { Harina de cáscara de piña }+ \\
\text { P. pentosaceus }\end{array}$ & $14.40^{\mathrm{dC}}$ & $15.50^{\mathrm{dA}}$ & $15.10^{\mathrm{dB}}$ & $0.28^{\mathrm{eB}}$ & $0.28^{\mathrm{eB}}$ & $0.27^{\mathrm{eA}}$ & $0.63^{\mathrm{dB}}$ & $0.63^{\mathrm{dB}}$ & $0.61^{\mathrm{dA}}$ \\
\hline
\end{tabular}


El incorporar las harinas de las cáscaras de fruta a los productos cárnicos modificó la textura, dependiendo del alto contenido de fibra en estas harinas. La fibra insoluble infiere sobre la textura de los alimentos debido a su capacidad de retención de agua y habilidad de hinchazón (Thebaudin y col., 1997). La proporción de fibra insoluble puede incrementar la consistencia de los productos cárnicos a través de la formación de una red insoluble tridimensional capaz de modificar las propiedades reológicas de la fase continua de la emulsión cárnica (Backers y Noll, 1998), lo que favorece a la formación de una matriz de gel de proteína más rígida (López-López y col., 2009). Las harinas utilizadas tienen un porcentaje de fibra dietética total de 64.15 y $62.54 \%$ para harina de cáscara de tuna y harina de cáscara de piña, respectivamente. El contenido de fibra insoluble es mayor para la harina de cáscara de piña $(40.88 \%)$ en comparación con la harina de cáscara de tuna (3.48\%) (Díaz-Vela y col., 2013).

\subsubsection{Micro estructura}

La microscopia de barrido de electrones muestra el desarrollo de la bacteria láctica en las salchichas. En el tratamiento control (no bacteria inoculada, no harina de cáscara de frutas) se aprecian algunas colonias de bacterias lácticas entre los componentes del batido cárnico, sobre todo después de 20 días de almacenamiento (Fig. 2b), en comparación con el día 9 (Fig. 2a). Las bacterias lácticas no se consideran flora de contaminación en este tipo de productos cárnicos cocidos, pues el tratamiento térmico destruye la carga microbiana al centro térmico de las salchichas (Korkelara y Björkroth., 1997; Dykes y col., 1991; Sachindra y col., 2005), pero las condiciones de almacenamiento (temperaturas de refrigeración y empaque al vacío) hacen que la flora bacteriana sea gradualmente seleccionada por las condiciones ambientales, dominando microorganismos psicotrópicos, micro-aerófilos y resistentes a nitritos y concentraciones relativamente altas de cloruro de sodio, como las bacterias lácticas (von Holy y col., 1991; Samelis y col., 2000; Vermeiren y col., 2004). La incorporación de harina de cáscara de tuna a la formulación incrementó el número de bacterias lácticas en batidos cárnicos cocidos (Tabla 8), aumentando el número de bacterias visibles, siendo mayor el número de colonias visibles con el tiempo de 
almacenamiento. También pueden ser observados parte de los componentes insolubles de la harina de cáscara de tuna rodeados de colonias de bacterias lácticas: Estos materiales tienen aspecto de un material fibroso y un tono más claro (extremo izquierdo de la microfotografía Fig. 2c) o fragmentos amorfos irregulares de color más claro en la parte baja de la microfotografía (Fig. 2d). Microfotografías de barrido de electrones de salchichas de pollo con una mezcla de goma guar y goma xantana muestran la formación de estructuras tipo-gel, con color y densidad diferentes a la matriz fibrosa del batido cárnico (Andrés y col., 2006). Del mismo modo, microfotografías de SEM muestran que fibras extraídas de raíces de piña (Ananas comosus Merr.) y de cáscara de naranja amarga (Citrus junos) tienen una apariencia continua y lisa (Hameed y col., 2009; Tanaka y col., 2012). Al inocular $P$. pentosaceus junto a la harina de cáscara de tuna el número de bacterias lácticas fue mucho mayor que en los tratamientos control y con harina de cáscara de tuna (Tabla 8), sobre todo al día 20 de almacenamiento (Fig. 2e y f). Es notable la producción de exopolisacáridos por $P$. pentosaceus, lo cual podría explicar la textura más dura y menos cohesiva de este tratamiento, además de aumentar el contenido de humedad y disminuir la humedad expresable. Este comportamiento ya había sido reportado previamente por Pérez-Chabela y col. (2013) quienes observaron la formación de exopolisacáridos por bacterias lácticas termotolerantes inoculadas en batidos cárnicos bajos en sal y grasa. 

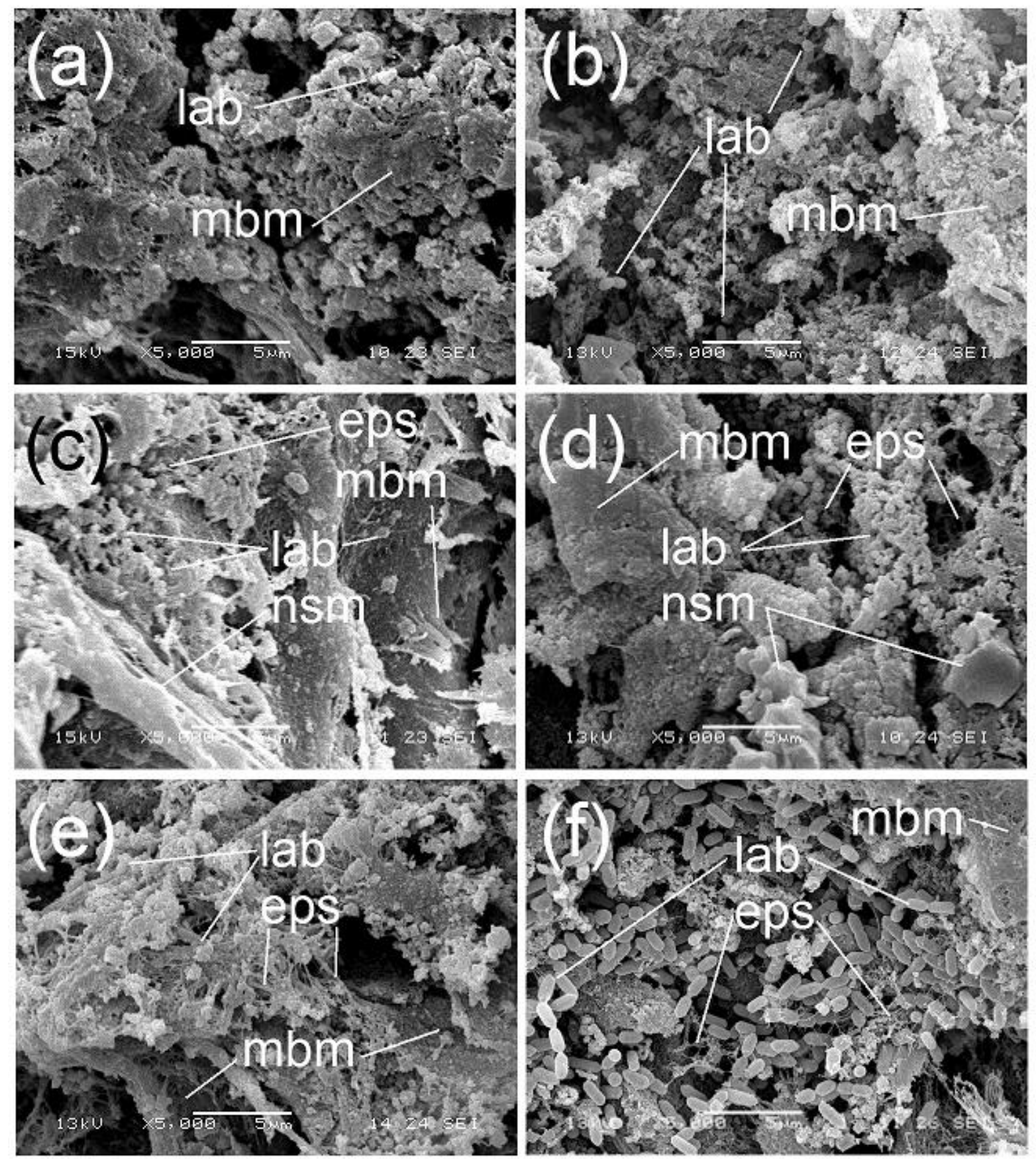

Figura 2. Microfotografías de las salchichas durante almacenamiento: control día 9 (a) y 20 (b); harina de cáscara de tuna día 9 (c) y 20 (d); harina de cáscara de tuna-BAL día 9 (e) y 20 (f). LAB: bacteria ácido láctica. MBM: matriz de batido cárnico. EPS: exopolisacárido. NSM: material no soluble. 


\subsection{CONCLUSIONES}

El uso de harinas de cáscaras de frutas mejoró las propiedades fisicoquímicas de las salchichas. La harina de cáscara de tuna presentó las mejores características al retener más agua, aumentando el rendimiento y disminuyendo la rancidez oxidativa en salchichas cocidas. La inoculación de las bacterias lácticas ( $P$. pentosaceus) con harina de cáscara de tuna se tradujo en más luminosidad y menos salchichas rojas y amarillas. En igual forma, las muestras inoculadas fueron más duras pero menos cohesivas y resilientes. Este efecto se puede atribuir a la producción de exopolisacáridos que se observaron en las microfotografías por esta cepa en las condiciones experimentales empleadas. La inoculación de las bacterias lácticas probióticas termotolerantes en productos cárnicos cocidos con harina de cáscara de tuna puede ser una alternativa viable en la búsqueda de productos cárnicos simbióticos. 


\subsection{BIBLIOGRAFÍA}

Akamittath, J. G., Brekke, C. J. y Schanus, E. G. (1990). Lipid oxidation and color stability in restructured meat systems during storage. Journal of Food Science. 67: 1364-1369.

Andrés S, Zaritzky, N. y Califano, A. (2006). The effect of whey protein concentrates and hydrocolloids on the texture and colour characteristics of chicken sausages. International Journal of Food Science and Technology, 41, 954-961

AOAC, (1996): Official Method of Analysis of AOAC International, $16^{\text {th }}$ edition. Washington, DC.

Backers, T. y Noll, B. (1998). Dietary fibres move into meat processing. Fleischwirtschaft. 78(4): 316. 319-320, 344.

Batifoulier, F., Mercier, Y., Gatellier, P. y Renerre, M. (2002). Influence of vitamin E on lipid and protein oxidation induced by $\mathrm{H}_{2} \mathrm{O}_{2}$-activated MetMb in microsomal membranes from turkey muscle. Meat Science. 61: 389-395.

Bourne, M. C. (1978). Texture profile analysis. Food Technology. 32(7): 62-66, 72.

Cáceres, E., García, M. L., Toro, J. y Selgas, M. D. (2004). The effect of fructooligosaccharides on the sensory characteristics of cooked sausages. Meat Science. 68: 87-96.

Caprita, A., Caprita, R., Gianet-Simulescu, V. O. y Raluca-Madalina, D. (2010). Dietary fiber: chemical and functional properties. Journal of Agroalimentary Processes and Technologies. 16(4): 406-416.

Carballo, J., Cavestany, M. y Jiménez-Colmenero, F. (1991). Oxidation in a cooked meat product. Meat Science. 30: 235.

Cardador-Martínez, A., Jiménez-Martínez, C. y Sandoval, G. (2011). Revalorization of cactus pear (Opuntia spp.) wastes as a source of antioxidants. Ciencia e Tecnologia de Alimentos, Campinas. 31(3): 782-788.

Cerezal, P. y Duarte, G. (2005). Utilización de cáscaras en la elaboración de productos concentrados de tuna (Opuntia ficus-índica (L.) Miller). Journal of the Proffesional Association for Cactus Development. 7: 61-83.

Courtin, C. M., Swennen, K., Verjans, P. y Delcour. (2009). Heat and pH stability of prebiotic arabinoxylooligosaccharides, xylooligosaccharides and fructooligosaccharides. Food Chemistry. 112: 831-837.

Crehan, C. M., Hughes, E., Troy, D. J. y Buckley, D. J. (2000). Effects of fat level and maltodextrin on the functional properties of frankfurters formulated with 5, 12 and 30\% fat. Meat Science. 463-469. 
De Man, J. C., Rogosa, M. y Sharpe, M. E. (1960). A medium for the cultivation of lactobacilli. Journal of Applied of Bacteriology. 23:130-135.

Dello-Staffolo, M., Bertola, N., Martino, M. y Bevilacqua, A. (2004). Influence of dietary fiber addition on sensory and rheological properties of yogurt. International Dairy Journal. 14: 263-268.

Der, G. y Everitt, B. S. (2002). Handbook of statistical analyses using SAS. Boca Raton, FL: Chapman \& Hall/CRC.

Deveroux, H. M., Jones, G. P., McCormack, L. y Hunter, W. C. (2003). Consumer acceptability of low fat foods containing inulin and oligofructose. Journal of Food Science. 68: 1850-1854.

Díaz-Vela, J., Totosaus, A. Cruz-Guerrero, A. E. y Pérez-Chabela, M. L. (2013). In vitro evaluation of the fermentation of added-value agroindustrial byproducts: cactus pear (Opuntia ficus-indica L.) peel and pineapple (Ananas comosus) peel as functional ingredients. International Journal of Food Science and Technology. 48(7): 1460-1467.

Dykes, G.A.; Cloete, T.E. y von Holy, A. (1991) Quantification of microbial populations associated with the manufacture of vacuum-packaged, smoked Vienna sausages. International Journal of Food Microbiology 13(4), 239248.

El Kossori, R. L., Villaume, C., El Boustani, E., Sauvaire, Y. y Méjean, L. (1998). Composition of pulp, skin and seeds of prickly pears fruit (Opuntia ficusindica sp.). Plant Foods for Human Nutrition. 52(3): 263-270.

Estévez, M. y Cava, R. (2004). Lipid and protein oxidation, release of iron from heme molecule and colour decoloration during refrigerated storage of liver pâté. Meat Science. 68: 551-558.

Furda, I. (1977). Fractionation and examination of biopolymers from dietary fiber. Cereal Foods World. 22:252.

García, M. L., Dominguez, R., Galvez, M. D., Casas, C. y Selgas, M. D. (2002). Utilization of cereal and fruit fibres in low fat dry fermented sausages. Meat Sience. 60: 227-236.

Grigelmo-Miguel, N., Abadías-Serós, M. y Martín-Belloso, O. (1999). Characterization of low-fat high-dietary fibre frankfurters. Meat Science. 52(3): 247-256.

Habibi, Y., Mahrouz, M. y Vignon, M. R. (2005). Isolation and structural characterization of protopectin from the skin of Opuntia ficus-indica prickly pear fruits. Carbohydrate Polymers. 60: 205-213. 
Habibi, Y., Mahrouz, M., Marais, M. F. y Vignon, M. R. (2004). An arabinogalactan from the skin of Opuntia ficus-indica prickly pear fruits. Carbohydrate Research. 339(6): 1201-1205.

Hameed, B.H., Krishni, R.R. y Sata, S.A. (2009). A novel agricultural waste adsorbent for the removal of cationic dye from aqueous solutions. Journal of Hazardous Materials 162: 305-311.

Hernández-García, S. y Güemes-Vera, N. (2010). Efecto de la adición de harina de cascara de naranja sobre las propiedades fisicoquímicas, texturales y sensoriales de salchichas cocidas. Nacameh. 4(1): 23-36.

Hunt, M. C., Acton, J. C., Benedict, R. C., Calkins, C. R., Cornforth, D. P., Jeremiah, L. E., Olson, D. P., Salm, C. P., Savell, J. W. y Shivas, S. D. (1991). Guidelines for meat color evaluation (pp. 1-12). Chicago: American Meat Science Association and National Live Stock and Neat Board.

Jauregui, C. A., Regenstein, J. M. y Baker, R. C. (1981). A simple centrifugal method for measuring expressible moisture, a water-binding property of muscle foods. Journal of Food Science. 46: 1271-1273.

Jo, C., Lee. J. I. y Ahn, D. U. (1999). Lipid oxidation, color changes and volatiles production in irradiated pork sausage with different fat content and packaging during storage. Meat Science. 51: 355-361.

Johansson, G., Berdagué, J-L., Larsson, M., Tran, N. y Borch, E. (1994). Lipolysis, proteolysis and formation of volatile components during ripening of a fermented sausage with Pediococcus pentosaceus and Staphylococcus xylosus as starter as cultures. Meat Sciences. 38(2): 203-218.

Julavittayanukul, O., Benjakul, S. y Visessanguan, W. (2006). Effect of phosphate compounds on gel-formation ability of surimi from bigeye snapper (Priacanthus tayenus). Food Hydrocholoids. 20: 1153-1163.

Kaban, G. y Kaya, M. (2009). Effects of Lactobacillus plantarum and Staphylococcus xylosus on the quality characteristics of dry fermented sausage "sucuk". Journal of Food Science. 74(1): S58-S63.

Ketnawa, S., Chaiwut, P. y Rawdkuen, S. (2012). Pineapple waste. A potential source for bromelain extraction. Food and Bioproducts Processing. 90: 385391.

Korkeala, H.J. y Björkroth, K.J. (1997). Microbiological spoilage and contamination of vacuum-packaged cooked sausages. Journal of Food Protection. 60: 724731.

Ktari, N., Smaoui, S., Trabelsi, I., Nasri, M. y Salah, R. B. (2014). Chemical composition, techno-functional and sensory properties and effects of three dietary fibers on the quality characteristics of Tunisian beef sausage. Meat Science. 96(1): 521-525. 
Landvogt, A. (1991). Errors in $\mathrm{pH}$ measurement of meat and meat products by dilution effects. Proceedings of the 37th International Congress on Meat Science and Technology, ICoMST, Kulmbach, Germany, pp. 1159-1162.

Larrauri, J., Ruperez, P. y Saura, F. C. (1997). Pineapple shell as a source of dietary fiber with associated polyphenols. Journal of Agricultural and Food Chemistry. 45: 4028-4031.

Lawlor, J. B., Sheey, P. J. A., Kerry, D. J., Buckely, P. A., Morrissey, P. A. (2000). Measuring oxidative stability of beef muscles obtained from animals supplemented with vitamin E using conventional. Jornal of Food Science. 65: 1138-1141.

López-López, I., Cofrades, S. y Jiménez-Comenero, F. (2009). Low-fat frankfurters enriched with $n-3$ PUFA and edible seaweed: Effects of olive oil and chilled storage on physicochemical, sensory and microbial characteristics. Meat Science. 83: 148-154.

Pérez-Chabela, M.L., Díaz-Vela, J., Menéndez, C.V. y Totosaus, A. (2013). Improvement of moisture stability and textural properties of fat and salt reduced cooked sausages by inoculation of thermotolerant lactic acid bacteria. International Journal of Food Properties. 16: 1789-1808.

Ramadan, M. F. y Mörsel, J. T. (2003). Recovery lipids from prockly pear (Opuntia ficus-indica L.) peel: a good source of polyunsaturated fatty acids, natural antioxidant vitamins and sterols. Food Chemistry. 83: 447-456.

Ramírez-Chavarin, N. L., Wacher, C., Eslava-Campos, C. A. y Pérez-Chabela, M. L. (2013). Probiotic potential of thermotolerant lactic acid bacteria strains isolated from cooked meat products. International Food Research Journal. 20: 991-1000.

Ramírez-Chavarin, N. L., Wacher-Rodarte, C. y Pérez-Chabela, M. L. (2010). Characterization and identification of thermotolerant lactic acid bacteria isolated from cooked sausage as bioprotective cultures. Journal of Muscle Foods. 21: 585-596.

Rezzadori, K., Benedetti, S. y Amante, E. R. (2012). Proposal for the residues recovery: Orange waste as raw material for new products. Food and Bioproducts Processing. 90: 606-614.

Robertson, J. y Eastwood, M. (1981). An investigation of the experimental conditions which could affect water-holding capacity of dietary fiber. Journal of Science Food Agriculture., 32: 819-825.

Sachindra, N.M., Sakhare, P.Z., Yashoda, K.P. y Rao, D.N. (2005). Microbial profile of buffalo sausage during processing and storage. Food Control. 16: 31-35. 
Samelis, J., Kakouri, A. y Rementzis, J. (2000). Selective effect of the product type and the packaging conditions on the species of lactic acid bacteria dominating the spoilage microbial association of cooked meats at $4{ }^{\circ} \mathrm{C}$. Food Microbiology.17: 329-340.

Shand, P.J. (2000). Textural, water holding, and sensory properties of low-fat pork bologna whit normal or waxy starch hull-less barley. Journal of Food Science. 65:101-107.

Southgate, D. A. T. (1975). Food and fiber, discussion. Nutrition Reviews. 35:60.

Szczesniak, A. S. (1963). Classification of textural characteristics. Journal of Food Science. 28: 385-389.

Tanaka M, A. Takamizu, M. Hoshino, Sasaki, M. y Goto, M. (2012). Extraction of dietary fiber from Citrus junos peel with subcritical water. Food and Bioproducts Processing. 90:180-186.

Thebaudin, J. Y., Lefebvre, A. C., Harrington, M. y Bourgeois, C. M. (1997). Dietary fibers: Nutritional and technological interest. Trends Food Science Technology. 8: 41-48.

Toldrá, F., Sanz, Y. y Flores, M. (2001). Meat fermentation technology. In: Hui YH, Nip WK, Rogers RW, Young OA, editors. Meat Science and Applications. New York: Marcel Dekker Inc. pp. 537-561.

Tomaschunas, M., Zorb, R., Fischer, J., Kohn, E., Hinrichs, J. y Bush-Stockfisch, M. (2013). Changes in sensory properties and consumer acceptance of reduced fat pork Lyon-style and liver sausage containing inulin and citrus fiber as fat replacers. Meat Science. 95: 629-640.

Ulrich-Endress, H. y Mattes, F. (2012). Pectin. In: Dietary Fiber and Health, Ed. Cho, S. and Almeida, N. $1^{\text {st }}$ edition. CRC Press, Boca Raton, Florida. pp. 385-408.

Vermeiren, L.; Devlieghere, F. y Debevere, J. (2004). Evaluation of meat born lactic acid bacteria as protective cultures for the biopreservation of cooked meat products. International Journal of Food Microbiology. 96: 149-164

Victoria-León, T., Totosaus, A., Guerrero, I. y Pérez-Chabela, M. L. (2006). Efecto de bacterias ácido lácticas termoresistentes en salchichas cocidas. Ciencia y Tecnología Alimentaria. 5: 135-141.

von Holy, A.; Cloete, T.A. y Dykes, G.A. (1991). Quantification and characterization of microbial populations associated with spoil, vacuum packed Vienna sausages. Food Microbiology. 8: 95-104.

Yamazaki, E., Murakami, K. y Kurita, O. (2005). Easy preparation of dietary fiber with the high water-holding capacity from food source. Plant Foods for human nutrition. 60: 17-23. 
Zipser, M. y Watts, B. (1962). A modified 2-tiobarbituric acid (TBA) method for the determination of malonaldehide in cured meats. Food Technology. 17: 102104. 
8. CAPÍTULO IV. EFECTO DE LA HARINA DE CÁSCARA DE TUNA (Opuntia ficus indica) Y PIÑA (Ananas comosus) SOBRE LAS CARACTERISTICAS SENSORIALES DE SALCHICHAS COCIDAS.

Díaz-Vela, J., Cruz-Guerrero, A. E., Totosaus, A., Pérez-Chabela, M. L. y Escalona-Buendía, $\boldsymbol{H}$. B. Effect of cactus pear (Opuntia ficus indica) and pineapple (Ananas comosus) peel flour on sensorial characteristics of cooked sausages. Enviado.

\subsection{OBJETIVO}

Determinar el efecto de la harina de cáscara de tuna (Opuntia ficus indica) o cáscara de piña (Ananas comosus) sobre las características sensoriales de salchichas cocidas.

\subsection{PROLEGÓMENO}

Los productos cárnicos juegan un papel importante en la nutrición humana, debido al aporte de proteínas y micronutrientes (Biesalski, 2005). En México, las salchichas cocidas representan el embutido más consumido de los productos cárnicos procesados (CMC, 2012); debido su bajo costo, fácil preparación y sabor. Sin embargo, el consumo en exceso de estos productos se ha relacionado con diversas enfermedades tales como obesidad e hipertensión (Weiss y col., 2010). Debido a lo anterior, la generación de nuevos productos alimenticios que aporten beneficios a la salud más allá del aporte nutricional ha sido tema de estudio en la actualidad, en donde se ha tratado de incluir ingredientes como la fibra dietética. La fibra dietética es un compuesto derivado principalmente de las cáscaras de frutos, vegetales y cereales, con diversas propiedades funcionales que dependen de la fuente y tipo de procesamiento (Cáprita y col., 2010). La tuna (Opuntia ficus indica) es un fruto de las plantas pertenecientes a las cactáceas del genero Opuntia; en México la producción anual es aproximadamente de 527,000 toneladas (SIAP, 2012). La cáscara de tuna contiene compuestos funcionales y bio-activos, con un contenido de fibra dietética total de $64.15 \%$ superior a lo encontrado en cáscaras de frutos como: jícama, plátano, manzana, mango, zanahoria, hoja de maguey y albedo de toronja (Chávez-Zepeda y col., 2009); 
además de presentar actividad antioxidante (89\%). Mientras que la piña, un fruto de la familia de las Bromeliaceae, es uno de los 8 frutos de mayor producción a nivel mundial, tan solo en el año 2012 en México se reportó una producción aproximada de 760,000 toneladas (SIAP, 2012). La cáscara de la piña representa el $10 \%$ del peso total del fruto, del cual el $96 \%$ es materia orgánica y el $4 \%$ materia inorgánica (Hajar y col., 2012). Además, se ha reportado un nivel de fibra dietética total de $62.54 \%$, así como capacidad antioxidante (Chávez-Zepeda y col., 2009)

La fibra dietética presente en las cáscaras de los frutos ha sido considerada como ingrediente funcional en la formulación de productos cárnicos, debido a su capacidad de retención de agua y disminución en pérdidas por cocción (García y col., 2002). El aprovechamiento de diferentes subproductos de origen vegetal en productos cárnicos cocidos se ha realizado principalmente en la formulación de nuevos productos $y$ se ha determinado su efecto sobre características fisicoquímicas, texturales y sensoriales (Yun-Sang y col., 2010; Ju-Hui y col., 2013; Tomaschunas y col., 2013).

Existen diversas metodologías para determinar el nivel de aceptación de nuevos productos alimenticios, así como el análisis sensorial en estos, tales como: determinación del nivel de neofobia en alimentos, Índice $\mathrm{R}$ y análisis descriptivo cuantitativo.

El estudio de neofobia alimentaria es una herramienta psicométrica desarrollada por Pliner y Hobden (1992). Ha sido desarrollado para cuantificar y clasificar el nivel de temor de los consumidores por su tendencia de acercarse o evitar nuevos alimentos (Pliner, 1994). Consiste en un cuestionario con 5 enunciados positivos y 5 negativos sobre los alimentos y situaciones relacionadas con el consumo de alimentos. Este análisis ha sido objeto de diversos estudios en los últimos años, ya que han determinado el grado de aceptación de nuevos alimentos antes de su procesamiento y consumo (Raudenbush y Frank, 1999; Falciglia y col., 2000; Dovey y col., 2008; Schnettler y col., 2013).

El parámetro Índice $R$ es una medición de sensibilidad que indica la probabilidad de que un juez pueda distinguir entre una condición experimental (la presencia de la señal) y otra (la ausencia de esta señal o bien la presencia de otra); también 
conocido como la teoría de la detección de señales (Brown, 1974), la cual se propone como una alternativa a las pruebas discriminativas convencionales, tales como la comparación por par, Dúo-Trio y la triangular, donde éstas permiten determinar las diferencias entre determinados muestras a comparar sin la necesidad de cuantificar las características sensoriales. El análisis de los datos generados por la técnica de Índice $R$ se realiza mediante estadística paramétrica (O’Mahony, 1979). El Índice R estima el porcentaje de cuantas comparaciones pareadas son evaluadas de manera correcta por parte de los jueces de acuerdo a la señal buscada. Se considera una estimación de la probabilidad con la que un juez detecta la diferencia entre dos muestras de acuerdo al parámetro evaluado, de esta manera, la probabilidad de acierto por casualidad es 0.5 , un indice de $50 \%$ indicaría que no hay diferencia, mientras este porcentaje se acerque a $100 \%$ mayor es la diferencia (O’Mahony, 1983).

Por último, el análisis descriptivo cuantitativo es un método desarrollado por Siedel y Stone (1985), el cual es considerado como una forma de caracterizar un producto, donde se obtiene una terminología que lo defina para obtener los adecuados atributos sensoriales de algún alimento (Moskowitz, 1983).

En este estudio la realización de diferentes métodos para la evaluación sensorial, permitirá dar la suficiente información para la caracterización sensorial de un producto cárnico cocido adicionado de harina de cáscara de tuna o piña. 


\subsection{METODOLOGÍA}

El desarrollo experimental se dividió en tres secciones. La primera consistió en la realización de 278 encuestas para determinar el nivel de aceptación en el consumo de alimentos saludables, de manera simultánea se realizaron encuestas al mismo grupo de encuestados para conocer el grado de neofobia para el consumo de salchichas adicionadas con harina de cascara de tuna o piña. En la segunda sección, una vez realizadas las encuestas se realizaron dos evaluaciones de diferenciación de textura y firmeza en salchichas adicionadas con harina de cáscara de tuna o piña para determinar el Índice R. Por último, se realizó un análisis de perfil descriptivo cuantitativo para determinar las principales características sensoriales de las salchichas adicionadas con ambas harinas experimentales.

\subsubsection{Análisis de consumo de alimentos saludables y Neofobia alimentaria}

Para conocer el interés de consumo de productos alimenticios saludables se realizó de acuerdo al cuestionario propuesto por Roininen y col. (1999) (Tabla 10). El estudio se realizó a 278 personas (214 mujeres y 64 hombres) con edad entre 30 y 50 años. De manera simultánea se realizó un segundo cuestionario al mismo grupo de personas para el análisis de neofobia de acuerdo al método y cuestionario propuesto por Pliner y Hobden (1992), el cual se compone por preguntas enfocadas a costumbres alimenticias (tipo de alimentos, frecuencia de consumo, exploración en el consumo, etc.) relacionadas con el consumo de productos nuevos (Tabla 11); en esta prueba, a las personas encuestadas se les presento una tarjeta con la información que se muestra en la Tabla 12. Cada escala múltiple se compone de un grupo de enunciados, diez para la escala neofóbica y ocho para el nivel de interés por el consumo de alimentos benéficos para el organismo. Para responder a estas afirmaciones se utilizó una sub-escala la cual aporta una cierta cantidad de puntos en la prueba según la opción que se seleccione, de esta manera la primera opción de la sub-escala (completamente desacuerdo) aporta 1 punto, mientras que la última (completamente desacuerdo) 
otorga 5 puntos. En cada una de las pruebas realizadas (neofobia e interés por consumo de alimentos saludables) existen enunciados marcados con la letra "R", estos enunciados son negativos, por esta razón, para calificar estos enunciados la escala se invierte otorgando 5 puntos a la primera opción y 1 punto para la última opción. Por la tanto, la calificación mínima para las pruebas realizadas de la escala neo-fóbica es 10 y la máxima es 50 , en el otro caso la calificación mínima para la prueba de consumo de alimentos saludables es 8 y la máxima es 40 . De acuerdo con esto la sub-escala queda de la siguiente manera:

- Completamente en desacuerdo (1 punto).

- Desacuerdo (2 puntos).

- Ni acuerdo ni desacuerdo (3 puntos).

- De acuerdo (4 puntos).

- Completamente de acuerdo (5 puntos). 
Tabla 10. Escala múltiple de consumo de alimentos saludables. Versión original y su traducción correspondiente*.

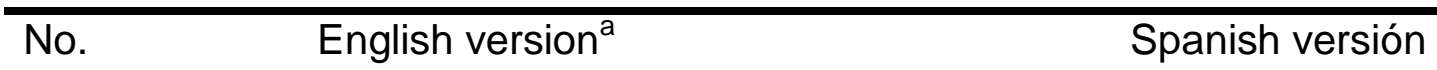

$1 \mathrm{R}$ The healthiness of food has a little Cuando elijo un alimento me importa poco que impact on my food choice sea o no saludable

2 I am very particular about the Considero importante que los alimentos que healthiness of food I eat consume sean saludables

3R I eat what I like and not worry Como lo que me gusta sin preocuparme si es o much about the healthiness of food no es saludable

4 It is important for me that my diet is Para mi es importante que mi dieta sea baja en low in fat grasa

5 I always follow a healthy and Siempre sigo una dieta equilibrada y saludable balanced diet

6 It is important for me that my daily Para mi es importante que mi dieta sea rica en diet contains a lot of vitamins and vitaminas y minerales minerals

7R The healthiness of snacks makes Cuando tomo algo de aperitivo o entre comidas, no differences to me no me preocupa si es o no saludable

8R I do not avoid foods, even if they No me privo de tomar algunos alimentos may raise my cholesterol aunque su consumo pueda elevar mi colesterol

* Las afirmaciones negativas se marcan con una ' $R$ ' después del número de afirmación. Las afirmaciones fueron recodificadas para los resultados finales.

a. Roininen y col., 1999. 
Tabla 11. Escala múltiple de neofobia alimentaria. Versión original y su traducción correspondiente.

\begin{tabular}{|c|c|c|}
\hline No. & English version $^{a}$ & Spanish versión \\
\hline 1 & $\begin{array}{l}\text { I am constantly sampling new } \\
\text { and different foods }\end{array}$ & $\begin{array}{l}\text { Siempre tiendo a elegir alimentos nuevos y } \\
\text { diferentes }\end{array}$ \\
\hline $2 \mathrm{R}$ & I don't trust new foods & No confío en los alimentos nuevos \\
\hline $3 R$ & $\begin{array}{l}\text { If I don't know what is in a food, I } \\
\text { won't try it }\end{array}$ & $\begin{array}{l}\text { Si no sé qué es lo que contiene un alimento, no lo } \\
\text { pruebo }\end{array}$ \\
\hline 4 & $\begin{array}{l}\text { I like foods from different } \\
\text { countries }\end{array}$ & Me gustan los alimentos de distintos países \\
\hline $5 \mathrm{R}$ & Ethnic food looks too weird to eat & $\begin{array}{l}\text { Me resulta demasiado extraña la comida típica de } \\
\text { otros países para comerla }\end{array}$ \\
\hline 6 & $\begin{array}{l}\text { At dinner parties, I will try a new } \\
\text { food }\end{array}$ & $\begin{array}{l}\text { En las fiestas y celebraciones estaría dispuesto a } \\
\text { probar algún nuevo alimento }\end{array}$ \\
\hline $7 \mathrm{R}$ & $\begin{array}{l}\text { I am afraid to eat things I have } \\
\text { never had before }\end{array}$ & $\begin{array}{l}\text { No me atrevo a comer cosas que no he probado } \\
\text { antes }\end{array}$ \\
\hline $8 \mathrm{R}$ & $\begin{array}{l}\text { I am very particular about the } \\
\text { foods I will eat }\end{array}$ & $\begin{array}{l}\text { Soy muy escrupuloso con los alimentos que } \\
\text { tengo que comer }\end{array}$ \\
\hline 9 & I will eat almost anything & Me comería casi cualquier cosa \\
\hline 10 & I like to try new ethnic restaurants & $\begin{array}{l}\text { Me gusta probar nuevos restaurantes típicos de } \\
\text { distintos países }\end{array}$ \\
\hline
\end{tabular}

'Las afirmaciones negativas se marcan con una ' $R$ ' después del número de afirmación. Las afirmaciones fueron recodificadas para los resultados finales.

a. Pliner y Hobden (1992) 
Tabla 12. Tarjeta de información para la prueba de Neofobia.

\section{Alimento funcional}

Es aquel que contiene una sustancia nutritiva o no nutritiva con efectos benéficos en la salud.

\section{Fibra dietética}

Sustancia de origen vegetal que mejora la salud promoviendo el crecimiento de bacterias benéficas, además de ayudar a disminuir los niveles de colesterol y glucosa en sangre.

\section{Harina de cáscara de tuna /Harina de cáscara de piña}

Son fuente importante de fibra dietética y antioxidante. Siendo una alternativa como alimento funcional.

\subsubsection{Obtención de las harinas de cáscara de tuna y cáscara de piña}

Las cáscaras se recogieron semanalmente y transportaron al campus de la Universidad en cajas de plástico (aproximadamente $2 \mathrm{~kg}$ cada uno), fueron lavadas con agua fría y se almacenaron un día antes de su procesamiento en condiciones de refrigeración $\left(4 \pm 1^{\circ} \mathrm{C}\right)$. Las cáscaras de ambas frutas fueron equilibradas a temperatura ambiente durante 2 horas antes de ser cortadas en piezas de $2 \times 2 \mathrm{~cm}$ y se secaron a $60^{\circ} \mathrm{C}$ durante aproximadamente 24 horas en un horno de convección de aire (Barco Instrumentos Científicos, Ciudad de México). Las cáscaras secas se molieron en un molino de discos motorizado (Arisa Maquinaria S.A de C.V, México) y se tamizaron consecutivamente con tamaños de malla $100,80,50$ y 20 para obtener un polvo regular y homogéneo, llamado harina. Las harinas de cáscara de tuna y piña fueron almacenadas en recipientes herméticamente cerrados hasta su uso.

\subsubsection{Elaboración de salchichas}

Se elaboraron tres diferentes formulaciones de salchichas de acuerdo a la formulación de salchichas tipo-Vienna. La formulación control contenía: carne de cerdo $(50 \% \mathrm{p} / \mathrm{p})$, lardo $(20 \% \mathrm{p} / \mathrm{p})$, hielo $(22.3 \% \mathrm{p} / \mathrm{p})$, cloruro de sodio $(2 \% \mathrm{p} / \mathrm{p})$, fosfato de sodio $(0.4 \% \mathrm{p} / \mathrm{p})$, nitritos $(0.3 \% \mathrm{p} / \mathrm{p})$ y harina de trigo $(5 \% \mathrm{p} / \mathrm{p})$. Las otras 
dos formulaciones (experimentales) fueron adicionadas con harina de cáscara de tuna o harina de cáscara de piña $(2 \% \mathrm{p} / \mathrm{p})$, la cual fue ajustada al contenido de harina de trigo. La pasta obtenida fue embutida en fundas de celulosa y cocinadas hasta alcanzar una temperatura interna de $72^{\circ} \mathrm{C}$, después fueron empacadas al vacío y almacenadas a $4^{\circ} \mathrm{C}$ hasta su análisis.

\subsection{4 Índice $\mathbf{R}$}

Se seleccionaron treinta personas, todas estudiantes de la Universidad Autónoma Metropolitana-Iztapalapa, con hábitos de consumo de salchichas cocidas. Este grupo de personas realizaron dos diferentes pruebas: Índice R por "rating" (categorización) para análisis de sabor, e Índice R por "ranking" (ordenamiento) para análisis de firmeza. Para ambas pruebas se proporcionaron muestras de salchichas con un tamaño de $2 \mathrm{~cm}$ de altura y $2 \mathrm{~cm}$ de diámetro. Para el caso de Índice R por "rating" se proporcionaron dos muestras diferentes, una de estas contenía $2 \%$ de harina de cáscara de tuna o piña identificada como "S" (formulación señal) y otra la otra sin alguna de las harinas experimentales identificada como "N" (formulación no-señal), las cuales se usaron como muestras de referencia. Así mismo, fueron proporcionadas seis muestras codificadas de manera aleatoria, de las cuales tres corresponden a la formulación señal ( $S$ ) y tres a la formulación no-señal $(\mathrm{N})$. Los jueces determinaron cuales de las seis muestras codificadas aleatoriamente pertenecían a " $\mathrm{S}$ " o "N", de acuerdo a las siguientes categorías de respuesta:

- "S" seguro (S)

- "S" inseguro (S?)

- "N" inseguro (N?)

- "N" seguro $(\mathrm{N})$

Los resultados fueron colocados en una matriz de respuesta, como se muestra en la Tabla 13. 
Tabla 13. Matriz de respuesta para Índice $R$ por rating para sabor.

\begin{tabular}{llllll}
\hline Sample & S & S? & N? & N & Total \\
\hline S & a & b & c & d & $N_{S}$ \\
N & e & f & g & $h$ & $N_{N}$ \\
\hline
\end{tabular}

Para la prueba de Índice R por "ranking", se proporcionaron cuatro muestras codificadas aleatoriamente (dos muestras señal "S" con harina de cáscara de tuna o piña, y dos muestras sin señal "N"); a los jueces se les indico que tenían que ordenar las muestras de acuerdo al nivel de percepción de firmeza sobre una escala de 1 a 4 , donde 1 correspondía a menor firmeza y 4 mayor firmeza.

Los resultados fueron colocados en una matriz de respuesta como se muestra en la Tabla 14.

Tabla 14. Matriz de respuesta para el Índice $\mathrm{R}$ por ranking para firmeza.

\begin{tabular}{llllll}
\hline Muestra & $\mathbf{4}$ & $\mathbf{3}$ & $\mathbf{2}$ & $\mathbf{1}$ & Total \\
\hline $\mathrm{S}$ & $\mathrm{a}$ & $\mathrm{b}$ & $\mathrm{c}$ & $\mathrm{d}$ & $\mathrm{N}_{\mathrm{S}}$ \\
$\mathrm{N}$ & e & $f$ & $\mathrm{~g}$ & $\mathrm{~h}$ & $\mathrm{~N}_{\mathrm{N}}$ \\
\hline
\end{tabular}

El cálculo del Índice R, tanto por "rating" como para "ranking", se basa en los resultados de la tabla de matriz de respuesta, a partir de la siguiente ecuación:

$$
R-\text { index }=\frac{a(f+g+h)+b(g+h)+c(h)+1 / 2(a e+b f+c g+d h)}{N_{S} N_{N}} \times 100(\text { Ec. 1) }
$$

Dónde:

$a=$ total de respuestas seguras " $S$ " de la muestra $S$

$b=$ total de respuestas inseguras "S?" de la muestra $S$

$c=$ total de respuestas inseguras "N?" de la muestra $S$

$d=$ total de respuestas seguras "N" de la muestra S 
$e=$ total de respuestas seguras "S" de la muestra N

$f=$ total de respuestas inseguras "S?" de la muestra N

$g=$ total de respuestas inseguras "N?" de la muestra N

$h=$ total de respuestas seguras "N" de la muestra N

\subsubsection{Análisis descriptivo cuantitativo (QDA)}

La realización de este estudio se llevó a cabo mediante la metodología de QDA ${ }^{\circledR}$ (Quantitative Descriptive Analysis) propuesta por Siedel y Stone (1985). El procedimiento consistió en tres etapas. La primera etapa corresponde al entrenamiento de 12 estudiantes de la Universidad Autónoma MetropolitanaIztapalapa de la carrera de Ingeniería de Alimentos para la elección de jueces. La elección de los jueces se realizó mediante tres sesiones donde se realizaron pruebas discriminativas de acuerdo a sus capacidades de diferenciación de salchichas cocidas. De los 12 estudiantes se seleccionaron a los 10 jueces con mayor capacidad de evaluación sensorial. La siguiente etapa consistió en realizar tres sesiones para seleccionar y establecer el vocabulario descriptivo para la prueba sensorial de las salchichas. En la Tabla 15 se muestran los diferentes atributos y sus respectivos descriptores usados durante la evaluación de las muestras.

Tabla 15. Identificación de los atributos en la evaluación de las salchichas.

\begin{tabular}{ll}
\hline Atributo & Descriptores \\
\hline Apariencia & Color, brilloso, homogéneo y compacto. \\
Olor & $\begin{array}{l}\text { Consomé de pollo, ahumado, dulce, cocido, carne de cerdo, } \\
\text { fermentado y rancio. }\end{array}$ \\
Sabor & $\begin{array}{l}\text { Salado, dulce, ahumado, rancio, especias, cocido, grasa, carne de } \\
\text { cerdo, astringente, amargo, consomé de pollo y fibra. }\end{array}$ \\
Textura & Dureza, plasticidad, grasosa, fibrosa, gomosa y húmeda.
\end{tabular}


Una vez que se tuvo el vocabulario para la evaluación de las salchichas, se continúo con el análisis sensorial mediante el análisis cuantitativo descriptivo (QDA), el cual se realizó en dos sesiones. A cada uno de los jueces se les proporcionó tres muestras de salchichas codificadas aleatoriamente (testigo y con harina de cáscara de tuna y harina de cáscara de piña) con un tamaño de $2 \mathrm{~cm}$ de alto y $2 \mathrm{~cm}$ de diámetro, para que cada juez emitiera su calificación de cada uno de los atributos en una escala semiestructurada de $15 \mathrm{~cm}$, mediante el uso del software Compusense.

\subsubsection{Análisis Estadístico}

En la determinación del índice de consumo de alimentos saludables y nivel de neofobia se realizaron comparaciones entre las diferentes categorías mediante pruebas de bondad de ajuste para el caso de comportamiento general y pruebas de independencia para el caso de comportamiento por sexo y edad, usando el procedimiento de ji cuadrado $\left(x^{2}\right)$, mediante el uso del paquete estadístico WinSTAT (Add-In for Microsoft Excel). Para el análisis descriptivo cuantitativo se realizó un análisis de varianza $(\mathrm{P}<0.05)$ para cada uno de los descriptores, usando los factores muestra y juez, así como su interacción. Se realizó un análisis de medias para cada uno de los descriptores mediante la prueba de Duncan $(\mathrm{P}<0.05)$. Así mismo se realizó un análisis multivariado con los datos obtenidos en el análisis descriptivo cuantitativo, mediante un análisis de componentes principales y análisis de productos. Los estadísticos fueron realizados con el uso del paquete estadístico XLSTAT. 


\subsection{RESULTADOS Y DISCUSIÓN}

\subsubsection{Consumo de Alimentos saludables}

La Figura 3 muestra la distribución de la población total encuestada de acuerdo al consumo de alimentos saludables, donde se observa una tendencia hacia un mayor interés en consumir alimentos saludables, considerando un valor de 23 de la escala de interés utilizada como valor medio.

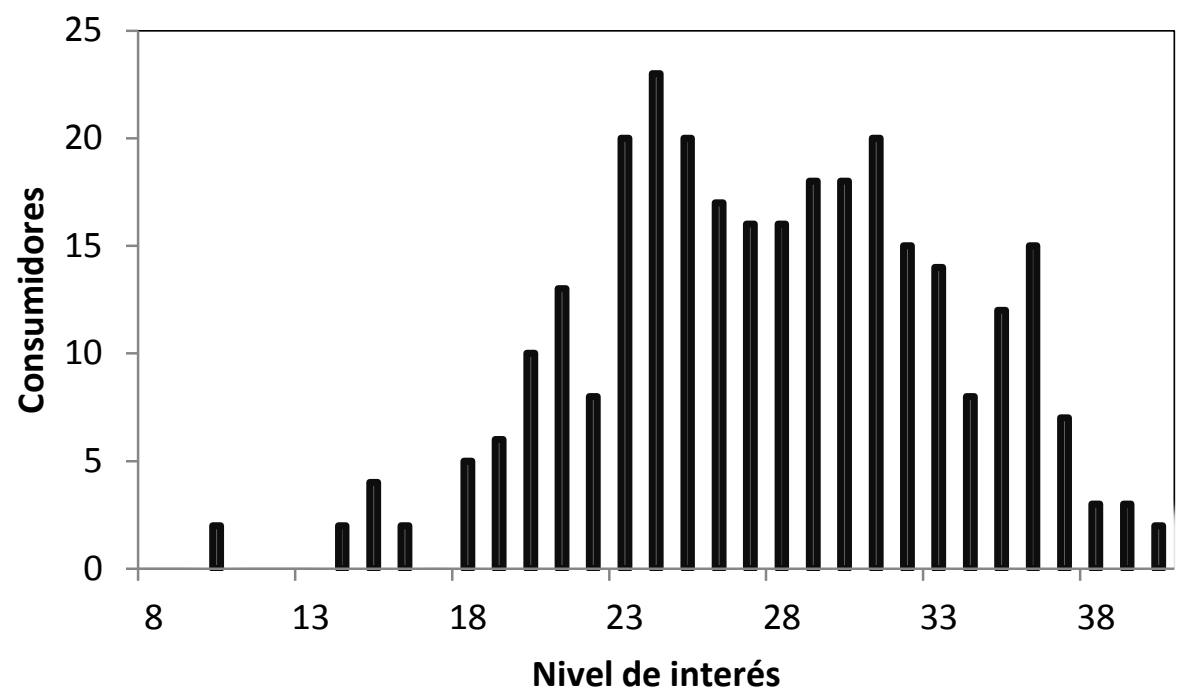

Figura 3. Distribución general de la población para el consumo de alimentos saludables.

La distribución de la población por género (Figura 4), se caracteriza por tener una mayor participación por parte de las mujeres, siendo probablemente este género el que más asiste a los establecimientos de venta de productos alimenticios. Sin embargo, considerando la media de la escala de interés (nivel 23), se observa una mayor proporción de la población con un interés en consumir alimentos saludables en ambos géneros. 


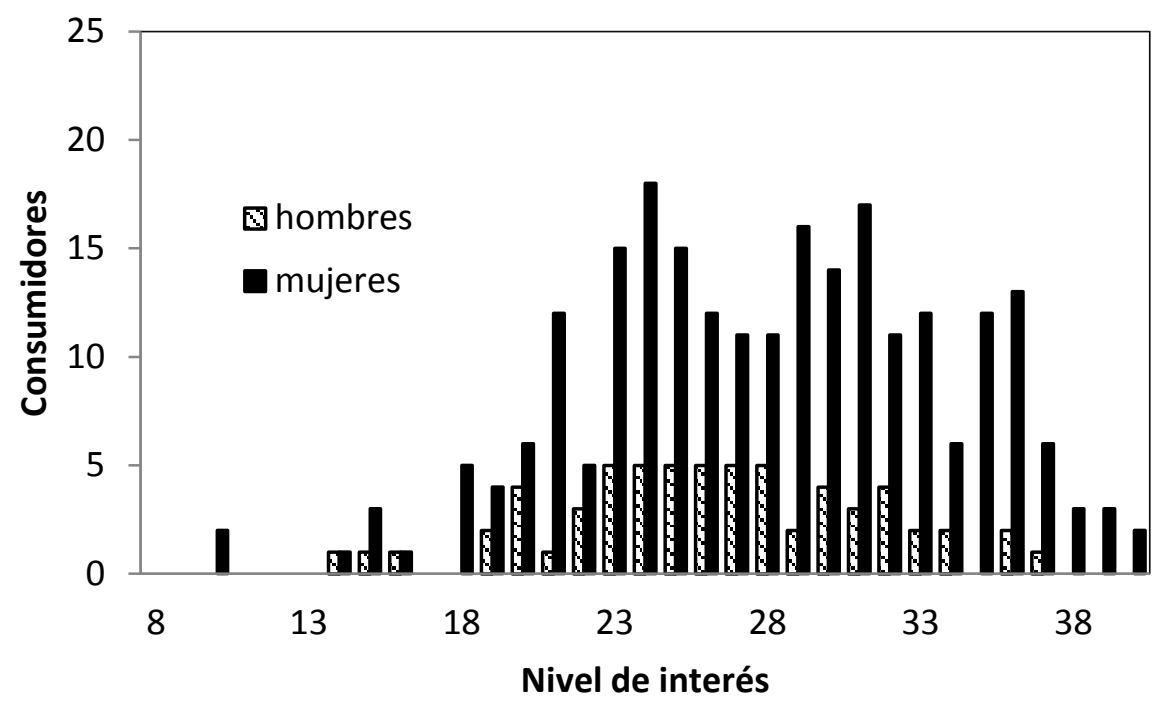

Figura 4. Distribución de la población para el consumo de alimentos saludables de acuerdo al género.

La distribución de la población de acuerdo a la edad se muestra en la Figura 5, donde se observa una tendencia hacia un mayor interés por consumir alimentos saludables en ambos grupos de edades, aun siendo mayor la participación en el grupo de personas entre 30 y 40 años de edad.

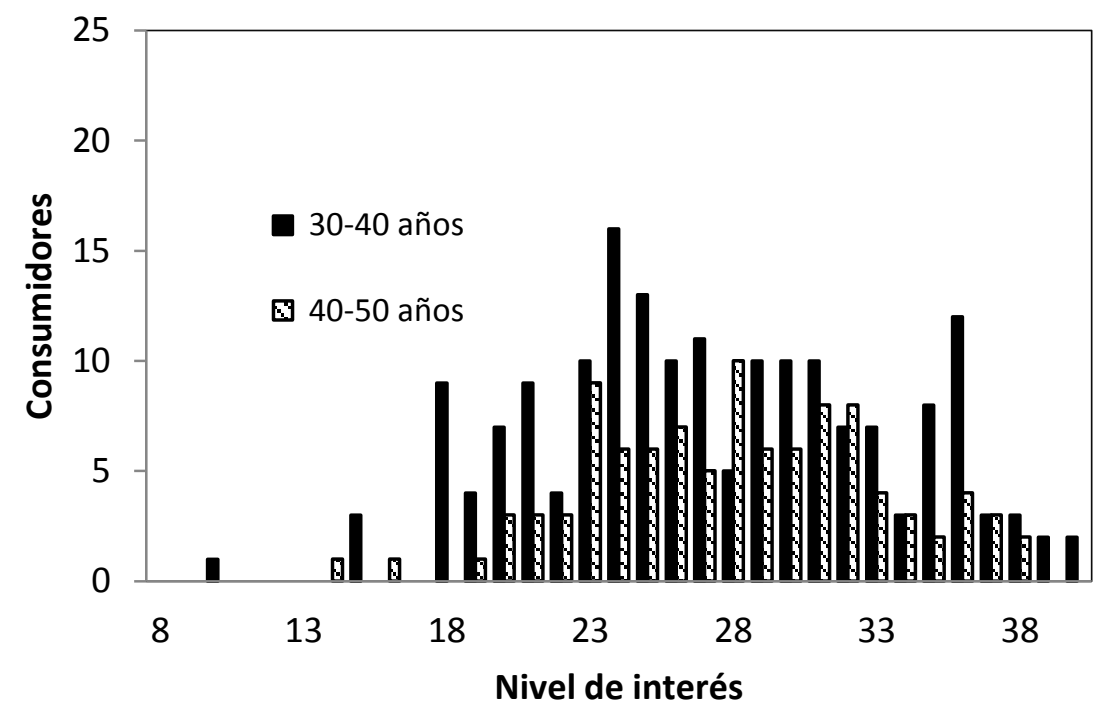

Figura 5. Distribución de la población para el consumo de alimentos saludables de acuerdo a la edad. 
De acuerdo al perfil de consumidores (Tabla 16), de manera general hay una diferencia significativa $(P<0.05)$ respecto al nivel de interés con un $68.3 \%$ en el nivel de interés alto. A pesar de presentar mayor participación por parte del género femenino, se obtuvo diferencia significativa $(P<0.05)$ en ambos niveles de interés tanto para hombres y mujeres. La edad de los consumidores se manifiesta con un mayor nivel de interés en consumir alimentos saludables en edades entre 40 y 50 años con un $73.3 \%$. Además, de acuerdo al análisis de la distribución de población mediante los valores de ji cuadrado, en todos los grupos evaluados se observó una diferencia entre ambos niveles de interés. Debido a lo anterior, se puede decir que en este estudio el interés de consumo de alimentos saludables es dependiente del género y edad. Young y col. (2009) reportaron que el género influye sobre la aceptación de alimentos más saludables, más aun cuando este alimento contiene elementos para una buena salud, más allá de ser novedosos.

Tabla 16. Perfil de consumidores de acuerdo al género y edad al consumo de alimentos nuevos.

\begin{tabular}{lcccc}
\hline $\begin{array}{l}\text { Tipo de población } \\
\boldsymbol{x}^{2}\end{array}$ & Valor $\boldsymbol{P}$ & $\begin{array}{c}\text { Interés Bajo } \\
(\%)\end{array}$ & $\begin{array}{c}\text { Interés Alto } \\
(\%)\end{array}$ \\
\hline $\begin{array}{l}\text { Consumidores generales } \\
\text { Género }\end{array}$ & 39.73 & 0.000 & 31.7 & 68.3 \\
Hombres & 4.58 & 0.032 & 36.5 & 63.5 \\
Mujeres & 35.86 & 0.000 & 30.5 & 69.5 \\
Edad & & & & \\
30-40 años & 15.69 & 0.000 & 35.2 & 64.8 \\
$40-50$ años & 21.87 & 0.000 & 26.7 & 73.3 \\
\hline
\end{tabular}

En esta parte del estudio no se realizó una demostración del alimento, solo se mostraron las fichas de información de cada una de las harinas. Se ha reportado que la información proporcionada junto con la degustación del nuevo alimento 
influye sobre la calificación y aceptación de los consumidores, de este modo la degustación tiene un impacto mayor en la intención de compra y la información impacta sobre la respuesta en una escala hedónica (Aaron y col., 1994; Tuorila y col., 1998).

\subsubsection{Neofobia Alimentaria}

Para una mejor interpretación del nivel de neofobia la escala se dividió en dos partes: Neofilico y Neofóbico. De acuerdo a la distribución de la población (Figura 4), se observa mayor nivel de neofobia hacia la harina de cáscara de tuna en relación a la harina de cáscara de piña considerando una media de 30 sobre la escala de Neofobia. De acuerdo a Villegas y col. (2008), cuando se proporciona información nutrimental de un nuevo producto la respuesta por parte de los consumidores se inclina hacia la aceptación de un nuevo producto, lo cual fue llevado a cabo en este experimento.

Las personas encuestadas presentaron un nivel significativamente mayor de Neofilia hacia el consumo de harina de cáscara de piña $\left(X^{2}=80.880 / P<0.05\right)$, mientras que para la harina de cáscara de tuna el porcentaje se encuentra en 50\% (Tabla 17) lo cual significa que las personas encuestadas no reflejan una decisión de aceptación para este tipo de harina $\left(x^{2}=0.005 / P>0.05\right)$, reflejándose en el comportamiento de la distribución de la población (Figura 6). Los resultados obtenidos en el estudio de alimentos saludables se vieron reflejados en el grado de neofobia al no presentar una decisión de neofobia para ambas harinas. 


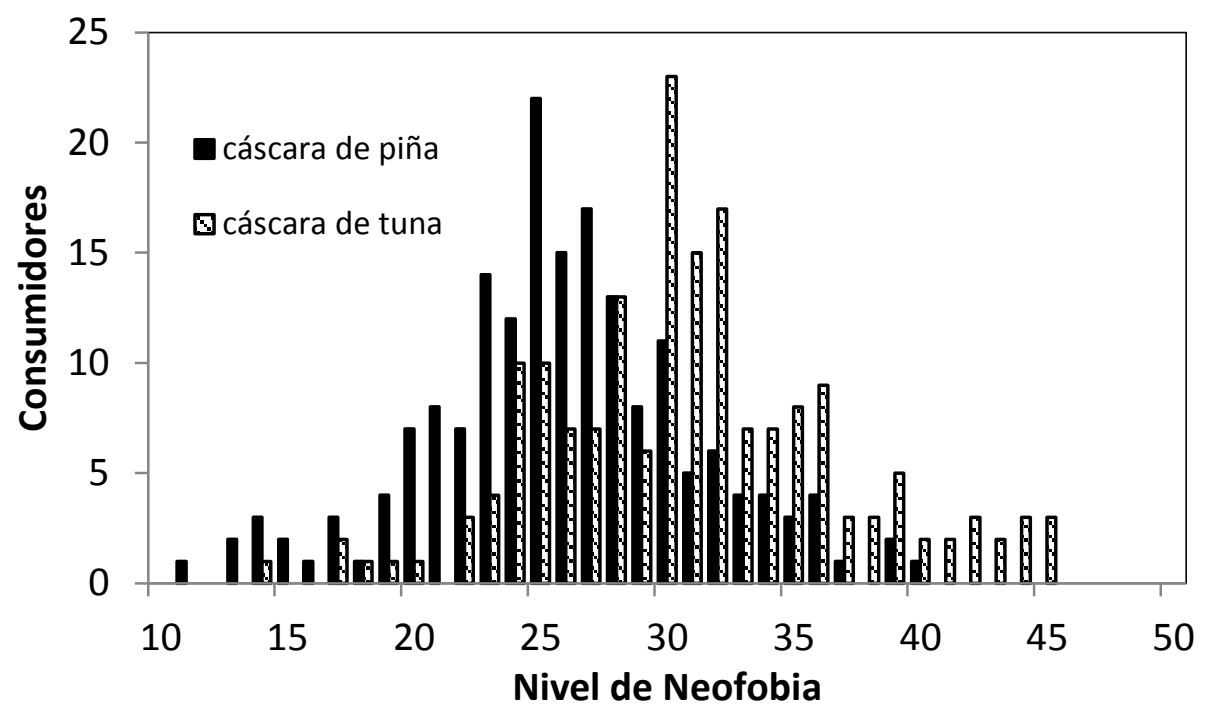

Figura 6. Distribución de la población para el nivel de neofobia de acuerdo al tipo de fibra.

Tabla 17. Ji cuadrado para el nivel de neofobia por tipo de fibra.

\begin{tabular}{|c|c|c|c|c|}
\hline Tipo de fibra & $x^{2}$ & Valor $\boldsymbol{P}$ & $\begin{array}{c}\text { Neofilicos } \\
\text { (\%) }\end{array}$ & $\begin{array}{c}\text { Neofóbicos } \\
(\%)\end{array}$ \\
\hline Harina de cáscara de piña & 80.880 & 0.000 & 83.4 & 16.6 \\
\hline Harina de cáscara de tuna & 0.005 & 0.940 & 50.0 & 50.0 \\
\hline
\end{tabular}

En este estudio, la categorización por parte del público encuestado en relación a la neofilia o neofobia alimentaria no fue difícil para el caso de la harina de cáscara de piña pero lo fue para la harina de cáscara de tuna. Se ha reportado que el estudio de neofobia no es una técnica de categorización difícil, más bien es un factor de modulación de aceptación por un nuevo alimento (Yamada y col., 2012). Otras investigaciones han sugerido que la neofobia es influenciada por factores como edad, nivel socio-económico, estado civil y sexo (Pliner y col., 1993; Pelchat y Pliner, 1995; Martins y col., 1997). 


\subsection{3 Índice $\mathbf{R}$}

La prueba de Índice R, tanto para pruebas de categorización (rating) como de ordenamiento (ranking), genera índices que van de valores 0 a 100 los cuales demuestran la capacidad de los jueces de diferenciar distintas muestras en base a diferentes atributos; donde los valores extremos ( 0 o 100) demuestran un mayor nivel de diferenciación, mientras que un valor 50 representa similitud en la magnitud de apreciación de atributos por parte del panel. En este experimento, la prueba para firmeza (ranking) solo se observó valores significativos de acuerdo a los valores críticos (Bi y O'Mahony, 2007) para las muestras con harina de cáscara de tuna ( $I R=90.29$ ), en tanto la prueba de sabor (rating) mostró efecto significativo para ambas formulaciones. Mientras tanto, la firmeza en muestras con harina de cáscara de piña se encuentra por debajo del valor crítico, lo cual refleja que los panelistas detectaron menor firmeza que el resto de las muestras. Para los casos de categorización (Rating/sabor) en ambas harinas y ordenamiento (Ranking/firmeza) para tuna, los jueces significativamente $(\mathrm{P}<0.05)$ discriminantes al obtener valores cercanos a $100 \%$ (Lee y van Hout, 2009). El valor de Índice $R$ para ranking en firmeza de las salchichas con harina de cáscara de piña (50 \%) demuestran menor firmeza percibida que las muestras con harina de cáscara de tuna, contrario a lo obtenido en el análisis de perfil de textura (ver Capitulo III, tabla 9), además la fibra insoluble infiere sobre la textura de los alimentos debido a su capacidad de retención de agua y habilidad de hinchazón (Thebaudin y col., 1997), lo cual impactó sobre la percepción de los jueces. De acuerdo a la teoría de detección de señales, también llamado modelo Thurstoniano, la cual se basa en la variabilidad en la percepción de un alimento; esto es, los cambios del medio ambiente de la lengua y fluctuaciones en el sistema nervioso causan varios cambios pequeños en la percepción de intensidad de un alimento sobre todo cuando hay varias evaluaciones (Lee y O’Mahony, 2004). 
Tabla 18. Índice R para diferentes tratamientos.

\begin{tabular}{llc}
\hline $\begin{array}{l}\text { Muestra/Atributo } \\
\text { sensorial }\end{array}$ & IR calculado (\%) & IR tabulado $\mathbf{+ 5 0 \% ^ { * }}$ \\
\hline Piña/firmeza (Ranking) & 50.00 & 61.92 \\
Piña/sabor (Rating) & $83.75^{* *}$ & 61.92 \\
Tuna/firmeza (Ranking) & $90.29^{* *}$ & 61.92 \\
Tuna/sabor (Rating) & $71.24^{* *}$ & 61.92 \\
\hline
\end{tabular}

*valores críticos (Bi y O’Mahony, 2007). $\mathrm{n}=30, \alpha=0.05$.

${ }^{* *}$ Significativo $(\mathrm{P}<0.05)$

\subsubsection{Análisis descriptivo cuantitativo (QDA)}

En la Tabla 19 se muestra el análisis de varianza de acuerdo a los diferentes atributos de las salchichas. En el factor muestra se observa que el jurado solo fue altamente discriminativo $(\mathrm{P}<0.05)$ en la apariencia clara/oscura, olor a consomé de pollo y carne de cerdo; sabor a dulce, especias, carne de cerdo, fibra; dureza y textura plasticada. El factor juez reveló diferencias significativas $(P<0.05)$ en el uso de la escala al evaluar los atributos de apariencia clara/oscura, brillosa y compacta así como en todos los atributos de olor, sabor y textura; lo cual revela que los jueces clasificaron de manera diferente las muestras sobre la escala utilizada al percibir de manera diferente los atributos de las salchichas (Sinesio y col., 1990; Sulmont y col., 1997). La interacción muestra*juez no mostró diferencias significativas ( $P>0.05)$ en los parámetros de textura, así como en la mayoría de los atributos de apariencia excepto en apariencia homogénea; pero se encontró diferencia significativa $(\mathrm{P}<0.05)$ en olor a consomé de pollo, cocido y carne de cerdo, además de sabor a salado, dulce, cocido y astringente, lo cual indica concordancia en el uso de la escala durante la evaluación de producto al no encontrar diferencias significativas $(P>0.05)$ en la mayoría de los atributos (Pagés y col., 2007). 
Tabla 19. Análisis de varianza para diferentes atributos en salchichas.

\begin{tabular}{lccc}
\hline Atributo & $\boldsymbol{\alpha}$ Muestra & $\boldsymbol{\alpha}$ Juez & $\boldsymbol{\alpha}$ Muestra*Juez \\
\hline Apariencia & & & \\
Claro/Oscuro & 0.000000 & 0.026299 & 0.46337 \\
Brilloso & 0.117414 & 0.000367 & 0.09317 \\
Homogéneo & 0.353653 & 0.071316 & 0.34026 \\
Compacto & 0.626064 & 0.001624 & 0.61688 \\
Olor & & & \\
Consomé de pollo & 0.051227 & 0.004862 & 0.06730 \\
Ahumado & 0.890852 & 0.000000 & 0.99864 \\
Dulce & 0.100936 & 0.000054 & 0.39328 \\
Cocido & 0.958116 & 0.000000 & 0.00450 \\
Carne de cerdo & 0.007326 & 0.000123 & 0.00084 \\
Fermentado & 0.864406 & 0.000000 & 0.99999 \\
Rancio & 0.819373 & 0.000000 & 0.34865 \\
Sabor & & & \\
Salado & 0.836112 & 0.039698 & 0.01368 \\
Dulce & 0.000719 & 0.000051 & 0.01233 \\
Ahumado & 0.168301 & 0.000000 & 0.87961 \\
Rancio & 0.139000 & 0.000048 & 0.53023 \\
Especias & 0.022772 & 0.000003 & 0.86699 \\
Cocido & 0.670867 & 0.001544 & 0.00150 \\
Grasa & 0.415328 & 0.029023 & 0.54142 \\
Carne de Cerdo & 0.081926 & 0.005556 & 0.12637 \\
Astringente & 0.111393 & 0.000000 & 0.00026 \\
Amargo & 0.634592 & 0.000001 & 0.55812 \\
Consomé de pollo & 0.588015 & 0.000002 & 0.83161 \\
Fibra & 0.010223 & 0.000000 & 0.61203 \\
Textura & & & \\
Dureza & 0.000022 & 0.000029 & 0.90841 \\
Plasticada & 0.000175 & 0.002513 & 0.99111 \\
Grasosa & 0.762447 & 0.003151 & 0.99773 \\
Fibrosa & 0.38923 & 0.000126 & 0.40722 \\
Gomosa & 0.40085 & 0.015432 & 0.14039 \\
Humedad & 0.089624 & 0.021660 & 0.96782 \\
\hline
\end{tabular}

La evaluación sensorial de los atributos de apariencia se muestra en la Figura 7, donde se puede observar que solo hubo un efecto significativo $(\mathrm{P}<0.05)$ sobre el atributo color: claro/oscuro. Los jueces evaluaron las salchichas con harina de cáscara de piña como las más oscuras seguidas de aquellas con harina de cáscara de tuna y testigo. Es evidente que el tipo fibra adicionada tuvo impacto sobre la evaluación de los jueces respecto al color, sin embargo, no afecto 
significativamente los demás atributos en relación a la formulación testigo, principalmente los atributos compacto y homogéneo, lo que refleja funcionalidad por parte de las harinas de frutos dentro de una matriz protéica.

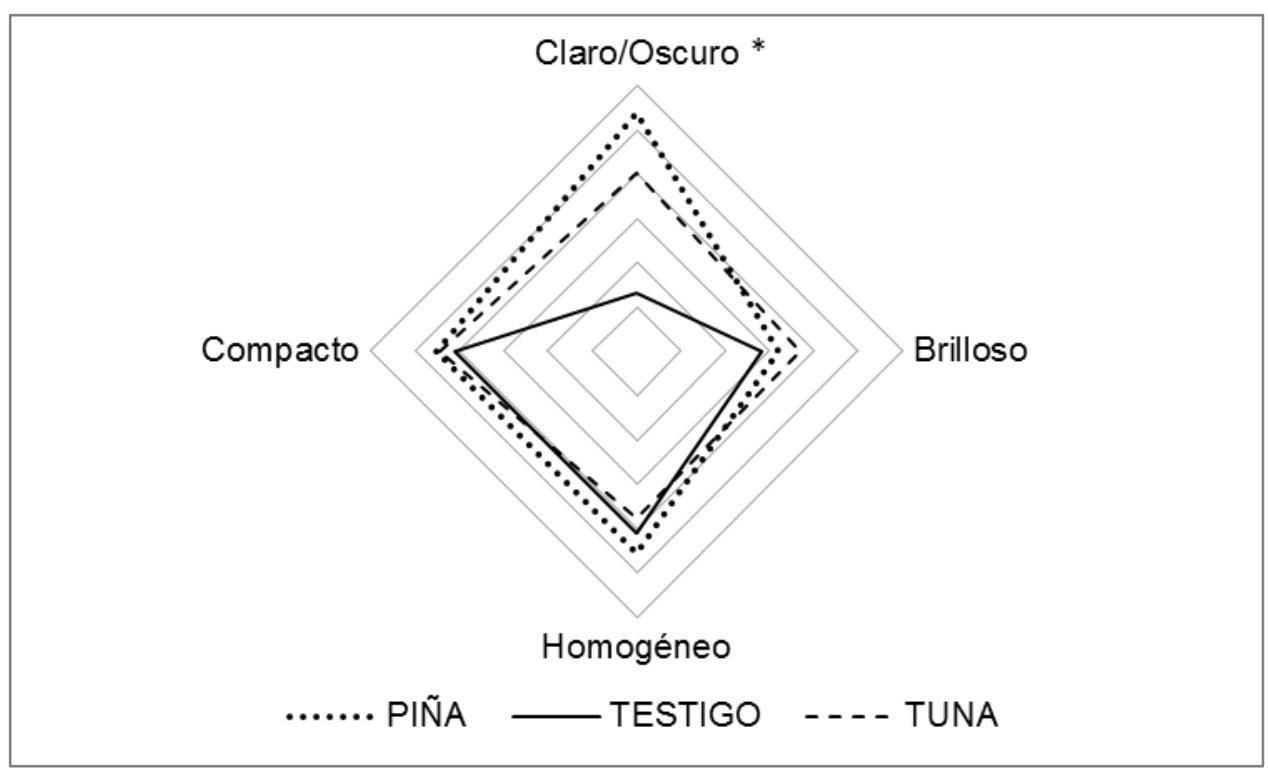

Figura 7. Comparación de diferentes atributos de apariencia entre diferentes formulaciones de salchichas. $\left({ }^{*}\right)$ Diferencias significativas $(P<0.05)$.

Respecto a los atributos de olor (Figura 8), los diferentes tratamientos solo tuvieron efecto significativo $(\mathrm{P}<0.05)$ sobre el olor a carne de cerdo, siendo la formulación testigo la que evaluaron los jueces con mayor intensidad seguida de la formulación con harina de cáscara de piña, y tuna con menor intensidad. Los jueces evaluaron con baja intensidad los atributos de ahumado, rancio y fermentado en todas las formulaciones, enfatizando la evaluación de este último atributo (fermentado) debido a la tasa de fermentabilidad que presentan las harinas de cáscara de tuna y piña, lo cual favorece la aceptación del producto.

El grado de madurez de la fruta modifica la composición general reflejándose en las características físicas y químicas de su cáscara (Hajar y col., 2012) lo cual pudo alterar la coloración de la harina durante su procesamiento influyendo en la percepción sensorial de los jueces. 


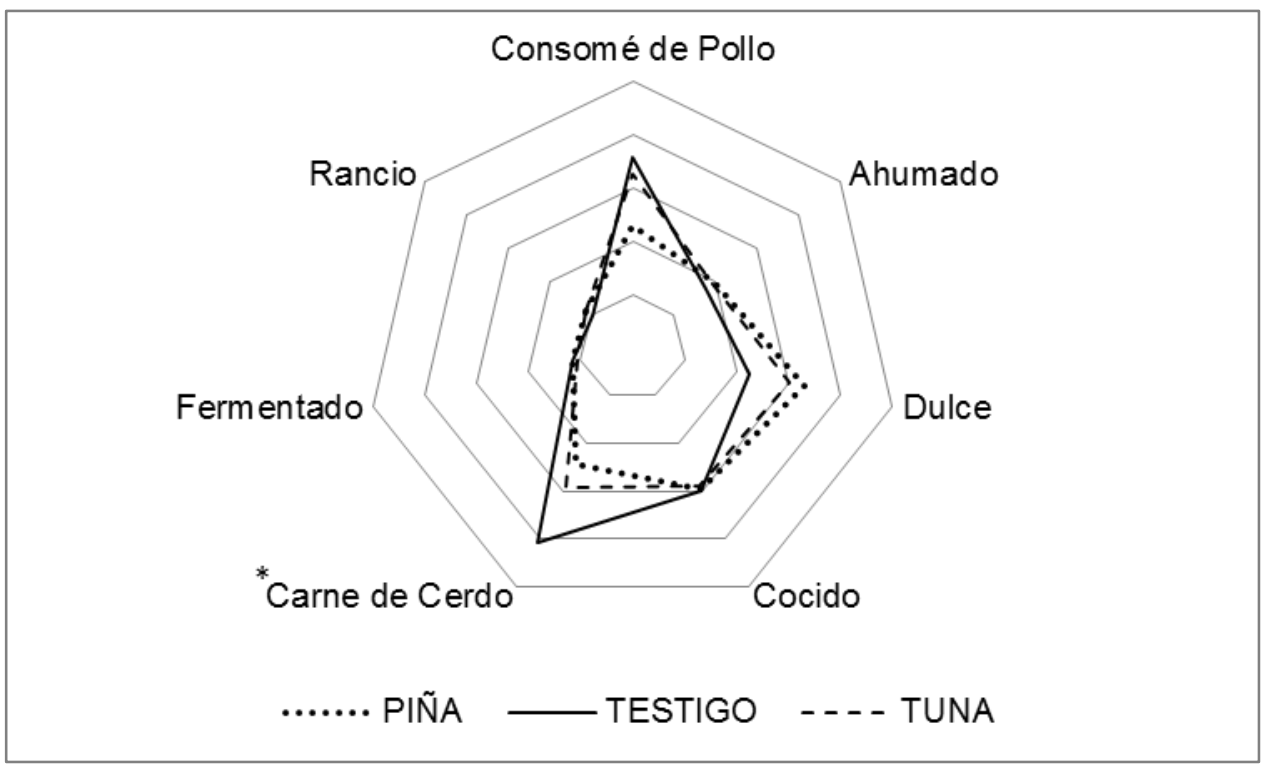

Figura 8. Comparación de diferentes atributos de olor entre diferentes formulaciones de salchichas. $\left(^{*}\right)$ Diferencias significativas $(P<0.05)$.

La Figura 9 muestra la evaluación de los atributos de sabor, la formulación con harina de cáscara de piña presentó un nivel significativamente $(P<0.05)$ mayor de intensidad en el atributo de sabor a dulce que las otras dos formulaciones. Con el resto de los atributos no se observaron diferencias significativas, sin embargo, los atributos de sabor carne de cerdo y cocido fueron atributos evaluados con mayor intensidad en relación al resto de los atributos. Además, el adicionar harinas de cáscaras de frutos como fuente de fibra a la formulación de salchichas, esta no fue percibida como tal, siendo similar la intensidad de sabor a fibra para las tres formulaciones. Siendo la cáscara de frutos la fuente de fibra adicionada, la cual contiene antioxidantes, no se reflejó en la intensidad del atributo amargo y fibra, pero si para el atributo astringente. 


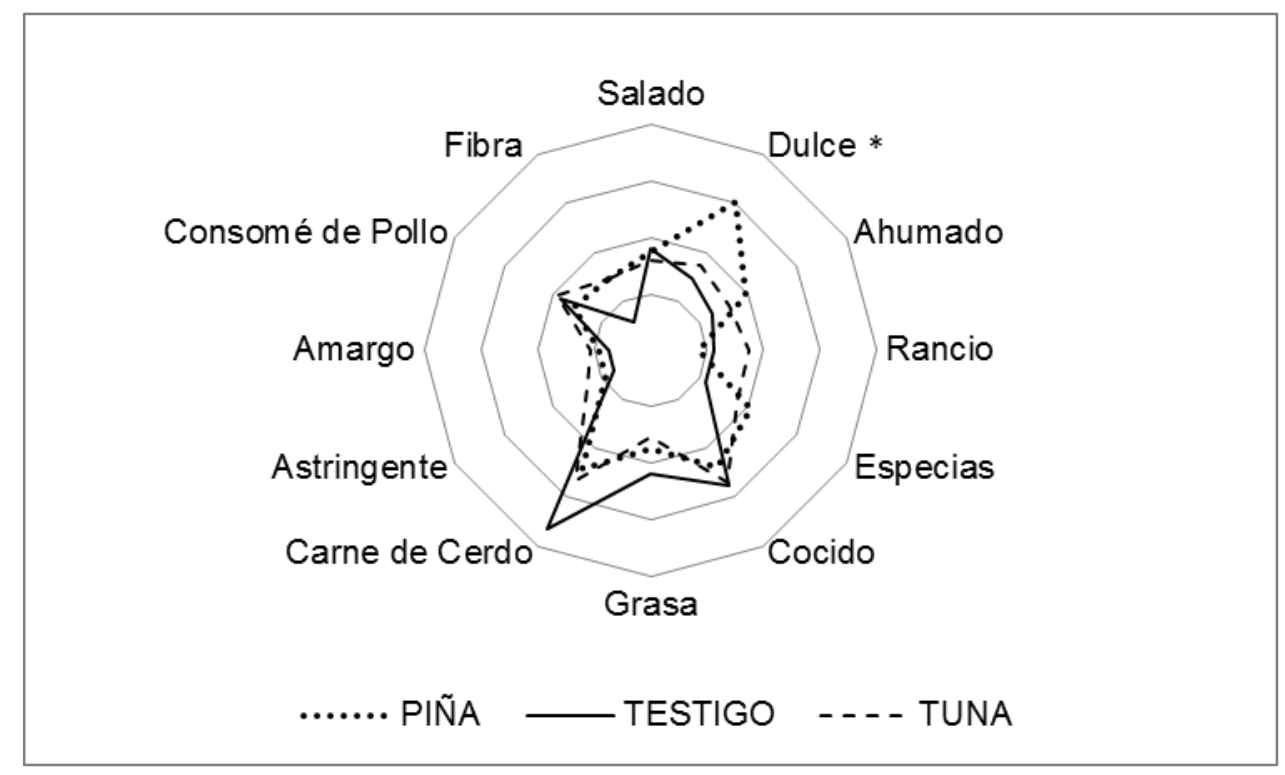

Figura 9. Comparación de diferentes atributos de sabor entre diferentes formulaciones de salchichas. $\left(^{*}\right)$ Diferencias significativas $(P<0.05)$.

En los atributos de textura (Figura 10), se observaron diferencias significativas $(\mathrm{P}<0.05)$ en dureza y plasticada, con harina de cáscara de tuna los jueces percibieron mayor intensidad de dureza y plasticada sin haber diferencias significativas $(P>0.05)$ con la formulación testigo. Aunque en el atributo de humedad no se observaron diferencias significativas $(P>0.05)$, este también fue uno de los atributos con mayor intensidad lo cual pudo ser debido a la retención de agua por parte de las harinas de cáscara de frutos. Así mismo, la textura fibrosa fue evaluada con una intensidad baja aun teniendo fibra adicionada a la formulación de las salchichas, comportándose de manera similar en sabor (Figura 9). 


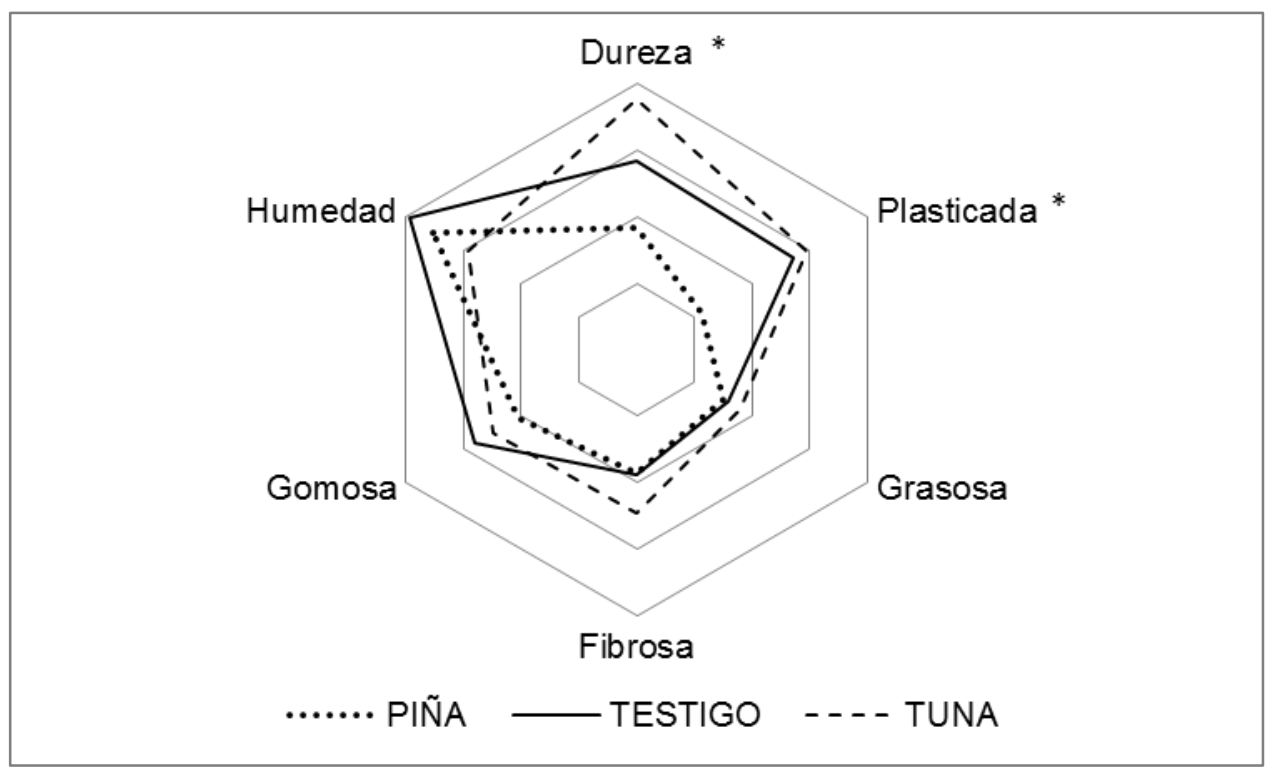

Figura 10. Comparación de diferentes atributos de textura entre diferentes formulaciones de salchichas. $\left(^{*}\right)$ Diferencias significativas $(P<0.05)$.

La Tabla 20 muestras la varianza explicada del análisis de componentes principales (ACP), donde se muestra que los primeros ocho componentes explican la mayor variabilidad de los datos analizados. El análisis de componentes principales (Figura 11) está representado por los dos primeros componentes, los cuales representan el $38.01 \%$ de la variabilidad de los datos. La primera dimensión del ACP esta explicada positivamente por todos los atributos evaluados, mientras que la segunda dimensión esta explicada positivamente por descriptores de olor (consomé de pollo, carne de cerdo, fermentado y rancio), sabor (salado, rancio, carne de cerdo, astringente y amargo) y textura (dureza, plástica, grasosa, y gomosa); todos los atributos del descriptor apariencia se encuentran en el espacio sensorial negativo de la segunda dimensión. Enfatizando que el análisis de componentes principales muestra que los atributos que más reflejan variabilidad de los datos son sabor astringente, amargo y rancio, a pesar de solo mostrar diferencias significativas entre las tres formulaciones de acuerdo a la Figura 9. Además, los atributos sabor a grasa, apariencia compacta y textura húmeda son críticos para la clasificación de las diferentes formulaciones de salchichas. Se ha reportado que los atributos del sentido del gusto tienen un mayor impacto sobre los atributos de otros sentidos como vista, olor y textura, 
influyendo sobre la aceptación o rechazo de un producto (Prescott, 1998; Asp, 1999; Hernández-Cervantes y col., 2010). La longitud de los vectores indica la importancia de los atributos asignada por los jueces (Waichungo y col., 1998), de esta manera, los atributos principales de acuerdo al tema de estudio, son sabor a astringente, amargo, rancio, así como textura fibrosa, plástica y grasosa, sin embargo, el atributo sabor a fibra no fue sobresaliente.

Tabla 20. Varianza explicada de componentes principales.

\begin{tabular}{cccc}
\hline $\begin{array}{c}\text { Componente } \\
\text { número }\end{array}$ & Valor propio & $\begin{array}{c}\text { Porcentaje de } \\
\text { varianza }\end{array}$ & $\begin{array}{c}\text { Porcentaje } \\
\text { acumulado }\end{array}$ \\
\hline 1 & 7.918 & 27.305 & 27.305 \\
2 & 3.103 & 10.701 & 38.006 \\
3 & 2.774 & 9.565 & 47.571 \\
4 & 1.937 & 6.679 & 54.250 \\
5 & 1.601 & 5.520 & 59.769 \\
6 & 1.463 & 5.044 & 64.813 \\
7 & 1.426 & 4.917 & 69.730 \\
\hline
\end{tabular}




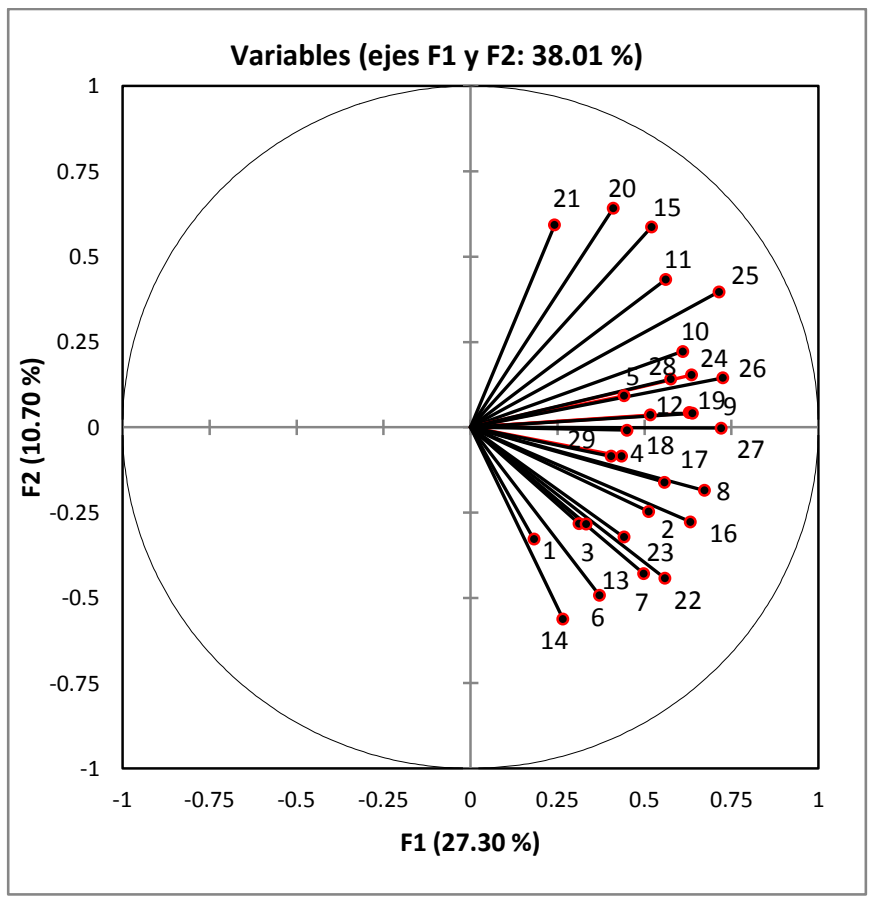

Figura 11. Análisis de componentes principales del análisis sensorial descriptivo de salchichas inoculadas con $P$. pentosaceus UAM22 adicionadas con harina de cáscara de tuna o piña. Apariencia (1-4;color claro/oscuro, brilloso, homogéneo y compacto, respectivamente); Olor (5-11; consomé de pollo, ahumado, dulce, cocido, carne de cerdo, fermentado y rancio, respectivamente); Sabor (12-23;

salado, dulce, ahumado, rancio, especias, cocido, grasa, carne de cerdo, astringente, amargo, consomé de pollo y fibra, respectivamente); Textura (24-29; dureza, plástica, grasosa, fibrosa, gomosa y humedad, respectivamente).

El Biplot de análisis de componentes principales (Figura 12) agrupa los descriptores con las diferentes muestras. La formulación con harina de cáscara de tuna se caracterizaron por tener mayor intensidad en los atributos de sabor a fibra, grasosa, astringente, amargo, sabor a carne de cerdo, más dura y plasticada. La formulación con harina de cáscara de piña se caracterizó por tener mayor intensidad en los atributos de sabor a rancio, olor y sabor a dulce, oscura, pero más homogénea. La diferenciación de los diferentes grupos de muestras es clara en función de los diferentes atributos evaluados. 


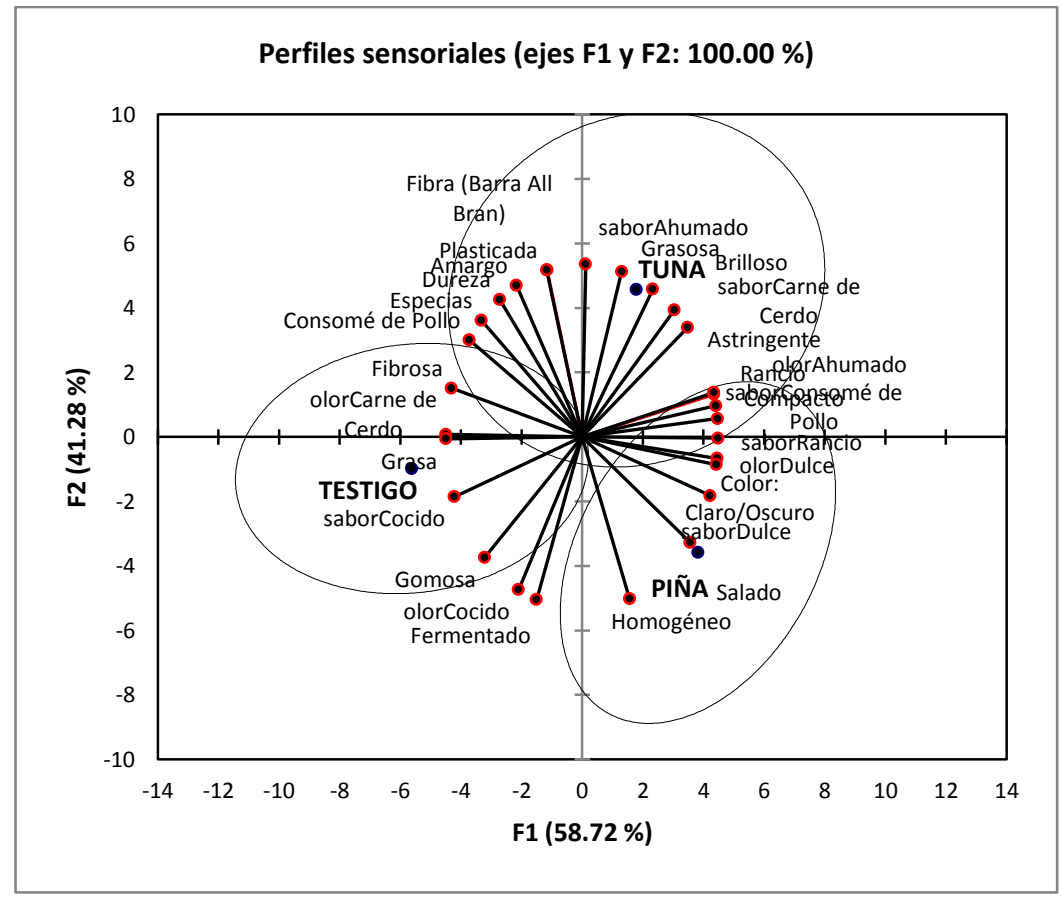

Figura 12. Biplot de Análisis de componentes principales mediante caracterización de productos (testigo, tuna y piña). 


\subsection{CONCLUSIONES}

El estudio de consumo de alimentos saludables y neofobia alimentaria demostró que existe posibilidad en desarrollar un alimento funcional, con un sector de la población de aceptación femenino y edad entre 40 y 50 años, principalmente; además de no importar el tipo de fibra dietética (harina de cáscara de tuna o piña). Los jueces fueron altamente discriminantes en la prueba de Índice R, permitiendo una diferenciación de las muestras. El análisis descriptivo cuantitativo determinó que los atributos de mayor significancia fueron: color de salchichas; sabor a dulce, astringente y amargo; olor a carne de cerdo y, textura dura y plasticada. Las diferentes metodologías utilizadas en el análisis sensorial permitieron establecer los sectores donde dirigir alimentos cárnicos adicionados de fibra dietética, así mismo establecer el vocabulario para la evaluación de salchichas cocidas adicionadas con fibra de cáscaras de frutas. 


\subsection{BIBLIOGRAFÍA}

Aaron, J. I., Mela, D. J. y Evans, R. E. (1994). The influences of attitudes, beliefs and label information on perceptions of reduced-fat spread. Appetite. 22: 25.37.

Asp, H. (1999). Factors affecting food decisions made by individual consumers. Journal of Food Policy. 24: 287-294.

$\mathrm{Bi}$, J. y O'Mahony, M. 2007. Update and extended table for testing the significance of the R-index. Journal of Sensory Studies. 22: 713-720.

Biesalski, H. K. (2005). Meat as a component of a healthy diet - Are there any risks or benefits if meat is avoided in the diet?. Meat Science. 70(3): 509-524.

Brown, J. (1974). Recognition assessed by rating and ranking. British Journal of Psichology. 65: 13-22.

Caprita, A., Caprita, R., Gianet-Simulescu, V. O. y Raluca-Madalina, D. (2010). Dietary fiber: Chemical and functional properties. Journal of Agroalimentary Process and Technologies. 16(4): 406-416.

Chávez-Zepeda, L.P., Cruz-Méndez, G., García de Caza., Díaz-Vela, J. Y PérezChabela, M.L. (2009). Utilización de subproductos agroindustriales como fuente de fibra para productos cárnicos. Nacameh. 3: 71-82.

CMC, Consejo Mexicano de la Carne. (2012). Compendio Estadístico. México.

Dovey, T. M., Staples, P. A., Gibson, E. L. y Halford, J. C. G. (2008). Food neophobia and 'picky/fussy' eating in children: A review. Appetite. 50: 181193.

Falciglia, G. A., Couch, S. C., Gribble, L. S., Pabst, S. M. y Frank, R. (2000). Food neophobia in childhood affects dietary variety. Journal of the American Dietetic Association. 100: 1474-1481.

García, M. L., Dominguez, R., Galvez, M. D., Casas, C. y Selgas, M. D. (2002). Utilization of cereal of fruit fibres in low fat dry fermented sausages. Meat Science. 60: 227-236.

Hajar, N., Zainal, S., Nadsirah, K. Z., Siti-Roha, A. M., Atika, O. y Tengku-Elida, T. Z. M. (2012). Physicochemical properties analysis of three indexes pineapple (Ananas comosus) peel extract variety N36. APCBEE Procedia. 4: 115-121.

Hernández-Cervantes, M., López-Velázquez, J., Gómez-Alvarado, T., SantiagoCabrera, R., Ramón-Canul, L. G., Delgado-Vidal, F., Shain-Mercado, A. J., Huante-González, Y. y Ramírez-Rivera, E. J. (2010). Comparación de la descripción sensorial del queso fresco "cuajada" mediante el análisis descriptivo cuantitativo y el perfil flash. Ciencia y Mar. 14: 3-12.

Ju-Hui, C., Hack-Youn, K., Jong-Moon, L., Yong-Jae, K. y Cheon-Jei, K. (2013). Quality of frankfurter-type sausage with added pig skin and wheat fiber mixture as fat replacers. Meat Science. 93: 849-854. 
Lee, H. S. y O’Mahony, M. (2004). Sensory difference testing: Thurstonian models. Food Science and Biotechnology. 13: 841-847.

Lee, H. S. y van Hout, D. (2009). Quantification of sensory and food quality: The Rindex analysis. Journal of Food Science. 74: 57-64.

Martins, Y., Pelchat, M. L. y Pliner, P. (1997). Try it; it's good and it's good for you: Effects of taste and nutrition information on willingness to try novel foods. Appetite. 28: 89-102.

Moskowitz, H. (1983). Descriptive analysis of perceptions. En: Product testing and sensory evaluation of foods. Food Nutrition Press, Westport, CT, Estados Unidos.

O’Mahony, M. (1983). Adapting short cut signal detection measure to the problem of multiple diferential: $R$ index. En: Sensorial qualities of foods and beverages. Editores. The Williams and Atkins. Chapman Inc. Gran Bretaña. pp. 69-81.

O'Mahony, M. (1979). Short-cut signal detection measures for sensory analysis. Journal of Food Science. 44: 302-303.

Pagés, J. C., Bertrand, C., Ali, R., Husson, F. y Lé, S. (2007). Sensory analysis comparison of eight biscuit by French and Pakistani panels. Journal of Sensory Studies. 22: 665-686.

Pelchat, M. L. y Pliner, P. (2005). Try it. You'll like it. Effects of information on willingness to try novel foods. Appetite. 24: 153-165.

Pliner, P. (1994). Development of measures of food neophobia in children. Appetite. 23: 147-163.

Pliner, P. y Hobden, K. (1992). Development of a scale to measure the trait of food neophobia in humans. Appetite. 19: 105-120.

Pliner, P., Pelchat, M. y Grabski, M. (1993). Reduction of neophobia in humans by exposure to novel foods. Appetite. 20: 111-123.

Prescott, J. (1998). Comparison of taste perceptions and preferences of Japanese and Australian cosumers: overview and implications for cross-cultural sensory research. Journal of Food Quality and Preference. 9: 393-402.

Raudenbush, B. y Frank, R. A. (1999). Assessing food neophobia: The role of stimulus familiarity. Appetite. 32: 261-271.

Roininen, K., Lähteenmäki, L. y Tuorila, H. (1999). Quantification of consumer attitudes to health and hedonic characteristics of foods. Appetite. 33: 71-88.

Schnettler, B., Crisóstomo, G., Sepúlveda, J., Mora, M., Lobos, G., Miranda, H. y Grunert, K. G. (2013). Food neophobia, nanotechnology and satisfaction with life. Appetite. 69: 71-79.

SIAP, Servicio de Información Agroalimentaria y Pesquera. (2012). Cierre de la producción agrícola por cultivo. Consultado en: 
http://www.siap.gob.mx/cierre-de-la-produccion-agricola-por-cultivo/. Fecha de consulta: 1 Abril del 2014.

Siedel, J. y Stone, H. (1985). Sensory evaluation practice. Academic Press, Nueva York, E. U. A.

Sinesio, F., Risvik, E. y Rodbotten, M. (1990). Evaluation of panelist performance in descriptive profiling of rancid sausage. A multivariate study. Journal of Sensory Studies. 5:33-32.

Sulmont, C., Lesschaeve, I., Sauvegeot, F. y Issanchou, S. (1997). Comparative training procedures to learn odor descriptors: Effects on profiling performance. Journal of Sensory Studies. 14: 467-490.

Thebaudin, J. Y., Lefebvre, A. C., Harrington, M. y Bourgeois, C. M. (1997). Dietary fibers: Nutritional and technological interest. Trends Food Science Technology. 8: 41-48.

Tomaschunas, M., Zorb, R., Fischer, J., Kohn, E., Hinrichs, J. y Bush-Stockfisch, M. (2013). Changes in sensory properties and consumer acceptance of reduced fat pork Lyon-style and liver sausages containing inulin and citrus fiber as fat replacers. Meat Science. 95: 629-640.

Tuorila, H., Anderson, A., Martikainen, A. y Salovaara, H. (1998). Effect of product formula, information and consumer characteristics on the acceptance of a new snack food. Food Quality Preference. 9: 313-320.

Villegas, B., Carbonell, I. y Costell, E. (2008). Effect of product information and consumer attitudes on responses to milk ans soybean vanilla beverages. Journal of the Science of Food and Agriculture. 88: 2426-2434.

Waichungo, W. W., Heymann, H. y Heldman, D. R. (1998). Using descriptive analysis to characterize the effects of moisture sorption on the texture of low moisture foods. Journal of Sensory Studies. 15: 35-46.

Weiss, J., Gibis, M., Schuh, V. y Salminen, H. (2010). Advances in ingredient and processing systems for meat and meat products. Meat Science. 86(1): 196213.

Yamada, Y., Kawabe, T. y Ihaya, K. (2012). Can you eat it?. A link between categorization difficulty and food likability. Advances in Cognitive Psychology. 8: 248-254.

Young, M. E., Mizzau, M., Mai, N. T., Sirisegaram, A. y Wilson, M. (2009). Food for thought. What you eat depends on your sex and eating companions. Appetite. 53: 268-271.

Yun-Sang, Ch., Jin-Hun, Ch., Doo-Jeong, H., Hack-Youn, K., Mi-Ai, L., Jong-Youn, J., Hai-Jung, Ch. y Cheon-Jei, K. (2010). Effects of replacing pork back fat with vegetable oils and rice bran fiber on the quality of reduced-fat frankfurters. Meat Science. 84: 557-563. 


\section{CAPÍtUlO V. EFECTOS FISIOLÓGICOS Y}

MICROBIOLÓGICOS DE LA CÁSCARA DE TUNA (Opuntia ficus indica) E INULINA DE AGAVE COMO FUENTES DE FIBRA EN LA ALIMENTACION DE RATAS (Rattus norvegicus) CEPA WISTAR

Pérez-Chabela, M.L., Cerda-Tapia, A., Díaz-Vela, J., Díaz, M., Delgadillo, P.C. Physiological effects of agroindustrial subproducts (cactus (Opuntia ficus) pear peel flour) in Wistar rats (Rattus norvegicus). Enviado.

\subsection{OBJETIVO}

Evaluar el efecto in vivo de la harina de cáscara de tuna sobre parámetros fisiológicos y microbiológicos de la rata (Rattus norvegicus) cepa Wistar.

\subsection{PROLEGÓMENO}

La cáscara de frutos representa una fuente importante de compuestos funcionales, como la cáscara de tuna (Opuntia ficus indica), ya que en su composición química contempla fibra dietética representada como el $40 \%$ de polisacáridos no celulósicos, además de polisacáridos como celulosa en un 27\% (Habibi y col., 2004a), otros polisacáridos como pectina debido a su contenido de ácido galacturónico y dependiendo del tipo de extracción también se pueden obtener azúcares neutros como arabinosa, xilosa y galactosa (Habibi y col., 2004b.). Estos carbohidratos dietéticos presentes en las cáscaras de frutos escapan de la digestión y adsorción del intestino delgado sometiéndolos a la fermentación en el colon e incrementando la producción de ácidos grasos de cadena corta (Hijova y Chmelarova, 2007) e incrementando el crecimiento de bacterias benéficas como lactobacilos y bifidobacterias. Los principales ácidos grasos de cadena corta producidos por fermentación de fibra dietética son acetato, propionato y butirato, de gran importancia fisiológica; el acetato, es metabolizado dando glutamina y cuerpos cetónicos principales fuentes de energía del sistema digestivo y tejidos periféricos (Souba y col., 1985); el ácido propiónico es metabolizado en el hígado actuando de precursor en la gluconeogénesis y lipogénesis (Levrat y col., 1994); mientras que el butirato es la principal fuente de energía de los colonocitos favoreciendo la actividad antiinflamatoria del colon (Inan y col., 2000). 
La realización de estudios in vivo mediante el uso de sistemas biológicos como las ratas de laboratorio puede demostrar de manera complementaria los resultados obtenidos en estudios in vitro utilizando subproductos agroindustriales como alimentos funcionales. Se ha estudiado el efecto de suministrar fibra soluble sintética, fructanos derivados del trigo y cebada (Artiss y col., 2006) y harina de cáscara de plátano (Scarminio y col., 2012) sobre parámetros fisiológicos, microbiológicos y enfermedades digestivas en ratas cepa Wistar y cepa Sprague-Dawley (Belobrajdic y col., 2012) los cuales reportaron de manera similar un efecto sobre la población de bifidobacterias y lactobacilos, pero sin variar la ingesta de alimento y ganancia de peso corporal, pero si con variaciones en la digestibilidad de los compuestos no-digeribles y con una producción mayor de ácidos grasos de cadena corta en relación a dietas control. También se ha documentado el empleo de carbohidratos poliméricos con efecto prebiótico (Monro y col., 2012) y fructanos de origen vegetal en la alimentación de ratas (Pascoal y col., 2013) determinando mayor producción de ácidos grasos de cadena corta, principalmente ácido acético y butírico y mayor producción de bifidobacterias, además de no observar cambios en la ganancia de peso pero si en el consumo de alimento reflejándose en el volumen del bolo fecal.

De esta forma, el uso de compuestos oligoméricos no-digeribles o fibra dietética de origen vegetal ha sido empleado con resultados favorables en relación a efectos fisiológicos y microbiológicos, lo cual puede beneficiar a la salud de los animales de estudio con la intención de mejorar la salud humana. Sin embargo, existe gran variedad de subproductos agroindustriales que pueden ser aprovechados debido a su composición de carbohidratos. 


\subsection{METODOLOGÍA}

\subsubsection{Animales y Alojamiento}

Se utilizaron 16 ratas machos (Rattus norvegicus) cepa Wistar, estos animales fueron criados en el Departamento de Investigación Experimental y Bioterio del INCMNSZ (Instituto de Nacional de Ciencias Médicas y Nutrición Salvador Zubirán). Los animales fueron utilizados de acuerdo al Reglamento para la obtención, mantenimiento y utilización de animales para investigación del INNSZ, basado en la Norma Oficial Mexicana para la producción, uso y cuidado de animales de laboratorio (NOM-062-ZOO-1999). Los animales fueron distribuidos a la prueba después del destete, con un peso vivo promedio de $54.4 \mathrm{~g}$ se alojaron en jaulas metabólicas individuales durante 84 días; provistas con cama de viruta convencional que garantizó la absorción de su orina, excremento y desperdicio de agua, además de favorecer su aislamiento térmico y construcción de nido (NOM-062-ZOO-1999) siendo este material el empleado por el Bioterio del INNSZ. Las jaulas fueron colocadas en anaqueles, en una habitación con temperatura entre 21 y $23^{\circ} \mathrm{C}$, una humedad relativa de 40-60\% y ciclos de luz-oscuridad de $12 \times 12 \mathrm{~h}$. La adaptación de los animales incluyó el contacto físico durante el cambio de caja, revisión de la cantidad de alimento, llenado/cambio de botella de agua a fin de disminuir la sensibilidad propia de la especie frente a las modificaciones de su rutina.

\subsubsection{Dieta de ratas}

Las ratas se ordenaron aleatoriamente en dos grupos experimentales $(n=8)$ en jaulas independientes en base al tipo de dieta: adicionada con inulina y adicionada con harina de cáscara de tuna. A cada una de las ratas se les proporcionó el alimento ad libitum durante 84 días. La Tabla 21 muestra las diferentes formulaciones de la dieta, la cual está basada en la dieta AIN-93 G (Reeves y col., 1993). 
Tabla 21. Formulaciones de la dieta para el crecimiento de las ratas.

\begin{tabular}{lcc}
\hline Ingredientes & $\begin{array}{c}\text { Dieta con } \\
\text { inulina }\end{array}$ & $\begin{array}{c}\text { Dieta con harina de cáscara } \\
\text { de tuna }\end{array}$ \\
\hline Almidón de maíz & 397.486 & 397.486 \\
Caseína & 200.000 & 200.000 \\
Almidón de maíz dextrinizado & 132.000 & 132.000 \\
Sacarosa & 100.000 & 100.000 \\
Aceite de soya & 70.000 & 70.000 \\
Inulina & 50.000 & - \\
Harina de cáscara de tuna & - & 50.000 \\
Mezcla de minerales & 35.000 & 35.000 \\
Mezcla de vitaminas & 10.000 & 10.000 \\
L-cistina & 3.000 & 3.000 \\
Bitrartrato de colina & 2.500 & 2.500 \\
\hline
\end{tabular}

\subsubsection{Obtención de harina de cáscara de tuna (Opuntia ficus indica).}

Las cáscaras se recogieron semanalmente y transportaron al campus de la Universidad en cajas de plástico (aproximadamente $2 \mathrm{~kg}$ cada uno), fueron lavadas con agua fría y se almacenaron un día antes de su procesamiento en condiciones de refrigeración $\left(4 \pm 1^{\circ} \mathrm{C}\right)$. Las cáscaras de ambas frutas fueron equilibradas a temperatura ambiente durante 2 horas antes de ser cortadas en piezas de $2 \times 2 \mathrm{~cm}$ y se secaron a $60^{\circ} \mathrm{C}$ durante aproximadamente 24 horas en un horno de convección de aire (Barco Instrumentos Científicos, Ciudad de México). Las cáscaras secas se molieron en un molino de discos motorizado (Arisa Maquinaria S.A de C.V, México) y se tamizaron consecutivamente con tamaños de malla 100, 80, 50 y 20 para obtener un polvo regular y homogéneo, llamado harina, la cual fue almacenada en recipientes herméticamente cerrados hasta su uso.

\subsubsection{Características fisiológicas}

\subsubsection{Ganancia de peso y consumo de alimento}

Las ratas fueron pesadas una vez por semana con ayuda de una balanza analítica y un contenedor individual. Así mismo, se registró el consumo diario de alimento. Al término del experimento, los animales fueron anestesiados en una cámara de $\mathrm{CO}_{2}$. Una vez perdidos los reflejos se procedió al sacrificio con uso de una guillotina, para después iniciar con la disección para recuperación del ciego. 


\subsubsection{Análisis fecales de polisacáridos no digeridos}

Para la determinación de polisacáridos no digeridos se utilizó el contenido del ciego, el cual se secó, molió finamente y se almacenó a temperatura ambiente. Los polisacáridos no digeridos fueron determinados de acuerdo a la metodología propuesta por Paturi y col. (2012). En un tubo de ensaye se colocaron $100 \mathrm{mg}$ de muestra, después se realizaron dos lavados con $5 \mathrm{~mL}$ de etanol al $80 \%$ y se centrifugó para colectar el residuo. El residuo fue lavado con $2 \mathrm{~mL}$ de acetona y secado con aire a $60^{\circ} \mathrm{C}$. Posteriormente, el residuo se hidrolizó usando $1 \mathrm{~mL}$ de ácido sulfúrico $12 \mathrm{M}\left(35^{\circ} \mathrm{C}\right.$ durante $\left.1 \mathrm{~h}\right)$, después se adicionaron $7 \mathrm{~mL}$ de agua destilada y se calentó a $100^{\circ} \mathrm{C}$ durante $1 \mathrm{~h}$. Los polisacáridos totales en el hidrolizado fueron determinados como azucares totales usando el método propuesto por Dubois (1956).

\subsubsection{Producción de ácidos grasos de cadena corta en el ciego}

Para la cuantificación de ácidos grasos de cadena corta se utilizó la metodología propuesta por Richardson y col. (1989) con algunas modificaciones. Se analizó el contenido del ciego el cual se colectó inmediatamente después del sacrificio del animal, se almacenó a $-80^{\circ} \mathrm{C}$ hasta su análisis. El estudio se realizó mediante Cromatografía de gases usando un Cromatografo HP 5890 Series II (Perkin Elmer, Shelton) con una columna AT1000 (10 m x $0.250 \mathrm{~mm}$ ), detector de ionización de flama, $\mathrm{N}_{2}$ como gas de arrastre, un flujo de $1 \mathrm{~mL} / \mathrm{min}$ y una rampa de temperatura $\left(90-120^{\circ} \mathrm{C} @\right.$ $5 \% \mathrm{~min}$ ). Las muestras fueron descongeladas y mezcladas con $8 \mathrm{~mL}$ de una solución compuesta de $\mathrm{NaCl}(0.9 \%) \mathrm{p} / \mathrm{v}$ y Tween $20(0.1 \%)$, además de $1 \mathrm{~mL}$ de estándar interno (ácido 2-etil butírico, $100 \mathrm{mM}$ ) por cada gramo de muestra. La extracción de ácidos orgánicos se realizó con ácido clorhídrico y éter dietílico. Las muestras fueron centrifugadas a $1600 \mathrm{~g}$ durante 15 minutos hasta separar la fase acuosa y orgánica. Las muestras se almacenaron por 48 horas antes de su análisis. 


\subsubsection{Características microbiológicas}

\subsubsection{Conteo de bacterias ácido lácticas, bifidobacterias,}

Bacteroides sp. y enterobacterias en el contenido del ciego

El análisis microbiológico se realizó siguiendo la metodología reportada por Monro y col. (2012). Inmediatamente después del sacrificio, el contenido del ciego se removió asépticamente y se preparó para las pruebas microbiológicas. Se pesó $1 \mathrm{~g}$ del contenido del ciego y se colocó en un tubo de plástico que contenía $9 \mathrm{ml}$ de caldo glicerol para evitar modificaciones cualitativas y cuantitativas de la microbiota, las muestras se almacenaron a $-80^{\circ} \mathrm{C}$ hasta su análisis. Posteriormente se descongelaron y se realizaron las diluciones necesarias, utilizando PBS (buffer fosfato salino $\mathrm{pH} 7.2$ ), $1.0 \mathrm{ml}$ de cada dilución se colocó en cajas de Petri por triplicado para la prueba de siembra en placa. Los microorganismos cuantificados fueron: bacterias ácido lácticas, bifidobacterias, Bacteroides sp. y enterobacterias. Para el conteo de bacterias ácido lácticas se utilizó el medio MRS (De Man y col., 1960). Para bifidobacterias se usó agar TPY (Tripona-Peptona-Extracto de levadura), para enterobacterias se usó agar bilis y rojo violeta, y para Bacteroides sp. se usó agar infusión cerebro-corazón. Las condiciones de crecimiento se realizaron en jarras de anaerobiosis (Gaspack system) a $35^{\circ} \mathrm{C}$ durante $24 \mathrm{~h}$.

\subsubsection{Análisis estadístico}

Los resultados de ganancia de peso, consumo de alimento, análisis de polisacáridos no digeridos, concentraciones de ácidos grasos de cadena corta y cuantificación de bacterias fueron analizados por análisis de varianza (ANOVA) $(\mathrm{P}<0.05)$. Los animales por grupo fueron considerados como repeticiones. Todos los datos fueron analizados utilizando el sistema estadístico S.A.S (S.A.S. Institute, Cary, North Carolina). El análisis de medias se realizó a través de la prueba de Duncan $(\mathrm{P}<0.05)$ del mismo paquete estadístico. 


\subsection{RESULTADOS Y DISCUSIÓN}

\subsubsection{Crecimiento de ratas y consumo de alimento}

El incremento o disminución en el peso de masa corporal se ha reportado como un cambio fenotípico y ha sido determinado como un índice de requerimiento basal de energía cuando la dieta se modifica, principalmente por compuestos poco digeribles (Liu y Wang, 2007).

El crecimiento de las ratas durante las primeras 6 semanas de experimentación fue similar con ambas fibras, sin embargo, a partir de la sexta semana hasta el final de la experimentación (semana 13) con harina de cáscara de tuna la ganancia de peso fue significativamente $(P<0.05)$ menor que con inulina (Figura 13). Con inulina, durante las primeras nueve semanas se observó un crecimiento exponencial del peso corporal, siendo menor las últimas cuatro semanas hasta alcanzar un peso de $514 \mathrm{~g}$ para este grupo de ratas; mientras que con harina de cáscara de tuna, el crecimiento exponencial fue hasta la sexta semana, alcanzando un peso final promedio de $455 \mathrm{~g}$. Considerando el peso inicial de las ratas $(54.4 \mathrm{~g})$ estas presentaron una ganancia de peso promedio de $450 \mathrm{~g}$.

De acuerdo con Liu y col. (2002) la calidad de la dieta representada por la adición o ausencia de compuestos ricos en energía, como la adición de fibra dietética, es factor importante en la ganancia o pérdida de masa corporal. Por ejemplo, Artiss y col. (2006) reportaron que la inclusión de fibra dietética insoluble a la dieta provoca la disminución de peso en ratas, asociado a la rápida saciedad, además de tener menos energía biodisponible, lo cual coincide con lo reportado en este experimento al usar la harina de cáscara de tuna. Así mismo, Ebihara y Najamoto (1998) hacen mención de un aumento en el tránsito del bolo fecal cuando se administra fibra insoluble en la dieta, provocando menor peso lo cual es atribuido a la disminución de adsorción de nutrientes. Otros estudios reportan ganancia de peso similar en ratas aun cuando se adicionen diferentes tipos de fibra dietética (Campbell y col., 1997; Grasten y col., 2002; Cani y col., 2004; Belobrajdic y col., 2012), sin embargo, contrario al método experimental de este trabajo, estos experimentos se realizaron con ratas adultas o durante un tiempo no superior a 4 semanas de experimentación. 


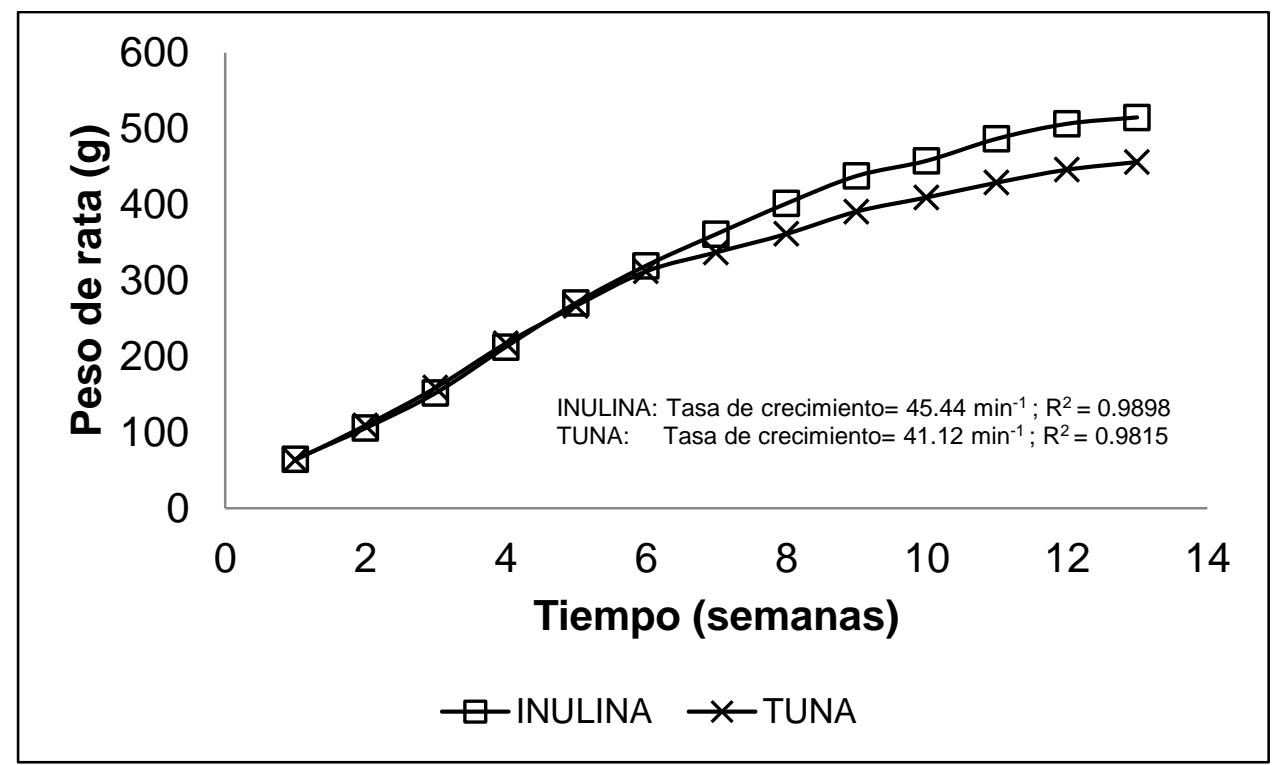

Figura 13. Crecimiento de las ratas durante 13 semanas de alimentación con diferentes tipos de fibra.

La Figura 14 muestra el consumo semanal de alimento por cada uno de los grupos de ratas. El consumo de alimento fue similar para ambos grupos hasta la quinta semana, ya que hasta la semana 10 se observó menor consumo de alimento con harina de cáscara de tuna. Para ambos grupos se observó un consumo exponencial durante las primeras seis semanas alcanzando los $25 \mathrm{y}$ $30 \mathrm{~g}$ de alimento (cáscara de tuna e inulina, respectivamente) diariamente con incrementos semanales de $5 \mathrm{~g}$. por semana. A partir de la semana ocho hasta el final del experimento el consumo se mantuvo constante con un promedio de $25 \mathrm{~g}$. al día.

El consumo de fibra dietética aporta energía lo cual se ve reflejado en la ganancia de peso así como en el consumo de alimento (Belobrajdic y col., 2012). Sin embargo, se ha reportado que la ingesta de fructanos no-digeribles disminuye la ingesta total de alimento y como consecuencia de energía alrededor de un 5 y 10\% (Delzenne y Kok, 2001), lo que puede explicar la disminución en la ingesta de alimento entre la semana 5 y 10 para el caso de la harina de cáscara de tuna (Figura 14). Se ha reportado que en ratas, el efecto de saciedad y menor consumo de alimento como consecuencia, provocan que los carbohidratos no-digeribles, resultan de la sobreexpresión de péptidos gástricos anorexigénicos (GLP-1, glucagón tipo péptido-1) y una disminución en péptidos orexigénicos (grelina) (Cani y col., 2004). Paturi y col. (2012) no 
observaron diferencias significativas $(P>0.05)$ entre la ingesta de alimento suplementado con inulina o fibra de papa, pero si hubo menor consumo en relación a la dieta con celulosa, argumentando una mayor retención de agua por parte de la fibra soluble y almidones aumentando el volumen gástrico. Otros estudios como Maljaars y col. (2008) reportaron que la administración de fibra dietética insoluble en la dieta favorece la saciedad disminuyendo significativamente el consumo de alimento, atribuido al retardo del vaciado gástrico.

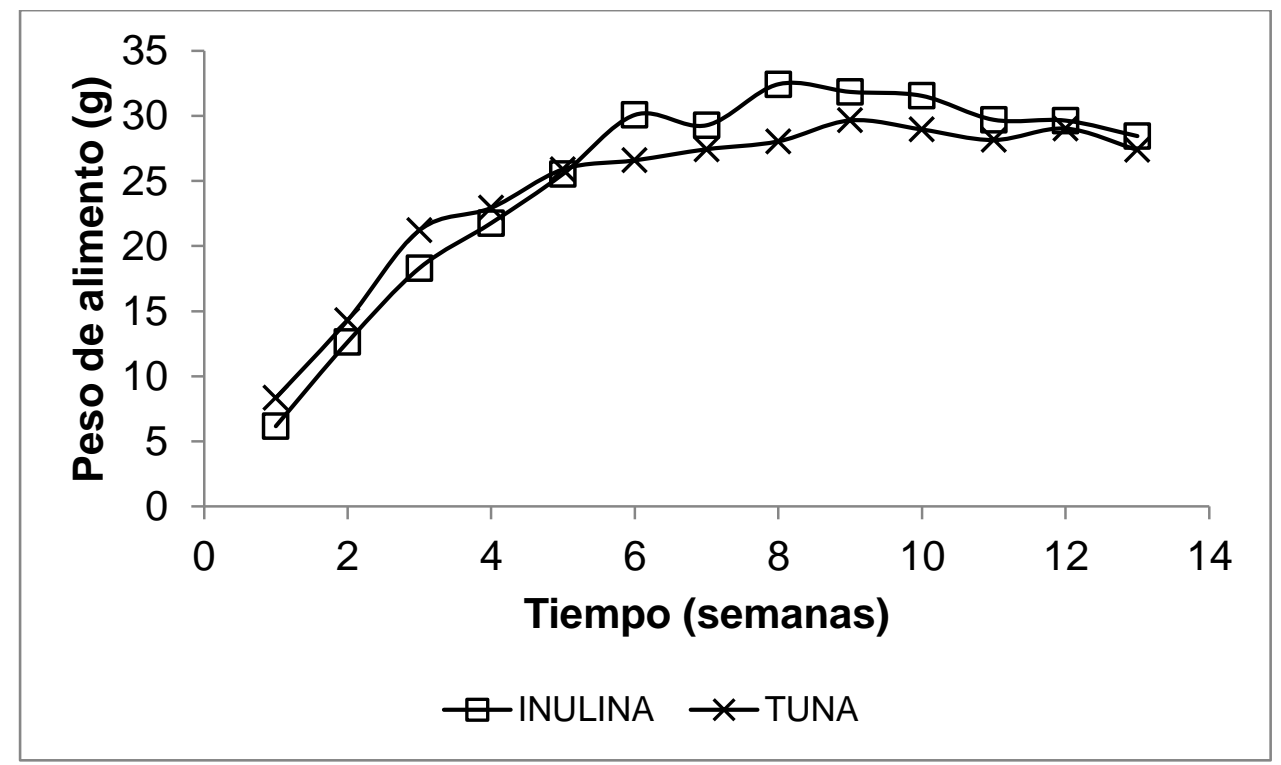

Figura 14. Consumo de alimento semanal de diferentes tipos de fibra por parte de las ratas.

\subsubsection{Polisacáridos no-digeridos}

El efecto de las diferentes fibras sobre la determinación de polisacáridos no digeridos fue significativo $(P<0.05)$. En la Tabla 22 se observa que la dieta con cáscara de tuna provocó mayor porcentaje de polisacáridos no digeridos $(12.1153 \%)$ que con inulina $(2.8905 \%)$.

La digestibilidad de los alimentos depende de la estructura y composición química de estos. La fibra soluble presente en la inulina y la fibra insoluble presente en paredes celulares de frutos presentan diferencias en estructura y tipos de enlaces (alfa o beta), teniendo como consecuencia el grado de digestibilidad de los componentes (Ebihara y Nakamoto, 1998). A pesar de que la cáscara de tuna contiene celulosa (fibra insoluble) y pectina (fibra soluble) dentro de su composición, la fracción insoluble representa la mayor proporción de la fibra dietética total, mientras que la inulina es solo fibra soluble lo que 
implica mayor digestibilidad en el intestino delgado y ciego (ConceicaoApolinário y col., 2014). Los resultados obtenidos con inulina son comprensibles, ya que además de ser un carbohidrato no-digerible, contiene una gran cantidad de fibra dietética soluble siendo fermentado rápida y fácilmente por las bacterias del colon (Roland y col., 1995). Paturi y col. (2012) reportaron menor digestibilidad de celulosa en relación a la inulina, lo que coincide con este experimento, ya que la cáscara de tuna presenta un porcentaje de celulosa de 27\% (Habibi y col., 2004a).

\subsection{3 Ácidos grasos de cadena corta}

La fermentabilidad de la fibra dietética genera la producción de ácidos grasos de cadena corta, tales como ácido acético, propiónico y butírico, los cuales contribuyen a modificar las funciones del sistema digestivo (Huang y col., 2014). Los ácidos grasos de cadena corta producidos en el colon, son absorbidos y pueden ser utilizados como fuente de energía por medio de la oxidación de éstos ácidos grasos en el orden de ácido butírico>ácido propiónico>ácido acético (Clausen y Mortensen, 1994).

La Tabla 22 muestra la producción de ácidos grasos de cadena corta en función al tipo de fibra en la dieta de las ratas. Para ambos tipos de fibra se observó un efecto significativo $(P<0.05)$ sobre la producción de ácidos grasos de cadena corta. La producción de ácido acético fue mayor que los demás ácidos grasos con ambos tipos de fibra, produciéndose más con cáscara de tuna $(17.99 \mu \mathrm{mol} / \mathrm{g})$. El ácido propiónico e isobutírico también se produjo más al usar cáscara de tuna en la dieta (3.72 y $0.19 \mu \mathrm{mol} / \mathrm{g}$, respectivamente), mientras que la producción de ácido butírico fue mayor con inulina (5.47 $\mu \mathrm{mol} / \mathrm{g})$. 
Tabla 22. Polisacáridos no-digeridos y producción de ácidos grasos de cadena corta en el ciego de la rata (Rattus norvegicus) de acuerdo a diferentes tipos de fibra incluidas en la dieta.

\begin{tabular}{lll}
\hline & INULINA & TUNA \\
\hline Polisacáridos no-digeridos (\% peso seco) & $2.89 \mathrm{~b}$ & $12.11 \mathrm{a}$
\end{tabular}

Ácidos grasos de cadena corta ( $\mu \mathrm{mol} / \mathrm{L})$

Acético

Propiónico

Butírico

Iso-butírico
$5.94 \mathrm{~b}$

$1.67 \mathrm{~b}$

$5.47 \mathrm{a}$

$0.13 \mathrm{~b}$
$17.99 \mathrm{a}$

$3.72 \mathrm{a}$

$0.63 \mathrm{~b}$

$0.19 \mathrm{a}$

a,b. Letras diferentes en la misma fila son significativamente diferentes $(P<0.05)$.

La inulina, ha sido reportada como precursora de ácido butírico frente a otras fuentes de polisacáridos no-digeribles debido a la solubilidad que presenta (Demigné y Rémésy, 1985; Karppinen y col., 2000; Grasten y col., 2002; Coudray y col., 2005). Se ha reportado que la diferencia en la estructura de las fuentes de fibra también afecta la tasa de producción de ácidos grasos de cadena corta en el ciego de ratas, tal es el caso de la inulina al producir menor cantidad de ácidos grasos de cadena corta en relación a oligosacáridos de cereales (Belobrajdic y col., 2012). Grasten y col. (2002) reportaron diferencias en la producción de ácidos grasos de cadena corta entre el uso de inulina y fibra de cereales en la alimentación de ratas, concluyendo que el tipo de fibra altera la actividad enzimática de la microbiota del ciego. La fibra soluble es altamente fermentable en comparación a la fibra insoluble lo que marca la diferencia en la tasa de producción de ácido grasos de cadena corta (Tan y col., 2014), sin embargo, existen estudios donde la producción de ácidos grasos es mayor con fibra dietética de cáscaras de frutos que con inulina. Huang y col. (2014) reportaron mayor producción de ácidos grasos de cadena corta, principalmente ácido láctico al usar harina de cáscara de piña como fuente de fibra en hámsters. Paturi y col. (2012) reportaron mayor producción de ácidos grasos de cadena corta usando inulina como fuente de fibra que con celulosa, sin embargo, en este trabajo a pesar de tener menor digestibilidad de polisacáridos (Tabla 2) la mayor producción fue con harina de cáscara de tuna. Además de los requerimientos enzimáticos; la expresión de proteínas transportadoras (ATP-casete de unión), la presencia de bifidobacterias y 
sistemas fosfotransferasa, también favorecen el transporte y absorción de sustratos como la fructosa requeridos para la producción de ácidos grasos volátiles (Tan y col., 2014) lo cual se vio reflejado en este trabajo. Guilloteau y col. (2010) reportaron que varias especies pertenecientes al género Bacteroide se caracterizan por una mayor producción de ácido butírico como producto principal de su fermentación así como de manera catabólica a partir del ácido acético, por lo que la presencia de Bacteroides sp. en el ciego de las ratas alimentadas con inulina pudo haber generado una mayor producción de ácido butírico. El contenido y producción de ácidos grasos de cadena corta es dependiente de la microflora del colon y/o tipo y cantidad de carbohidratos nodigeribles disponibles; así mismo, las diferentes bacterias en el colon usan diferentes rutas de fermentación, dando lugar a diferencias en el patrón de producción de ácidos grasos (Henningsson y col., 2001). La mayor producción de ácido butírico con inulina en el alimento de las ratas también fue reportada por Younes y col. (1995) cuando utilizaron fructooligosacáridos. Mientras tanto, la mayor producción de ácido acético y propiónico con harina de cáscara de tuna es importante a nivel fisiológico de la rata; el ácido acético siendo el principal ácido graso de cadena corta es utilizado a menudo para controlar los eventos de adsorción del colon, además de ser el precursor de la síntesis de colesterol y puede ser sustrato para otros microorganismos del colon (Hijova y Chmelarova, 2007); el ácido propiónico es el precursor de la gluconeogénesis en ratas, así mismo puede inhibir la síntesis de colesterol hepático (Cheng y Lai, 2000).

Debido a lo anterior, se demuestra que la tasa de producción de ácido grasos de cadena corta no solo es dependiente de la solubilidad de la fibra dietética, también es importante considerar el proceso de obtención de las harinas de cáscaras de fruto así como la microflora presente en el colon.

\subsubsection{Análisis microbiológico}

La microflora que habita el colon en animales es diversa, sin embargo, existen bacterias que se consideran benignas y necesarias para mantener en buen estado en el sistema digestivo (Prescott y col., 2000) las cuales actúan inhibiendo el crecimiento de bacterias alterantes o patógenas debido a la generación de metabolitos que tienen un efecto sobre el pH del ambiente. 
El análisis microbiológico del contenido del ciego de las ratas se muestra en la Tabla 23. Las fibras utilizadas en la dieta de las ratas tuvo un efecto significativo $(\mathrm{P}<0.05)$ en el conteo de las bacterias ácido lácticas, siendo mayor el conteo con harina de cáscara de tuna (6.23 Log UFC/g). Respecto al conteo de bifidobacterias, no se observaron diferencias significativas $(P>0.05)$ con ambas fibras. Sin embargo, el conteo de Bacteroides sp. y Enterobacterias fue significativamente $(\mathrm{P}<0.05)$ mayor con cáscara de tuna $(6.20$ y $3.84 \mathrm{Log} U \mathrm{FC} / \mathrm{g}$, respectivamente). Aunque el conteo de Bacteroides fue similar que el conteo de bacterias benéficas, la cantidad de Enterobacterias fue menor hasta en 3 ciclos logarítmicos aproximadamente, lo que supone una acción antimicrobiana de parte de las bacterias ácido lácticas probablemente por la acción de los ácidos grasos de cadena corta (Kleessen y col., 1997).

Tabla 23. Análisis microbiológico del contenido del ciego de la rata (Rattus norvegicus) de acuerdo a diferentes tipos de fibra incluidas en la dieta.

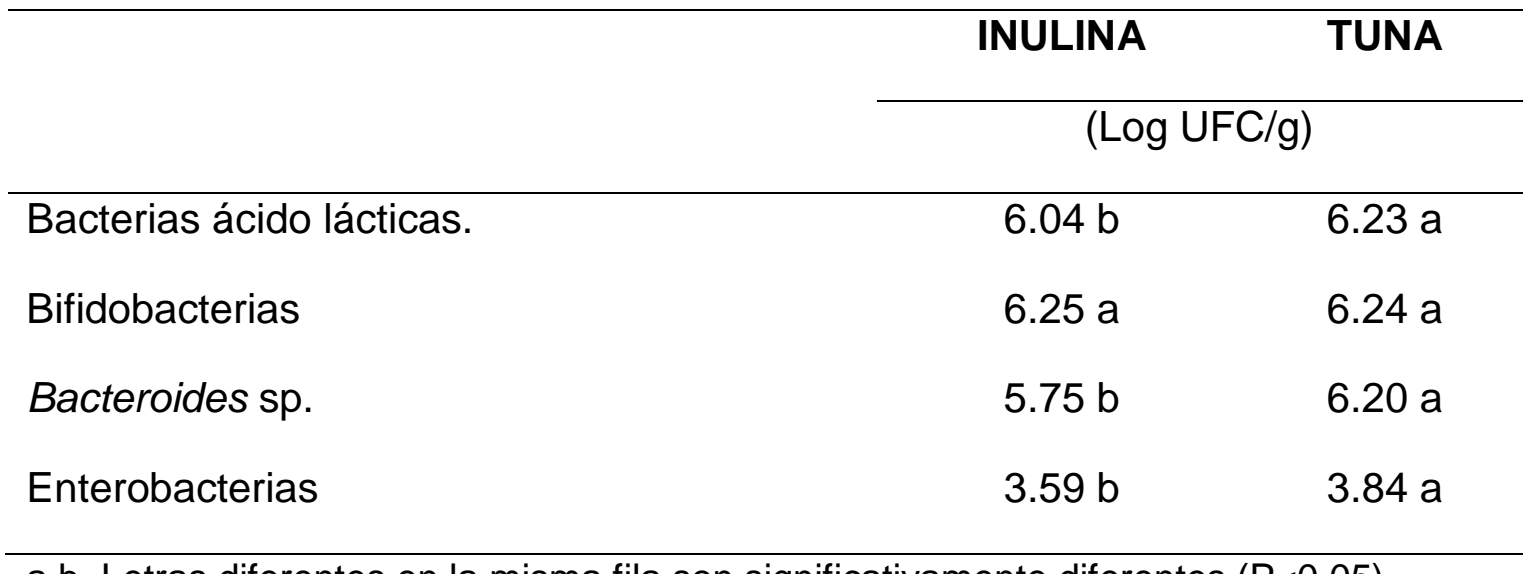

a,b. Letras diferentes en la misma fila son significativamente diferentes $(\mathrm{P}<0.05)$.

Stewart y col. (2008) reportaron una rápida fermentación de fructooligosacáridos comparado con inulina de achicoria, mencionando la importancia del grado de polimerización de la fuente de carbono para el crecimiento de las bacterias. La composición de la fuente de carbono tiene efecto marcado sobre la acidificación (disminución de pH por la producción de ácidos orgánicos volátiles) y crecimiento de bacterias probióticas (bifidobacterias o lactobacilos), donde el metabolismo fermentativo es más rápido con oligofructo-sacáridos que con inulinas, ya que éstas últimas al tener un mayor grado de polimerización tienen un prolongado efecto bifidogénico o prebiótico (Pompei y col., 2008), sin embargo, la actividad prebiótica de la 
inulina ha sido determinada, debido a que estos carbohidratos tienen una especificidad relacionada con bifidobacterias ya que estas presentan una enzima ( $\beta$-fructanofuranosidasa) compitiendo así con las distintas especies en el tracto gastrointestinal (Kolida y Gibson, 2008; Ramírez-Farías y col., 2009). Monro y col. (2012) reportaron mayor crecimiento de bifidobacterias con inulina que con fibra de cebada; Belobrajdic y col. (2012) y Campbell y col. (1997), usaron oligosacáridos no-digeribles y fructooligosacáridos en la dieta de ratas, donde el crecimiento de bifidobacterias fue significativamente $(P<0.05)$ mayor con fructooligosacáridos sin hallar diferencias en la cuenta de lactobacilos y enterobacterias. Por otro lado, van de Wiele y col. (2007) demostraron que la diferencia del grado de polimerización entre la inulina y oligosacáridos de fuentes vegetales puede afectar la fermentabilidad obteniendo diferentes conteos de crecimiento bacteriano. Es importante considerar que la producción de enzimas como $\beta$-glucosidasa y $\beta$-glucuronidasa por parte de las bacterias en el ciego de las ratas es importante para la degradación de diversas fuentes de carbono principalmente polisacáridos no-digeribles favoreciendo el crecimiento de bacterias como bifidobacterias y lactobacilos (Grasten y col., 2002) donde además se ha reportado que la inulina solo es capaz de favorecer la actividad de $\beta$-glucuronidasas, siendo probablemente lo que explique en este estudio un mayor número de bacterias con cáscara de tuna. Recientemente, se reportó que el uso de harina de cáscara de piña provocó un incremento en el crecimiento de lactobacilos y bifidobacterias, disminuyendo el crecimiento de bacterias enteropatógenas (Huang y col., 2014). Además, se ha reportado que el incremento de ciertos géneros de microorganismos en el ciego puede ser debido a la alta administración de fibra insoluble provocando la estimulación de excreción de sustratos del huésped hacia el ciego contribuyendo a una alta fermentabilidad (Maczulak y col., 1993). 


\subsection{CONCLUSIONES}

La ganancia de peso de las ratas fue mayor con inulina a partir de la sexta semana de experimentación, así mismo se observó que el consumo de alimento fue similar con ambas fibras. Las ratas alimentadas con la dieta de harina de cáscara de tuna presentaron mayor contenido de polisacáridos nodigeribles. Con la dieta de harina de cáscara de tuna hubo mayor producción de ácidos grasos de cadena corta siendo, principalmente ácido acético, excepto el ácido butírico producido en mayor proporción con inulina. El crecimiento de bacterias fue mayor con harina de cáscara de tuna, destacando el crecimiento de bacterias ácido lácticas, pero con un crecimiento similar de bifidobacterias con ambas fibras. Debido a lo anterior, la harina de cáscara de tuna puede ser una alternativa como fuente de fibra dietética al presentar efectos benéficos sobre las características fisiológicas y microbiológicas de la rata (Rattus norvegicus cepa Wistar). 


\subsection{BIBLIOGRAFÍA}

Artiss, J. D., Brogan, K., Brucal, M., Moghaddam, M. y Catherine-Jen, K. L. (2006). The effects of a new soluble dietary fiber on weight gain and select blood parameters in rat. Metabolism Clinical and Experimental. 55: 195-202.

Belobrajdic, D. P., Jenkins, C. L. D., Bushell, R., Morell, M. K y Bird, A. R. (2012). Fructan extracts from wheat stem and barley grain stimulate large bowel fermentation in rats. Nutrition Research. 32: 599-606.

Campbell, J. M., Fahey, G. C. y Wolf, B. W. (1997). Selected indigestible oligosaccharides affect large bowel mass, cecal and fecal short-chain fatty acids, $\mathrm{pH}$ and microflora in rats. The Journal of Nutrition. 127: 130136.

Cani, P. D., Dewever, C., Delzenne, N. M. (2004). Inulin-type fructans modulate gastrointestinal peptides involved in appetite regulation (glucagon-like peptide-1 and ghrelin) in rats. British Journal of Nutrition. 92: 521-526.

Cheng, H. H. y Lai, M. H. (2000). Fermentation of resistant rice starch produces propionate reducing serum and hepatic cholesterol in rats. Journal of Nutrition. 130: 1991-1995.

Clausen, M. R., Mortensen, P. B. (1994). Kinetic studies on the metabolism of short chain fatty acids and glucose by isolated rat colonocytes. Gastroenterology. 106: 423-432.

Conceicao-Apolinario, A., Goulart de Lima Damasceno, B. P., Esbera de Macedo-Beltrao, N., Pessoa, A., Converti, A. y da Silva, J. A. (2014). Inulin-type fructans. A review on different aspects on biochemical and pharmaceutical technology. Carbohydrate Polymers. 101: 368-378.

Coudray, C., Feillet-Coudray, C., Tressol, J. C., Gueux, E., Thien, S., Jaffrelo, L., Mazur, A. y Rayssiguier, Y. (2005). Stimulatory effect of inulin on intestinal absortion of calcium and magnesium in rats is modulated by dietary calcium intakes. European Journal of Nutrition. 44: 293-302.

De Man, J.C., Rogosa, M., Sharpe, M.E: (1960). A medium for the cultivation of Lactobacilli. Journal of Applied Microbiology. 23(1): 130-135.

Delzenne, N.M., y Kuk, N. (2001). Effects of fructans-type prebiotics on lipid metabolism. American Journal of Clinical Nutrition. 73:456S-458S.

Demigné, C. y Rémésy, C. (1985). Stimulation of absortion of volatile fatty acids and minerals in the cecum of rats adapted to a very high fiber diet. Journal of Nutrition. 115: 53-60.

Dubois, M. (1956). Colorimetric method for determination of sugars and related substances. Analytical Chemistry. 28: 350-356.

Ebihara, K. y Najamoto, Y. (1998). Comparative effect of water-soluble and insoluble dietary fiber on bowel function in rats fed a liquid elemental diet. Nutrition Research. 18: 883-891.

Guilloteau, P., Martin, L., Eeckhaut, V., Ducatelle, R., Zabielski, R. y Van Immerseel, F. (2010). From the gut to the peripheral tissues: The multiple effects of butyrate. Nutrition Research Reviews. 23: 366. 
Grasten, S. M., Pajari, A. M., Liukkonen, K. H., Karppinen, S. y Mykkanen, H. M. (2002). Fibers with different solubility characteristics alter similarly the metabolic activity of intestinal microbiota in rats fed cereal brans and inulin. Nutrition Research. 22: 1435-1444.

Habibi, Y., Heyraud, A., Mahrouz, M. y Vignon, M. R. (2004a). Structural features of pectic polysaccharides from the skin of Opuntia ficus-indica prickly pear fruits. Carbohydrate Research. 339: 1119-1127.

Habibi, Y., Mahrouz, M., Marais, M. F. y Vignon, M. R. (2004b). An arabinogalactan from the skin of Opuntia ficus-indica prickly pear fruits. Carbohydrate Research. 339: 1201-1205.

Henningsson, A., Björk, I. y Nyman, M. (2001). Short-chain fatty acid formation at the fermentation of indigestible carbohydrates. Scandinavian Journal of Nutrition/Näringsforskning. 45:165-168.

Hijova, E. y Chmelarova, A. (2007). Short chain fatty acids and colonic health. Bratislavske Lekarske Listy. 108: 354-358.

Huang, Y. L., Tsai, Y. H., Chow, C. J. (2014). Water-insoluble fiber-rich fraction from pineapple peel improves intestinal function in hamsters: evidence from cecal and fecal indicators. Nutrition Research. 34: 346-354.

Inan, H. S., Rasoulpour, R. J., Yin, I., Hubbard, A., Rosenberg, D. M., Giordina, C. (2000). The luminal short chain fatty acid butyrate modulates NF-KB activity in a human colonic ephitelial cell line. Gastroenterology. 118: 724-732.

Karppinen, S., Liukkonen, K., Aura, A. M., Forssell, P., Poutanen, K. (2000). In vitro fermentation of polisaccharides of rye, wheat and oat brans and inulin by human faecal bacteria. Journal of Science and Food Agriculture. 80: 1469-1476.

Kleessen, B., Stoof, G., Proll, J., Schmiedl, D., Noack, J. and Blaut, M. (1997). Feeding resistant starch fecal and cecal microflora and short-chain fatty acids in rats. Journal of Animal Science. 75: 2453-2462.

Kolida, S. y Gibson, G. R. (2008). The Prebiotic effect: Review of experimental and human data. En: Handbook of Prebiotics. Editores: Gibson, G. R. y Roberfroid, M. B. CRC Press, Boca Raton FL. pp: 69-92.

Levrat, M. A., Favier, M. L., Moundras, C., Rémésy, C., Demigné, C. y Morand, C. (1994). Role of dietary propionic acid and bile acid excretion in the hypocholesterolemic effects of oligosaccharides in rats. Journal of Nutrition. 124: 531-538.

Liu, H., Wang, D. H. y Wang, Z. W. (2002). Maximum metabolizable energy intake in the Mongolian gerbil (Meriones unguiculatus). Journal of Arid Environments. 52: 405-411.

Liu, Q. C. y Wang, D. H. (2007). Effects of diet quality on phenotypic flexibility of organ size and digestive function in Mongolian gerbils. Journal of Comparative Physiology B. 177:509-518.

Maczulak, A. E., Wolin, M. J. y Miller, T. L. (1993). Amounts of viable anaerobes, methanogens, and bacterial fermentation products in feces of 
rats fed high-fiber or fiber-free diets. Applied and Environmental Microbiology. 59: 657-662.

Maljaars, P. W. J., Peters, H. P. F., Mela, D. J. y Masclee, A. A. M. (2008). lleal break: A sensible food target for appetite control. A review. Physiology and Behavior. 95: 271-281.

Monro, J. A., Paturi, G., Butts, C. A., Young, W., De Guzmán, C. E., McLachlan, A., Roy, N. C. y Ansell, J. (2012). Prebiotic effects of fermentable carbohydrate polymers may be modulated by faecal bulking of nonfermentable polysaccharides in the large bowel of rats. International Journal of Food Sciense and Technology. 47: 968-976.

NOM-062-ZOO-1999. Especificaciones técnicas para la producción, cuidado y uso de los animales de laboratorio.

Pascoal, G. B., Filisetti, T. M. C. C., Alvares, E. P., Lajolo, F. M. y Menezes, E. W. (2013). Impact of onion (Allium cepa L) fructans fermentation on the cecum of rats and the use of in vitro biomarkers to assess in vivo effects. Bioactive Carbohydrates and Dietary Fiber. 1: 89-97.

Paturi, G., Butts, C. A., Monro, J. A., Hedderley, D., Stoklosinski, H., Roy, N. C. y Ansell, J. (2012). Evaluation of gastrointestinal transit in rats fed dietary fibres differing $i$ their susceptibility to large intestine fermentation. Journal of Functional Foods. 4: 107-115.

Pompei, A., Cordisco ,L., Raimondi, S., Amaretti, A., Pagnoni, U., Matteuzzi, D., Rossi, M. (2008). In vitro comparison of the prebiotic effects of two inulintype fructans. Anaerobe. 14 (5): 280-286.

Prescott, L. M., Harley, J. P. y Klein, D. A. (2000). Microbiología. McGraw Hill

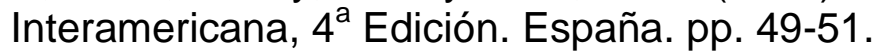

Ramírez-Farías, C., Slezak, K., Fuller, Z., Duncan, A., Holtrop, G. y Louis, P. (2009). Effect of inulin on the human gut microbiota: stimulation of Bifidobacterium adolescentis and Faecalibacterium prausnitzii. British Journal of Nutrition. 101: 541-550.

Reeves, P. G., Nielsen, F. H. y Fahey, G. C. Jr. (1993). AIN-93 Purifed diets for laboratory rodents: final report of the American Institute of Nutrition ad hoc writing committee on the reformulation of the AIN-76A rodent diet. The Journal of Nutrition. 123(11): 1939-1951.

Richardson, A. J., Calder, A. G., Steward, C. S. y Smith, A. (1989). Simultaneous determination of volatile and non-volatile acidic fermentation productos of anaerobes by capillary gas chromatography. Letters in Applied Microbiology. 9: 5-8.

Roland, N., Nugon-Baudon, L., Andrieux, C. y Szylit, O. (1995). Comparative study of the fermetative characteristics of inulin and different types of the fibre in rats inoculated with a human whole fecal flora. British Journal of Nutrition. 74: 239-249.

Scarminio, V., Fruet, A. C., Witaicenis, A., Rall, V. L. y Stasi, D. (2012). Dietary intervention with green dwarf banana flour (Musa sp AAA) prevents intestinal inflammation in a trinitrobenzenesulfonic acid model of rat colitis. Nutrition Research. 32: 202-209. 
Souba, W., Smith, R. y Wilmore, D. (1985). Glutamine metabolism by the intestinal tract. Journal of Parenteral and Enteral Nutrition. 9:608-617.

Stewart, M. L., Timm, D. A., Slavin, J.L. (2008). Fructooligosaccharides exhibit more rapid fermentation than long-chain inulin in an in vitro fermentation system. Nutrition Research. 28 (5): 329-334.

Tan, J., McKenzie, C., Potamitis, M., Thorburn, A. N., Mackay, C. R. y Macia, L. (2014). The role of short-chain fatty acids in health and disease. Advances in Immunology. 121: 91-119.

Van de Wiele, T., Boon, N., Possemiers, S., Jacobs, H., Verstraete, W. (2007). Inulin-type fructans of longer degree of polymerization exert more pronounced in vitro prebiotic effects. Journal of Applied Microbiology. 102: 452-460.

Younes, H., Garleb, K., Behr, S., Rémésy, C. y Demigné, C. (1995). Fermentable fibers or oligosaccharides reduce urinary nitrogen excretion by increasing urea disposal in the rat cecum. Journal of Nutrition. 125: 1010-1016. 


\section{CAPÍTULO VI. CONCLUSIONES GENERALES}

La composición de carbohidratos poliméricos en la harina de cáscara de tuna y piña favorecieron el crecimiento in vitro de la cepa probiótica termotolerante Pediococus pentosaceus UAM22 obteniendo el mayor crecimiento con $1.0 \%$ de cáscara de tuna como fuente de carbono. Mientras que la producción de ácidos grasos de cadena corta también fue mayor con harina de cáscara de tuna a una concentración de $1.0 \%$, siendo el ácido láctico el producido en mayor cantidad; demostrando además que la actividad prebiótica fue mayor durante el crecimiento de Pediococcus pentosaceus UAM22. Lo cual demuestra que las bacterias probióticas utilizadas fermentan los residuos agroindustriales dándole un valor agregado y demostrando su efecto prebiótico.

La harina de cáscara de tuna mantuvo sus propiedades funcionales en un producto cárnico cocido al mejorar sus propiedades fisicoquímicas, reduciendo el grado de rancidez oxidativa durante su almacenamiento, así mismo, la adición de la harina de cáscara de tuna favoreció el crecimiento de bacterias ácido lácticas durante el almacenamiento. La inoculación de las bacterias ácido lácticas probióticas termotolerantes en productos cárnicos cocidos con harina de cáscara de tuna puede ser una alternativa viable en la búsqueda de productos cárnicos simbióticos.

Los estudios sensoriales reflejaron el interés de los cosumidores por consumir alimentos saludables, teniendo menos neofobia alimentaria para la harina de cáscara de piña, pero sin temor a la harina de cáscara de tuna. Con el análisis de perfil cuantitativo se estableció un vocabulario para la evaluación de salchichas con harina de cáscara de frutos, con lo que se establecieron diferencias sensoriales en la mayoría de los descriptores determinados por consenso con esta técnica y con la prueba de Índice R. Estableciendo el uso de diferentes herramientas sensoriales para la caracterización de productos nuevos y saludables. 
Por último, los estudios in vivo con ratas de laboratorio (cepa Wistar) reflejaron que la adición de harina de cáscara de tuna en la dieta no presenta cambios en la ganancia de peso y consumo de alimento en relación a una alimentación con un prebiótico comercial como lo es la inulina. La digestibilidad de la harina de cáscara de tuna fue menor que la inulina, sin embargo, con esta harina se obtuvo la mayor producción de ácidos grasos de cadena corta, excepto el ácido butírico producido en mayor proporción con inulina.

Con todo lo anterior se concluye que el uso de cáscaras de frutos, principalmente de tuna, es una alternativa viable para ser usada como fuente de carbono para el crecimiento de bacterias benéficas y así formular productos simbióticos para la alimentación humana. 